Uma abordagem multi-escala para a geração de mosaicos

João Roberto de Godoy Sampaio 



\title{
Uma abordagem multi-escala para a geração de mosaicos
}

\author{
João Roberto de Godoy Sampaio
}

Orientador: Prof. Dr. João do Espírito Santo Batista Neto

Dissertação apresentada ao Instituto de Ciências Matemáticas e de Computação - ICMC-USP, como parte dos requisitos necessários para obtenção do título de Mestre em Ciências de Computação e Matemática Computacional. 

Ao meu pai, Orlando Villar Sampaio Filho.

(08-08-1940 - 11-02-2007) 

Gostaria de agradecer primeiramente ao meu pai, que sempre me apoiou e me incentivou a seguir este caminho mas que, por um acaso do destino, não pôde estar aqui presente para ver o resultado final deste trabalho do qual ele sentia tanto orgulho.

Agradecer ao restante da minha família por, depois de muito tempo, parar de perguntar "quando você vai terminar o mestrado?".

Agradecer também a todas as pessoas que conheci em São Carlos e que fizeram parte da minha vida nestes vários anos de mestrado. Seria injusto citar nomes pra não deixar ninguém importante de fora por deslize. Mas, gostaria de agradecer a todos os que estiveram presente nas jam sessions na Casa Velha, todos os que fizeram parte das lendárias viagens para Araraquara, todos os que me acompanharam em todas as ocasiões festivas e não festivas nesse período, enfim, todas as pessoas com as quais eu convivi ao longo dessa jornada e que eu espero estar por perto para sempre.

Um agradecimento especial à Marianna, por ter aturado todas as minhas crises de final de mestrado, ou melhor, final de tempo de mestrado.

Às pessoas da LSITec por todo o apoio e compreensão nessa fase final do trabalho e me liberarem para terminar isto o melhor possível.

Ao meu orientador João Batista, por todo o apoio e ensinamentos dados no decorrer de todo este processo e, principalmente, por toda a sua paciência.

Por fim, gostaria de agradecer à CAPES pelo apoio financeiro dado ao trabalho. 

Everything should be made as simple as possible, but not one bit simpler.

(Albert Einstein) 

Um mosaico é o conjunto de fotos de uma determinada área, recortadas e montadas técnica e artísticamente, de forma a dar a impressão de que todo o conjunto é uma única fotografia. No caso de fotografias aéreas, sua utilização soluciona o problema da necessidade de se retratar uma área de interesse mais extensa do que o campo de cobertura das lentes da câmera utilizada. O foco deste trabalho é a criação automática de mosaicos buscando encontrar a posição real de um conjunto de imagens imagens adquiridas em baixa altitude, de baixa escala, em relação à um Mapa de Base, de escala maior, realizando, assim, uma correlação entre imagens de escalas diferentes. Este problema é abordado por técnicas de análise multi-escala, mais precisamente, pela utilização de filtros de Gabor. A metodologia desenvolvida utiliza um banco de filtros de Gabor aplicado sobre uma imagem de referência de modo que, a partir da aplicação destes filtros sobre a mesma, seja possível gerar um processo automático de geração do mosaico para o restante do conjunto de imagens. Experimentos realizados utilizando o método proposto demonstram a eficácia do mesmo para imagens com texturas de orientação marcante, como o caso de imagens aéreas de plantação de eucaliptos. 

A mosaic is a set of pictures of a given area, technically and artistically cut and "glued" together, giving the impression that the entire set resembles a single picture. For aerial photography, the use of mosaics solves the problem of imaging an area of interest whose dimension is much larger than that covered by the majority of the cameras available. This work focuses on the automatic creation of mosaics and aims to compute the real position of a set of images acquired at low altitudes (lower scale), in relation with a base map (larger scale), by correlating images in different scales. Multi-scale analysis techniques, in particular, the Gabor filters, constitute an approach to this problem. The proposed methodology uses a bank of Gabor filters applied over a reference image in a way that an automatic process of mosaic generation, with the remaining set of images, could be carried out. Experiments have shown the efficiency of the proposed technique especially for images with clear textural orientation, for example, the case of aerial photographs of eucalyptus plantations. 

Sumário

Lista de Figuras $\quad$ vii

Lista de Tabelas $\quad$ xi

1 Introdução 1

1.1 Motivação . . . . . . . . . . . . . . . . . . . . . . 2

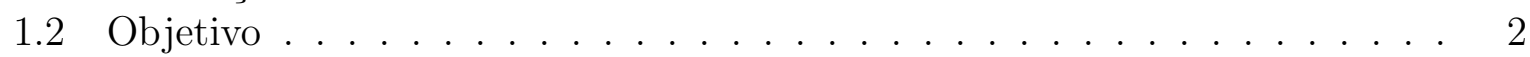

1.3 Organização do Trabalho . . . . . . . . . . . . . . . . . 2

2 Mosaicagem 5

2.1 Georeferenciamento . . . . . . . . . . . . . . . . . 5

2.1.1 Georeferenciamento Indireto . . . . . . . . . . . . . . . . . . 6

2.1.2 Georeferenciamento Direto . . . . . . . . . . . . . . . . . . 6

2.2 Metodologias Tradicionais para Geração de Mosaicos a partir de Fotografias

Aéreas . . . . . . . . . . . . . . . . . . . . . 9

2.2.1 Mosaicagem Pelo Método Direto . . . . . . . . . . . . . . . 11

2.2 .2 Mosaicagem Pelo Método Indireto . . . . . . . . . . . . . . . . . 12

2.2 .3 Mosaicagem com Correção Radiométrica . . . . . . . . . . . . . . 13

2.3 Considerações . . . . . . . . . . . . . . . . . . . . 14

3 Análise Multi-Escala 17

3.1 Espaço-Escala . . . . . . . . . . . . . . . . . . . . . 17

3.2 Wavelets . . . . . . . . . . . . . . . . . . . 18

3.2 .1 Definição . . . . . . . . . . . . . . . . . . 20

3.2 .2 Aplicações . . . . . . . . . . . . . . . . . . . . . . . . 22

3.3 Filtros de Gabor . . . . . . . . . . . . . . . . . . . . . . . 22

3.3 .1 Formulação . . . . . . . . . . . . . . . . . . 23

3.3 .2 Escolha dos Parâmetros . . . . . . . . . . . . . . . . 24

3.4 Considerações . . . . . . . . . . . . . . . . . . . 25

4 Metodologia 27

4.1 Escolha dos Filtros de Gabor . . . . . . . . . . . . . . . . 27

4.1.1 Selecionando a Imagem de Referência . . . . . . . . . . . . . . . 28

4.1 .2 Geração e convolução dos filtros . . . . . . . . . . . . . . . . 28

4.1 .3 Busca pelo melhor filtro . . . . . . . . . . . . . . . . . 29

4.2 Definindo a Região de Interesse no Mapa de Base . . . . . . . . . . . . . 31

4.3 Geração do Mosaico . . . . . . . . . . . . . . . . . . . . . . . 32 
4.4 Considerações . . . . . . . . . . . . . . . . . . . . . . . . . . . 33

5 Resultados $\quad 37$

5.1 Experimento 1: Imagem artificial gerada através da concatenação de texturas de Brodatz . . . . . . . . . . . . . . . . . . . . . 37

5.1.1 Teste 1: Utilizando uma boa imagem de referência . . . . . . . . . . 38

5.1.2 Teste 2: Utilizando uma má escolha como imagem de referência . . 39

5.2 Experimento 2: Cenas naturais de imagens aéreas . . . . . . . . . . . . 40

5.2.1 Teste 1: Imagens obtidas através do projeto Arara . . . . . . . . . . 41

5.2.2 Teste 2: Imagens obtidas através do Google Maps . . . . . . . . . . 42

5.3 Experimento 3: Imagens ruidosas . . . . . . . . . . . . . . . . 45

5.3.1 Aplicação dos filtros e seleção do melhor filtro . . . . . . . . . . . . 45

5.3 .2 Geração do mosaico . . . . . . . . . . . . . . . . . . . 46

5.4 Considerações . . . . . . . . . . . . . . . . . . . . . . . . . . . . 48

5.4 .1 Tempo de execução . . . . . . . . . . . . . . . . . . . . . . . 48

5.4 .2 Precisão do método . . . . . . . . . . . . . . . . . . . . . . 52

6 Conclusão $\quad 55$

6.1 Vantagens e desvantagens do método . . . . . . . . . . . . . . 55

6.2 Trabalhos Futuros . . . . . . . . . . . . . . . . . 56

Referências Bibliográficas $\quad 59$ 
2.1 Diagrama de blocos da configuração dos sensores baseada em filtro de Kalman $($ Santos, 2004) . . . . . . . . . . . . . . . . . . 7

2.2 Exemplo de ambiente de calibração laboratorial de câmeras (Santos, 2004). 9

2.3 Exemplo de ocorrência de HotSpot (imagem à esquerda) em espelhos de superfícies d'água (de Albuquerque Nóbrega, 2002) . . . . . . . . . . . . 10

2.4 Ocorrência do efeito de vinhete (imagem à esquerda) (de Albuquerque Nóbrega, 2002). Nota-se o escurecimento das bordas da imagem à esquerda em relação à imagem à direita. Tal escurecimento pode atrapalhar a homogeneidade do mosaico resultante. . . . . . . . . . . . . . . . 11

2.5 Aerofotografias tomadas de uma região extensa em diferentes épocas de recobrimento (de Albuquerque Nóbrega, 2002). É possível observar a diferença de tonalidade presente em cada grupo de fotografias. . . . . . . . . . . 11

2.6 Esquema do método direto de mosaicagem (Hasegawa e Junior, 2004). . . . 12

2.7 Falhas causadas pela aplicação do método direto (Hasegawa e Junior, 2004). 13

2.8 Esquema do método indireto de mosaicagem (Hasegawa e Junior, 2004). $\quad$. 13

2.9 Esquema do método de mosaicagem com correção radiométrica (Hasegawa e Junior, 2004). . . . . . . . . . . . . . . . . . . . . . . . . . . . . 14

2.10 Imagens com falta de continuidade radiométrica mosaicadas pelo método geométrico (Hasegawa e Junior, 2004). É possível notar a forte descontinuidade de tonalidade no mosaico. . . . . . . . . . . . . . . .

2.11 Imagens com falta de continuidade radiométrica mosaicadas pelo método com correção radiométrica (Hasegawa e Junior, 2004). Nota-se que houve uma suavização na junção das fotografias.

3.1 Sequência de suavizações gaussianas sobre um sinal, com $\sigma$ decrescente do topo para baixo (Witkin, 1984) . . . . . . . . . . . . . . 18

3.2 Contornos de uma Imagem Espaço-Escala de um sinal unidimensional (Wit-

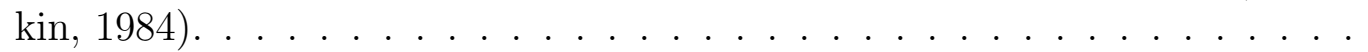

3.3 Alguns elementos de uma Imagem Espaço-Escala para uma determinada imagem (esquerda) e alguns dos contornos resultantes da aplicação do algoritmo Espaço-Escala (direita) (Lindeberg, 1996). . . . . . . . . . . . . . 19

3.4 Conjunto de wavelets pai (acima) e mãe (abaixo) de Daubechies (Wang,

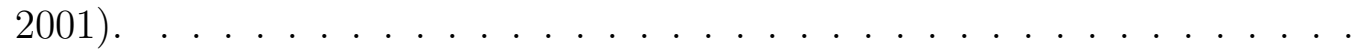


3.5 Aplicação da transformada wavelet de Daubechies de três níveis para uma imagem de MRI. Os pontos pretos indicam coeficientes diferentes de frequiência diferentes de zero (Wang, 2001) . . . . . . . . . . . . . . .

3.6 A partir de um filtro gerado em $0^{\circ}$, é possível obter os filtros em outras orientações através da rotação deste. . . . . . . . . . . . . . . . .

3.7 Filtro de Gabor no domínio espacial (acima) e domínio da freqüência (abaixo) (Jain e Farrokhnia, 1991). . . . . . . . . . . . . . . . . . . . . 24

3.8 Conjunto de filtros de Gabor (esquerda) e sua cobertura no plano de freqüência (direita) (Castañon, 2003) . . . . . . . . . . . . . . .

4.1 Etapa de seleção do filtro a ser utilizado. A partir de uma imagem de referência e de um banco de filtros gerados, é feita a escolha do filtro que melhor se adapta à mesma, ou seja, retorna a melhor resposta de sinal. . .

4.2 Exemplo de imagens de referência. A imagem da esquerda possui uma textura mais homogênea, sendo mais indicada para servir como referência em relação ao mapa de base (abaixo). Já a imagem da direita possui regiões que podem causar erros no decorrer do processo. . . . . . . . . . . . . . 29

4.3 Filtros com orientações e tamanhos definidos pelos parâmetros de entrada. 30

4.4 O resultado da aplicação dos filtros gerados sobre a imagem de referência. . 30

4.5 Histograma e Acumulada do conjunto de imagens filtradas correspondentes à imagem de referência utilizada de exemplo. . . . . . . . . . . . . . . . . 31

4.6 Resultado do processo de binarização do conjunto de filtros aplicados à imagem de referência. . . . . . . . . . . . . . . .

4.7 Contagem de runs em cada orientação de um determinado tamanho de filtro. Neste caso, pode-se notar que, o filtro de orientação igual a $0^{\circ}$ possui um coeficiente bastante superior às demais orientações.

4.8 Seleção do filtro relativo (Filtro MB) ao filtro escolhido de acordo com a alteração de escala entre a imagem de referência e o mapa de base. . . . . .

4.9 Etapa de definição da região de interesse sobre o mapa de base. Após a seleção do melhor filtro e definição do Filtro MB na etapa anterior, a partir do mapa filtrado é definida a região que possui características similares à da imagem de referência. . . . . . . . . . . . . . . . . .

4.10 Matriz de coeficientes gerada através da utilização de uma janela de contagem de runs que se desloca sobre a imagem filtrada e binarizada do mapa de base. À esquerda encontra-se em versão normalizada e à direita, em versão binarizada. . . . . . . . . . . . . . . . . . . 35

4.11 Região de interesse no selecionada mapa de base. . . . . . . . . . . . . . 35

4.12 Etapa final de geração do mosaico. Com a região de interesse definida, esta etapa tem por objetivo definir o posicionamento das imagens do conjunto sobre o mapa de base.

4.13 Comparação de uma imagem com o mapa de base através da subtração de modo a encontrar a sua posição ideal. . . . . . . . . . . . . . . . . . .

4.14 Resultado dos valores obtidos pela subtração da imagem a ser mosaicada sobre o mapa de base. Os pontos em branco (mostrados em destaque) são os pontos onde este valor é mínimo, portanto, são as melhores escolhas de posicionamento de uma das imagens do conjunto sobre o mapa de base. . .

5.1 Imagens utilizadas na produção do experimento 1. Acima estão as imagens a serem mosaicadas ( $a, b$ e $c$ ) e abaixo, o Mapa de Base. 
5.2 Filtro selecionado pela etapa de escolha do melhor filtro. . . . . . . . . . . 38

5.3 Região de interesse definida no teste 1 do experimento $1 . \quad$. . . . . . . . . 39

5.4 Mosaico gerado pelo teste 1 do experimento 1 (esquerda). À direita é exibido o posicionamento de cada imagem do conjunto de entrada no mosaico. 39

5.5 Filtro selecionado pela etapa de escolha do melhor filtro utilizando outra imagem de referência. . . . . . . . . . . . . . . . . . . . 40

5.6 Região de interesse definida erroneamente no teste 2 do experimento 1. . . 40

5.7 Mosaico gerado erroneamente pelo teste 2 do experimento 1 (esquerda) e o posicionamento das imagens do conjunto (direita). . . . . . . . . . . . . . . 41

5.8 Imagens utilizadas na produção do teste 1 do experimento 2. Acima estão as imagens a serem mosaicadas $(a$ e $b)$ e abaixo, o Mapa de Base a ser utilizado. . . . . . . . . . . . . . . . . . . 41

5.9 Filtro selecionado pela etapa de escolha do melhor filtro. . . . . . . . . . . 42

5.10 Região de interesse definida no teste 1 do experimento 2 . . . . . . . . . . . 42

5.11 Mosaico gerado pelo teste 1 do experimento 2 (esquerda) e o posicionamento das imagens do conjunto (direita). . . . . . . . . . . . . . .

5.12 Imagens utilizadas na produção do teste 2 do experimento 2. Acima estão as imagens a serem mosaicadas $(a, b, c$ e $d)$ e abaixo, o Mapa de Base a ser utilizado. . . . . . . . . . . . . . . . . . . . 43

5.13 Filtro selecionado pela etapa de escolha do melhor filtro. . . . . . . . . . . 44

5.14 Região de interesse definida no teste 2 do experimento 2 . . . . . . . . . . . 44

5.15 Mosaico gerado pelo teste 2 do experimento 2 (esquerda) e o posicionamento das imagens do conjunto (direita). . . . . . . . . . . . . 44

5.16 Imagens originais utilizadas na realização do experimento 3. Acima estão presentes as imagens em tamanho reduzido e, abaixo, uma região de cada uma das mesmas é exibida ampliada para que se perceba a diferença entre os conjuntos de imagens. . . . . . . . . . . . . . . . . . .

5.17 Imagens ruidosas também utilizadas na realização do experimento 3. Acima estão presentes as imagens em tamanho reduzido e, abaixo, uma região de cada uma das mesmas é exibida ampliada para que se perceba a diferença entre os conjuntos de imagens. É possível notar os efeitos causados pelo borramento e adição de ruído. . . . . . . . . . . . . . . . . 46

5.18 Mapa de base utilizado na produção do experimento 3. . . . . . . . . . . 46

5.19 Aplicação do filtro de 16 pixels de diâmetro e orientação igual a $90^{\circ}$ para as imagens de referência do conjunto original (esquerda) e do conjunto ruidoso (direita). É possível notar visualmente a forte semelhança entre as respostas obtidas após a aplicação do filtro. . . . . . . . . . . . . . .

5.20 Região de interesse sobre o mapa de base encontrado por ambas as imagens de referência para o experimento $3 \ldots \ldots \ldots$. . . . . . . . . .

5.21 Matriz de subtrações gerado por uma imagem do conjunto original (esquerda) e do conjunto ruidoso (direita) sobre o mapa de base. Note a maior presença da coloração azul, indicando um aumento no número de possíveis regiões de bom posicionamento. No detalhe, é exibido a posição ideal encontrada para os dois casos. . . . . . . . . . . . . . .

5.22 Mosaico gerado pelo experimento 3 para o conjunto de imagens originais (esquerda) e o posicionamento das imagens do conjunto (direita). . . . . .

5.23 Mosaico gerado pelo experimento 3 para o conjunto de imagens ruidosas (esquerda) e o posicionamento das imagens do conjunto (direita). . . . . . 


\section{Lista de Tabelas}

5.1 Tempo de execução do processo de geração dos bancos de filtros para cada experimento. . . . . . . . . . . . . . . . 5 50

5.2 Tempo de execução do processo de convolução das imagens com os filtros do banco de filtros. . . . . . . . . . . . . . . . . . 5 50

5.3 Tempo de execução do processo de seleção do filtro que produz a melhor resposta ao ser aplicado sobre a imagem de referência. . . . . . . . . . . . . 51

5.4 Tempo de execução do processo de definição da região de interesse sobre o mapa de base. . . . . . . . . . . . . . . . . . . 51

5.5 Tempo de execução do processo de posicionamento das imagens para a geração do mosaico. . . . . . . . . . . . . . . . . . . . . . . . . 51

5.6 Tabela do percentual de erro do teste 1 do experimento 1, utilizando imagens geradas pela concatenação de texturas naturais de Brodatz. . . . . . . 52

5.7 Tabela do percentual de erro do teste 2 do experimento 1, utilizando o mesmo conjunto de imagens do teste anterior, porém, utilizando uma outra imagem do conjunto como referência. . . . . . . . . . . . . . . . . . . 52

5.8 Tabela do percentual de erro do teste 1 do experimento 2, utilizando de cenas aéreas naturais. . . . . . . . . . . . . . . . . 52

5.9 Tabela do percentual de erro do teste 2 do experimento 2 , também utilizandose de cenas aéreas naturais, porém, de dimensões maiores. . . . . . . . . . 53

5.10 Tabela do percentual de erro do teste 1 do experimento 3, de comparação de funcionamento do método sobre um conjunto de imagens com e sem adição de ruído, sendo este primeiro teste utilizando imagens sem ruído. . . 53

5.11 Tabela do percentual de erro do teste 2 do experimento 3, onde ocorreu a aplicação de ruído sobre as imagens do teste anterior. . . . . . . . . . . . 53 


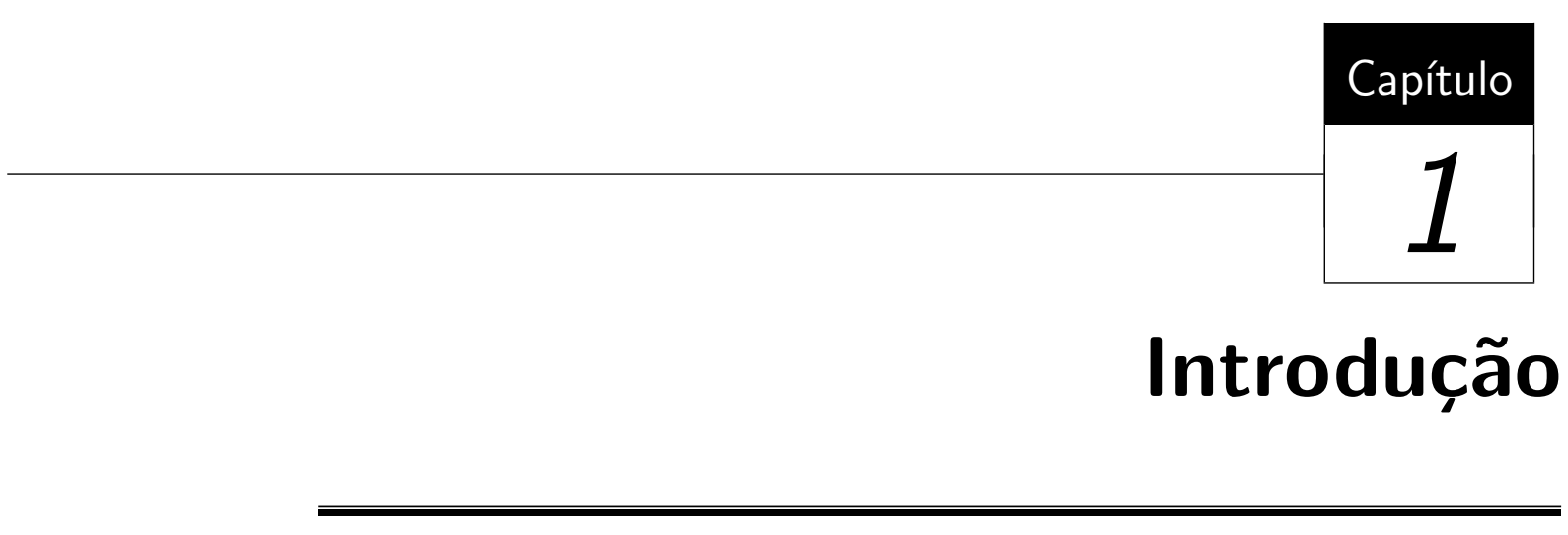

Um mosaico é o conjunto de fotos de uma determinada área, recortadas e montadas técnica e artísticamente, de forma a dar a impressão de que todo o conjunto é uma única fotografia (de Geografia e Estatística, 1997). No caso de fotografias aéreas, sua utilização soluciona o problema da necessidade de se retratar uma área de interesse mais extensa do que o campo de cobertura das lentes da câmera utilizada, reunindo duas ou mais fotografias recortadas e sistematicamente coladas para formar uma vista geral da área que foi fotografada (Wolf, 1983; Marcheti e Garcia, 1989).

Uma aplicação direta da utilização desses mosaicos é a inspeção de áreas de plantação de eucaliptos. Esta inspeção é fator primordial no controle da produção de celulose. Numa mesma plantação é possível encontrar regiões com crescimento reduzido, ou ainda áreas atacadas por pragas naturais. O bom monitoramento de tais regiões contribui para uma rápida tomada de medidas que visam resolver o problema. Pode-se dizer que quanto mais eficiente este controle, melhor será a produtividade da plantação.

Tradicionalmente, este controle é feito por terra. Nele, especialistas devem percorrer in-loco uma vasta área plantada em busca de regiões de risco. Tal procedimento é demorado, além de demandar um grande esforço físico dos especialistas. Como provável conseqüência desses fatores, podem surgir, ao longo do processo de inspeção, discrepâncias no processo de avaliação. Isto é, à medida que a avaliação vai sendo realizada, as condições climáticas e o desgaste físico podem introduzir distorções no resultado da avaliação.

Uma forma alternativa de inspeção é o sensoriamento aéreo dos plantios (Hasegawa et al., 2004). Nele, uma aeronave tripulada, equipada com dispositivos fotogramétricos, sobrevoa a região de interesse, obtém fotos e, posteriormente, as analisa.

Uma dificuldade que se avista na produção destes mosaicos é a necessidade de georeferenciamento das imagens a serem mosaicadas, havendo a necessidade de se realizar diversos cálculos sobre o conjunto de imagens. Este procedimento necessita da utilização de sensores e pontos de controle presente nas imagens de forma a auxiliar a geração do mosaico. Porém, um desafio seria obter uma maneira de se evitar tais procedimentos, realizando a tarefa de mosaicagem utilizando apenas informações já contidas nas próprias imagens. 


\subsection{Motivação}

A metodologia tradicional de sensoriamento aéreo por aeronave tripulada, tem como principal desvantagem o alto custo envolvido. Quer seja o custo do material fotogramétrico embarcado, quer seja o valor da mão de obra e custo da hora de vôo envolvidos.

Alternativamente, é possível fazer aquisição de imagens em baixa altitude para a geração dos mosaicos. Para tanto, existem os aeromodelos rádio-controlados desenvolvidos pelo projeto Arara (Santos, 2004; Neris, 2001; Jorge, 2001). Estas aeronaves são equipadas com câmera fotográfica digital e câmera de vídeo. Ao contrário de aeronaves tripuladas, os custos envolvidos são infinitamente menores. Embora ainda sejam necessários equipamentos fotográficos de qualidade e custos relativamente elevados (câmera digital, dispositivos de localização e controle remoto da aeronave), o custo de um aeromodelo não se compara ao de uma aeronave tripulada. Isso torna factível a implantação do sistema por várias companhias (mesmo as de pequeno e médio porte), uma vez que os custos envolvidos são bastante razoáveis.

Com estas imagens de baixa altitude, é possível criar mosaicos, não geo-referenciados, utilizando-se um mapa de base auxiliar. Este mapa, de escala bastante diferente das imagens de baixa altitude, pode ser obtido através de imagens de satélite da região a ser sobrevoada pelo aeromodelo. Com a combinação da utilização destas imagens de base com as fotografias de baixa altitude, é possível desenvolver um sistema de mosaicagem de imagens aéreas sem a necessidade de um elaborado e custoso processo de georeferenciamento sobre as mesmas.

\subsection{Objetivo}

O foco deste trabalho é a criação automática de mosaicos buscando encontrar a posição real de cada imagem adquirida no Mapa de Base, realizando uma correlação entre imagens de escala diferentes. O objetivo primordial é encontrar tal "função" de correlação capaz de estabelecer automaticamente essa relação geométrica. Um problema que se avista nesse processo é o mapeamento de um ponto ou área semelhante tanto no Mapa de Base quanto na imagem, devido principalmente à diferença de escala entre o Mapa e a imagem da área fotografada.

Tal problema pode ser abordado por técnicas de análise multi-escala. No trabalho serão discutidas técnicas como o Espaço-Escala(Scale-Space) as Wavelets e os filtros de Gabor. Para este trabalho, a solução empregada implementa os filtros de Gabor, devido às características do conjunto de imagens utilizadas pelo mesmo, que serão melhor explicadas nas seções que seguem.

\subsection{Organização do Trabalho}

Este texto está organizado em capítulos, que abordam os seguintes tópicos:

- No capítulo 2 são introduzidas algumas técnicas empregadas na confecção de mosaicos a partir de seqüencias de fotos aéreas e ainda apresenta conceitos de georeferenciamento de modo a ampliar o entendimento sobre tais técnicas.

- O capítulo 3 apresenta e discute algumas abordagens comummente utilizadas em processos de análise multi-escala. 
- O capítulo 4 descreve detalhadamente a metodologia empregada no trabalho com a utilização dos filtros de Gabor.

- No capítulo 5 são apresentados e analisados os resultados de diversos experimentos realizados utilizando a metodologia proposta.

- Por fim, o capítulo 6 discute a metodologia de maneira crítica e ainda apresenta possíveis trabalhos futuros a partir deste. 

Capítulo

Mosaicagem

Mosaicos são conjuntos de fotografias recortadas e alinhadas precisamente de modo a compor uma única fotografia. Esses mosaicos, segundo a maneira de sua geração, podem ser divididos em três classes (de Geografia e Estatística, 1997; Marcheti e Garcia, 1989): a dos mosaicos não-controlados, dos controlados e dos semi-controlados. Na primeira, os mosaicos são gerados a partir da simples mesclagem das margens de imagens aéreas adjacentes sem que estas passem por algum processo de retificação. É um processo rápido, porém, podendo causar uma grande quantidade de distorções. Na segunda classe, as imagens são submetidas a processos de retificação para que as distorções causadas por inclinações da câmera, lentes, irregularidades na superfície retratada e outros fatores sejam corrigidos. A junção das fotografias é realizada a partir do emparelhamento de pontos de controle homólogos. Já a última classe é uma mistura das duas anteriores. Nela os mosaicos podem ser gerados por imagens não retificadas mas através do emparelhamento dos pontos de controle ou não utilizar tais pontos em imagens retificadas (Santos, 2004).

Para entender melhor alguns conceitos relativos aos processos aos quais são submetidas as imagens durante o processo de mosaicagem, a seção seguinte abordará tópicos sobre Georeferenciamento. Deste modo, a outra seção sobre Metodologias para Geração de Mosaicos pode ser melhor compreendida.

\subsection{Georeferenciamento}

O georeferenciamento de imagens é definido encontrando-se uma transformação entre as coordenadas da imagem no plano da câmera e as coordenadas geográficas no plano geodésico. Para poder realizá-lo, os parametros de orienção interior e exterior da câmera no momento da exposição precisam ser determinados (Skaloud et al., 1996; Santos, 2004).

Os parâmetros que definem a orientação interna da câmera, que são as coordenadas do ponto principal, comprimento focal e características de distorções geométricas das lentes, são fornecidas por um processo de calibração da câmera em laboratório. Já a orientação externa é formada por seis parâmetros que compreendem as três coordenadas de posição correspondentes às coordenadas cartesianas $x, y$ e $z$, e três parâmetros de atitude 
conhecidos como ângulo de rolagem $(\omega)$, de guinagem $(\varphi)$ e de arfagem $(\kappa)$ (Cramer, 2001; Santos, 2004).

A obtenção desses seis parâmetros pode ser feita de duas maneiras: encontrando uma correlação entre os pontos de controle e os pontos na imagem (georeferenciamento indireto) ou através de sensores (georeferenciamento direto). Estes dois métodos de georeferenciamento serão apresentados a seguir.

\subsubsection{Georeferenciamento Indireto}

O médoto de georeferenciamento indireto é a abordagem mais freqüentemente utilizada. Ela se baseia na utilização de pontos de controle posicionados na superfície retratada cujas coordenadas geográficas são bem definidas e conhecidas. Neste método, os seis parâmetros externos de orientação são calculados através da correspondência entre estes pontos de controle na superfície e suas coordenadas correspondentes no plano da imagem. Tais pontos de controle devem ser de fácil distinção em relação ao resto da imagem. Eles podem ser naturais da região fotografada ou, caso seja necessário, artificialmente colocados na região antes da tomada das fotografias, o que encarece o processo (Cramer e Haala, 1999; Santos, 2004).

Um dos problemas que podem acarretar desse processo é o fato de, uma vez que os parâmetros de orientação exterior são obtidos através dos parâmetros de orientação interna da câmera, o caso de alguma falha de calibração laboratorial da mesma poder resultar em resultados errôneos de localização geográfica de pontos. Outro grande problema é no caso de triangulação aérea automática em conjuntos de imagens sem texturas, grandes porções d'água, fotos urbanas, entre outras. Nestes casos, a junção das imagens através da busca automática (computadorizada) de pontos homólogos pode se tornar difícil ou quase impossível).

\subsubsection{Georeferenciamento Direto}

Com a disponibilidade de sistemas de GPS e unidades de medições inerciais integrados, tornou-se possível a medição dos parâmetros de orientação externa durante a obtenção dos dados. Essa possibilidade de medida direta dos parâmetros de orientação é a principal diferença deste método para o método anterior tradicional (Cramer et al., 2000).

O georeferenciamento direto permite uma obtenção mais rápida dos parâmetros de orientação externa. Isso ocorre graças ao fato da carga computacional utilizada pelos cálculos de integração entre o GPS e os sensores inerciais é bem menor se comparada aos processos de comparações entre imagens e junção de pontos homólogos do método indireto (Cramer, 1999). A confiabilidade deste resultado depende muito do processo de integração destes sensores assim como vários fatores de calibragem. Tais processos e fatores serão explicados a seguir.

\section{Integração entre GPS e UMI}

O Sistema de Posicionamento Global (GPS) é capaz de oferecer informações de posicionamento e velocidade da aeronave com uma previsão absoluta muito alta. Porém, no caso de uma ausência momentânea dos sinais provenientes dos satélites, o sistema pode ficar sem os dados necessários.

A Unidade de Medição Inercial (UMI) é composta por uma combinação de três giroscópios ortogonalmente dispostos e três acelerômetros. Os giroscópios são responsáveis 
pelas medições da velocidade angular de rotação em torno dos três eixos ortogonais. Os acelerômetros, por sua vez, fornecem os valores de aceleração linear ao longo desses eixos. Esses elementos são submetidos a um processo inicial de alinhamento e, a partir daí, vão realizando suas medições, o que pode gerar erros acumulativos (Santos, 2004).

De modo a obter resultados mais precisos em termos de atitude e posicionamento, as medidas obtidas pelo GPS e pela UMI são integrados em uma configuração baseada em filtro de Kalman (Kalman, 1960). Desta forma, os erros são minimizados através de constantes reajustes realizados por ambos os sensores no sistema como um todo. A figura 2.1 apresenta o diagrama de blocos dessa configuração.

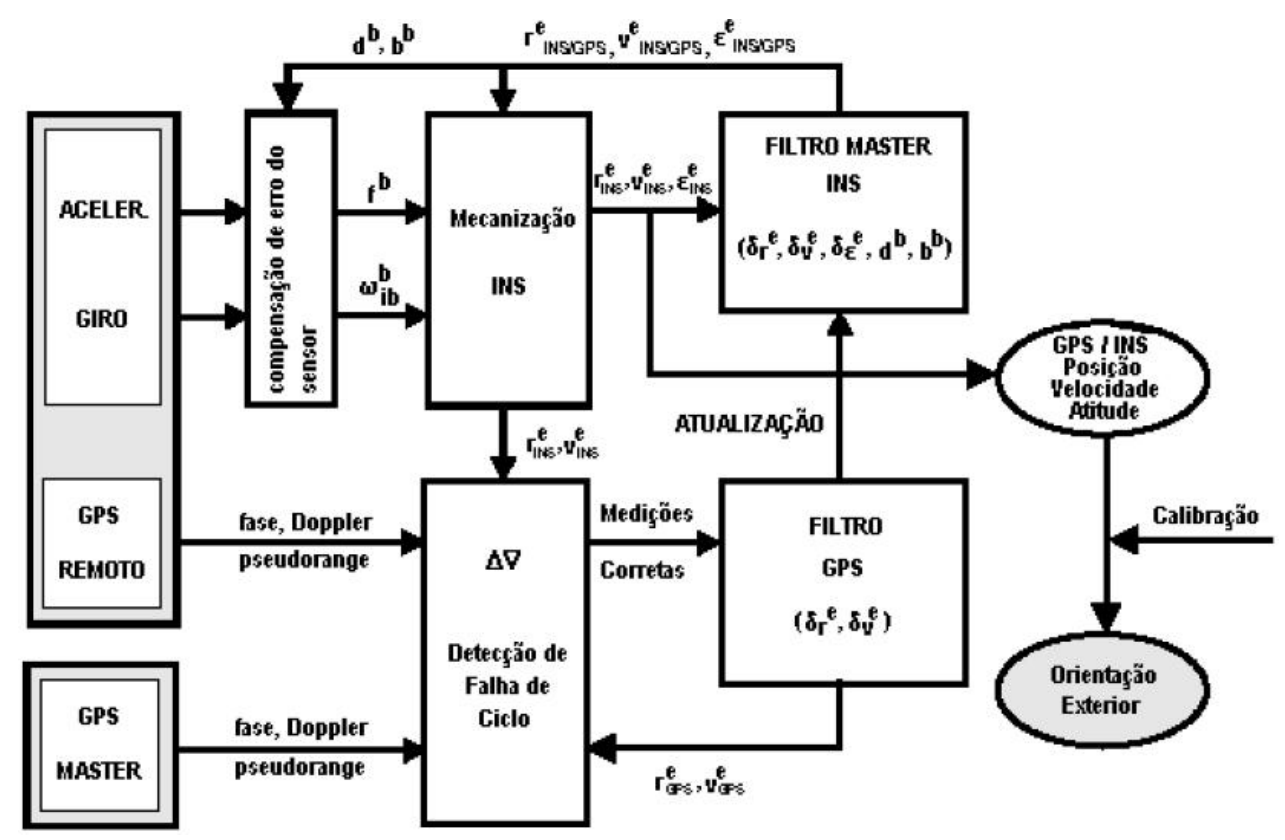

Figura 2.1: Diagrama de blocos da configuração dos sensores baseada em filtro de Kalman (Santos, 2004).

De acordo com essa configuração, o filtro GPS é independente do filtro da unidade inercial e sua saída é utilizada pra atualizar os estados de erro da mesma. O vetor de medições do filtro GPS são constituídos pelos valores de fase, doppler e pseudorange obtidos pelo receptor GPS. Tal filtro produz informações de posição $\left(\delta_{r}{ }^{e}\right)$ e velocidade $\left(\delta_{v}{ }^{e}\right)$, que serão utilizados para atualizar os estados de erro do filtro master do sistema inercial. Após esta etapa, o filtro master envia os parâmetros de posição $\left(r^{e}{ }_{I N S / G P S}\right)$, velocidade $\left(v_{I N S / G P S}^{e}\right)$ e atitude $\left(\epsilon_{I N S / G P S}^{e}\right)$ atualizados para passarem por um processo de retroalimentação do sistema, a fim de corrigir as medições iniciais da unidade inercial. Ao receber estes parâmetros, o módulo de mecanização gera os valores integrados de atitude, velocidade e posicionamento adequados para a realização da verificação da validade e integridade dos valores do GPS (Santos, 2004; Skaloud et al., 1996). Estes valores também serão enviados como saída do sistema.

Um dos problemas que precisa ser levado em conta no processo de georeferenciamento direto é o desalinhamento entre os sensores de orientação e a câmera. Isso se resolve através de processos de calibração entre eles, fundamentais para o funcionamento correto do sistema. 


\section{Calibração}

Calibração, segundo (Santos, 2004), é uma forma refinada de medição conduzida para associar números que representem relações entre propriedades particulares de um sistema de medição. Desta forma, para que os resultados do método de georeferenciamento direto sejam precisos e confiáveis, é necessária a realização de procedimentos de calibração. Tais procedimentos devem ser capazes de relacionar os eixos de coordenadas dos pontos das imagens com os dados de posicionamento e atitude obtidos pelos sinais do sistema integrado GPS/UMI (Cramer, 1999; Grejner-Brzezinska, 1999; Toth, 1999). Além da correspondência entre os elementos componentes do sistema, a calibração deve lidar com características próprias de cada um desses elementos que podem ser responsáveis pelo acúmulo de erros que podem interferir nos resultados da calibragem (Toth, 1999; Santos, 2004).

Dentre alguns dos procedimentos de calibração, existem três que podem ser considerados os mais importantes. Primeiramente, a calibração da câmera, que tem como objetivo permitir realizar medições nos parâmetros de orientação interna das mesmas. Tais parâmetros são constituídos pelo comprimento focal, pelas coordenadas da localização do ponto principal e coeficientes que permitam descrever as distorções visuais causadas pelas lentes. Estas distorções podem ser classificadas em distorções radiais média ou simétrica (referentes ao grau de refração sofrido pelos raios de luz ao cruzarem as lentes) e distorção tangencial (proveniente do alinhamento imperfeito dos eixos óticos das lentes) (Santos, 2004; Andrade, 1998).

Conforme (Andrade, 1998), as medidas de calibração precisam atender a três princípios: o método de mensuração deve ser completamente definido; as mensurações devem ter um estado de controle estatístico; e por fim, o método de calibração deve apresentar condições o mais próximas possíveis das condições normais de uso do instrumento, requerindo desta forma, uma calibração dos próprios sistemas de mensuração.

Ainda segundo (Andrade, 1998), os métodos de calibração de câmera podem ser divididos duas catégorias : de laboratório e de campo. Nos métodos de laboratório, são exigidos equipamentos especiais e condições de uso simuladas. Tal calibração tem como objetivo determinar o grau de refração dos raios luminosos através das lentes, as coordenadas do ponto principal, a distância focal e determinar se o valor máximo de distorção tangencial está dentro de limites aceitáveis de utilização (Santos, 2004).

Como um exemplo de ambiente de calibração laboratorial, temos a imagem 2.2, onde diversos pontos alvosão distribuídos de maneira ortogonal de modo a permitir a simulação de determinadas condições do ambiente externo (Santos, 2004).

Já os métodos de calibração de campo permitem retratar as condições reais de operação da câmera e oferecem resultados mais completos. Através de inúmeras repetições da execução deste método e análise dos resultados obtidos é possível estabelecer um controle estatístico do processo de modo a compreender o comportamento da câmera em situações reais (Santos, 2004).

Outro procedimento é o de calibração do Lever Arm. Este processo, através de uma relação geométrica, determina a localização da antena GPS e seu centro de fase em relação ao plano da UMI. Sua tarefa é corrigir os deslocamentos físicos que podem ocorrer na hora de se associar o GPS à UMI e de ambos com o centro de perspectiva da câmera (Cramer et al., 2000; Santos, 2004).

Por fim, o processo conhecido como calibração boresight está relacionado ao ajuste dos desalinhamentos lineares e angulares que podem ocorrer entre o corpo da UMI e a câmera fotográfica (Grejner-Brzezinska, 1999). A transformação que permite essa calibração deve 


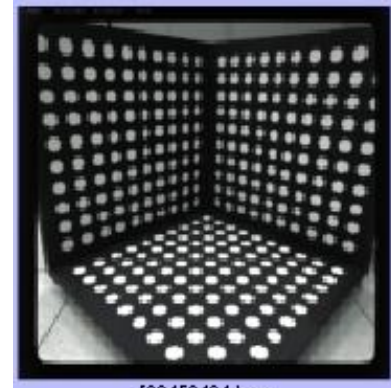

509458464.bmp

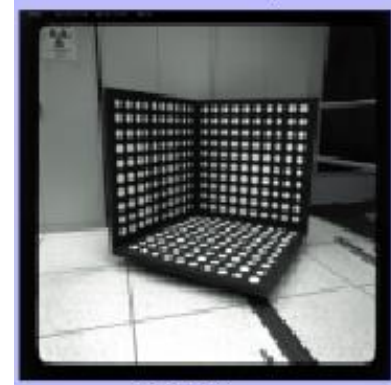

609459474.bmp

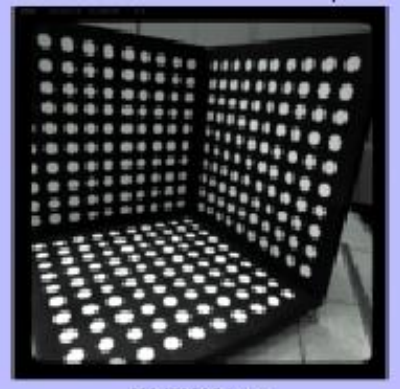

$509459305 . \mathrm{bmp}$

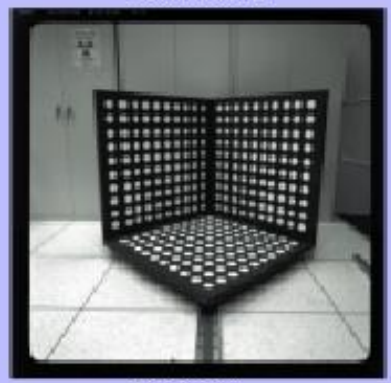

$609459510 . \mathrm{bmp}$

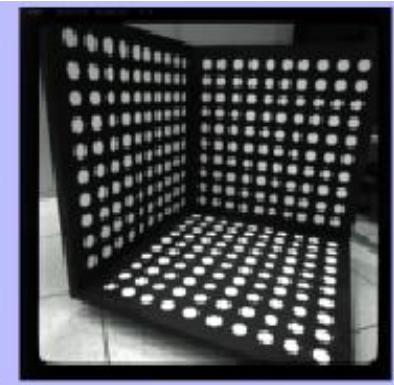

$509459432 . \mathrm{bmp}$

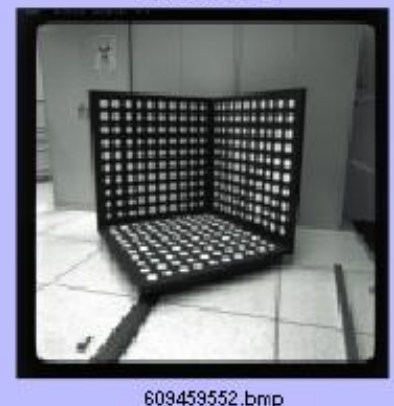

$609459552 . \mathrm{bmp}$

Figura 2.2: Exemplo de ambiente de calibração laboratorial de câmeras (Santos, 2004).

ser suficientemente precisa e pode ser determinada, segundo (Grejner-Brzezinska, 1999), a partir de comparações entre os resultados de posicionamento e orientação do sistema GPS/UMI e estimações independentes realizadas através do método de georeferenciamento indireto.

\subsection{Metodologias Tradicionais para Geração de Mosaicos a partir de Fotografias Aéreas}

O processo de geração de mosaicos obedece a um conjunto de etapas distintas. A primeira delas trata da aquisição das imagens aéreas. Tais imagens devem passar por uma etapa de orientação de modo a posicioná-las de acordo com um sistema de coordenadas geodésicas. Essa orientação pode ser feita através de duas maneiras. Na maneira convencional, através do georeferenciamento indireto (seção 2.1.1). Nela, a orientação é obtida através do estabelecimento de relações entre pontos de referência no solo e seus correspondentes na imagem. Para isso, é necessário ter em mãos dados como as coordenadas de referência no terreno, a distância focal da câmera calibrada de acordo com os requisitos da aplicação, as coordenadas do centro de perspectiva da câmera no momento da fotografia e os ângulos de atitude da aeronave (Santos, 2004). Tal processo pode ser bastante custoso devido aos excessivos cálculos para se obter essa correlação.

A segunda maneira, mais avançada, consegue obter os dados sobre os ângulos de atitude da aeronave e posicionamento da câmera através de sensores instalados na aeronave, por meio de georeferenciamento direto (seção 2.1.2). Com isso, a orientação das fotografias dispensa a fase de correlacionar grupos de fotos de modo a encontrar uma orientação comum, bastando ajustá-las de acordo com os dados dos sensores.

Após a etapa de orientação, é necessária a realização da retificação das fotografias a fim de evitar que distorções nas mesmas acarretem a formação de um mosaico de má qualidade (Marcheti e Garcia, 1989; Estes e Hemphill, 1998; Santos, 2004). Com o término 
destas etapas, as imagens estarão prontas para serem utilizadas pelos procedimentos de geração digital de mosaicos. Porém, na hora da mosaicagem, conforme (Andrade, 1998), podem ocorrer dois tipos de problemas: a ausência de coincidência geométrica das feições mescladas, gerado por uma má formação do modelo digital do terreno no processo de retificação e que deve ser refeito; e a falta de continuidade radiométrica entre as imagens, quando as imagens a serem mosaicadas possuírem diferenças de tonalidade, brilho, entre outras. Dentre os fatores que influenciam diretamente na diferença radiométrica, segundo (de Albuquerque Nóbrega, 2002), destacam-se:

- HotSpot, que correspondem a regiões com grandes alterações no valor de intensidade de brilho devido à reflexo de raios solares em feições da superfície retratada. Isto pode prejudicar o padrão homogêneo esperado no mosaico resultante. Um exemplo de fotografia aérea afetada pela presença de um HotSpot pode ser visto na figura 2.3 .
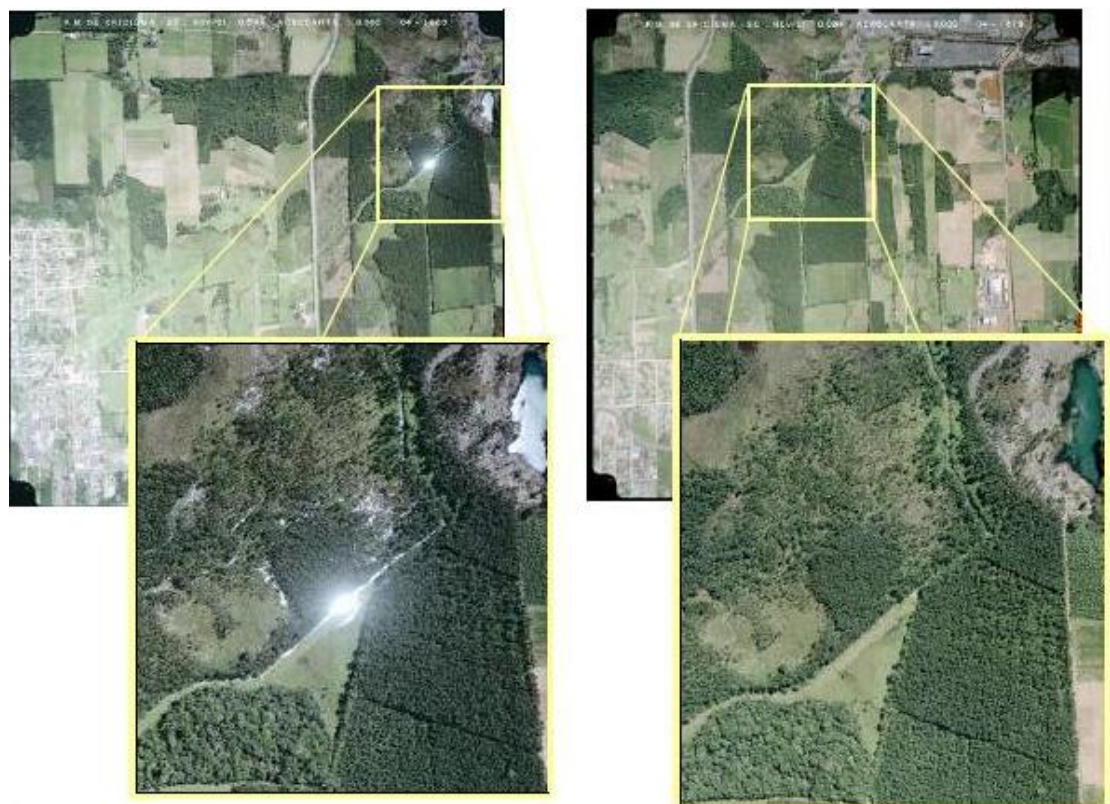

Figura 2.3: Exemplo de ocorrência de HotSpot (imagem à esquerda) em espelhos de superfícies d'água (de Albuquerque Nóbrega, 2002)

- Vinhete, que é o efeito causado pelo sistema de lentes da câmera, onde ocorre uma redução de intensidade dos feixes de luz captados pela mesma quando estes não se encontram dentro do eixo óptico principal. Isto causa o escurecimento das bordas das imagens em contraste com a região central da fotografia predominantemente clara. Este efeito visto na figura 2.4 .

- Diferenças entre materiais fotográficos, que pode ser causado pela falta de padronização do filme ou das condições dos agentes químicos durante o processo de revelação. Tal problema não aparece no caso de utilização de máquinas fotográficas digitais, desde que se mantenha um padrão de máquina.

- Falta de calibração do Scanner no ato da transformação de fotografias analógicas em imagens digitais, fazendo com que as imagens acabem sofrendo variações de tonalização e brilho no decorrer do processo devido à desgastes de uso do equipamento. 


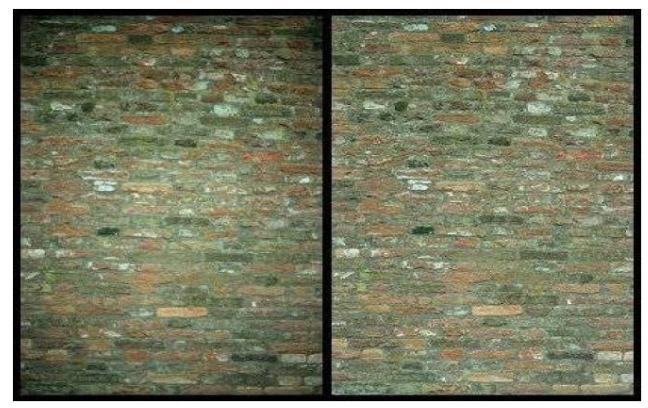

Figura 2.4: Ocorrência do efeito de vinhete (imagem à esquerda) (de Albuquerque Nóbrega, 2002). Nota-se o escurecimento das bordas da imagem à esquerda em relação à imagem à direita. Tal escurecimento pode atrapalhar a homogeneidade do mosaico resultante.

- Diferentes épocas de vôo, ocorridos no caso de projetos aerofotogramétricos de larga extensão, acabam prejudicando o padrão radiométrico das fotografias. Por mais que todos os cuidados em relação ao controle do equipamento, a coincidência dos horários de realização dos vôos e as condições atmosféricas adequadas, na maioria das vezes as fotografias resultantes de cada vôo não seguem o mesmo padrão de tonalidade, brilho e contraste. Um exemplo dessa falta de padronização radiométrica pode ser vista na figura 2.5 .

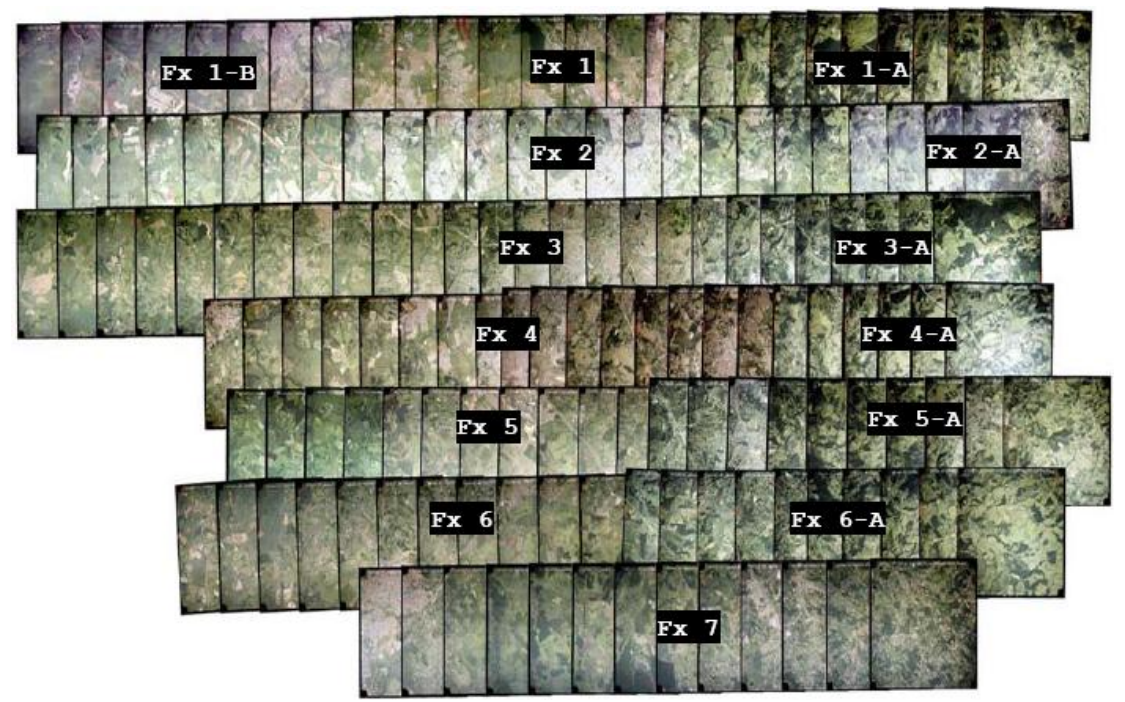

Figura 2.5: Aerofotografias tomadas de uma região extensa em diferentes épocas de recobrimento (de Albuquerque Nóbrega, 2002). É possível observar a diferença de tonalidade presente em cada grupo de fotografias.

Esses problemas podem ser corrigidos por meio de métodos de mosaicagem com correção radiométrica.

\subsubsection{Mosaicagem Pelo Método Direto}

Neste procedimento, as cores do pixel da imagem original são transferidas para a região do mosaico (Hasegawa e Junior, 2004). Tal transferência é auxiliada por transformações geométricas, que fornecem a possibilidade de re-posicionar os pixels de uma imagem. São 
utilizadas para mover, girar e alterar o tamanho e geometria das mesmas. Uma destas transformações é a Transformação Afim bi-dimensional. Tal transformação é capaz de manter o paralelismo entre os sistemas (Hasegawa e Junior, 2004). Sua fórmula é expressa pela equação 2.1:

$$
\left[\begin{array}{l}
X \\
Y
\end{array}\right]=\left[\begin{array}{ll}
a_{1} & a_{2} \\
a_{3} & a_{4}
\end{array}\right] *\left[\begin{array}{l}
x \\
y
\end{array}\right]+\left[\begin{array}{c}
\Delta x \\
\Delta y
\end{array}\right]
$$

onde $a_{1}, a_{2}, a_{3}, a_{4}, \Delta x$ e $\Delta y$ são os parâmetros de transformação e as coordenadas $(x, y)$ e $(X, Y)$ são as coordenadas do ponto nos dois sistemas.

A inversa desta transformação pode ser vista na equação 2.2 .

$$
\left[\begin{array}{l}
x \\
y
\end{array}\right]=\left[\begin{array}{ll}
a_{1} & a_{2} \\
a_{3} & a_{4}
\end{array}\right]^{-1} *\left[\begin{array}{l}
X-\Delta x \\
Y-\Delta y
\end{array}\right]
$$

Além da transformação afim, é necessário a realização de um processo de reamostragem dos pixels pelo fato de que nem sempre os pixels da imagem a ser concatenada atingem uma posição central nos pixels do mosaico (Hasegawa e Junior, 2004). Um esquema do funcionamento deste procedimento pode ser visto na figura 2.6 .

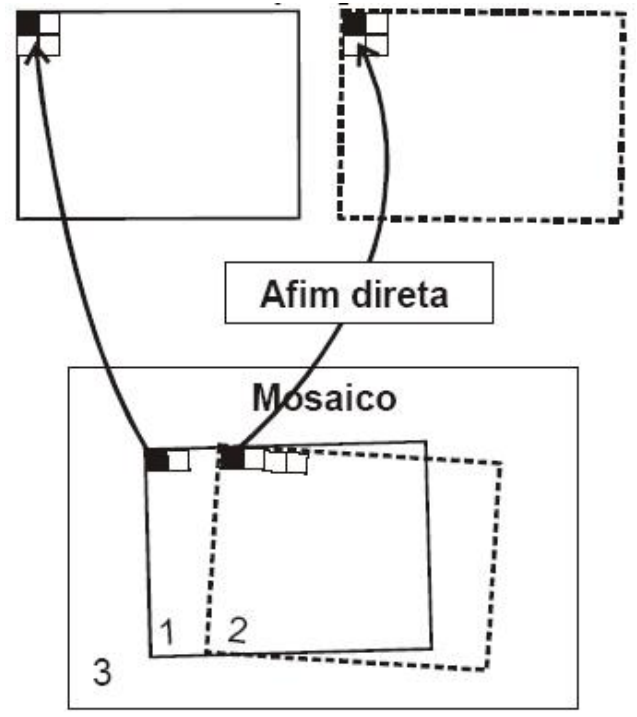

Figura 2.6: Esquema do método direto de mosaicagem (Hasegawa e Junior, 2004).

O problema com tal procedimento é que ele pode acabar não conseguindo mapear todos os pixels no mosaico, acarretando o aparecimento de pontos brancos dispostos de maneira regular na imagem resultante 2.7 .

\subsubsection{Mosaicagem Pelo Método Indireto}

Considerando um par de fotografias aéreas adjacentes, uma dessas fotografias (tomada como imagem de base) é copiada para a região onde vai ser formada o mosaico. Já a segunda fotografia é submetida a procedimentos de transformação afim. Esta transformação permite a sobreposição da segunda imagem com a primeira, concatenando-as (Santos, 2004). A imagem 2.8 mostra o esquema deste método. 


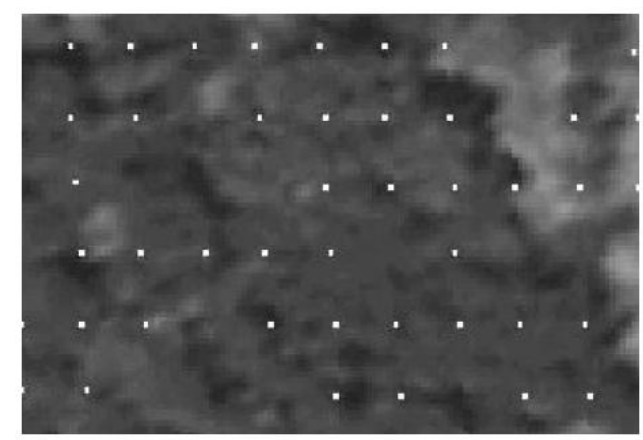

Figura 2.7: Falhas causadas pela aplicação do método direto (Hasegawa e Junior, 2004).

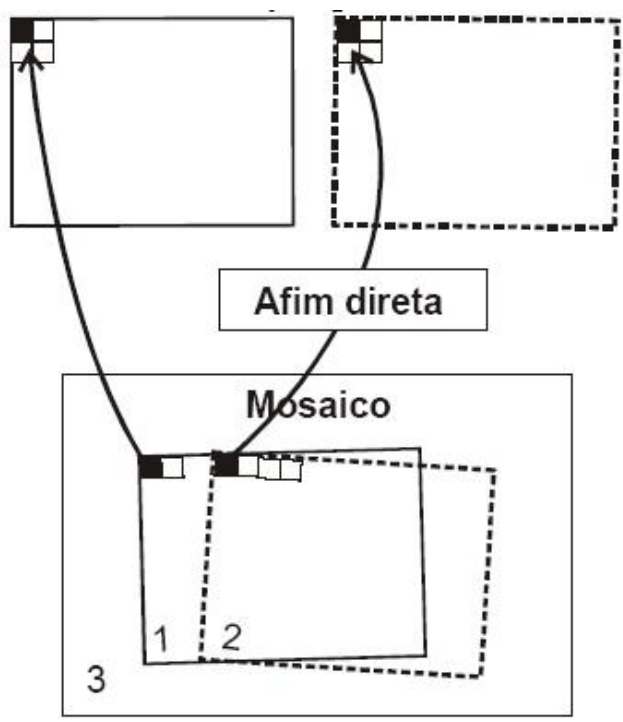

Figura 2.8: Esquema do método indireto de mosaicagem (Hasegawa e Junior, 2004).

\subsubsection{Mosaicagem com Correção Radiométrica}

Este método utiliza-se também da transformação afim direta como o anterior, com a diferença apenas do acréscimo de um processo de correção radiométrica na área de sobreposição entre as imagens de modo a suavizar as diferenças de intensidade entre as imagens (Hasegawa e Junior, 2004).

Na correção radiométrica, o valor de intensidade dos pixels retificados é baseado numa média ponderada das intensidades existentes em cada imagem do par de adjacências. Esta média tem como base a atribuição de pesos para tais valores, dando maior peso para o píxel que estiver mais próximo à região de sobreposição, e menor peso para o que estiver mais distante. A figura 2.9 mostra o esquema deste método.

A fim de exemplificar melhor a diferença de resultados que esse método pode fornecer, as figuras 2.10 e 2.11 exibem uma comparação entre duas imagens com falta de continuidade radiométrica mosaicadas pelos métodos indireto e com correção radiométrica, respectivamente. 


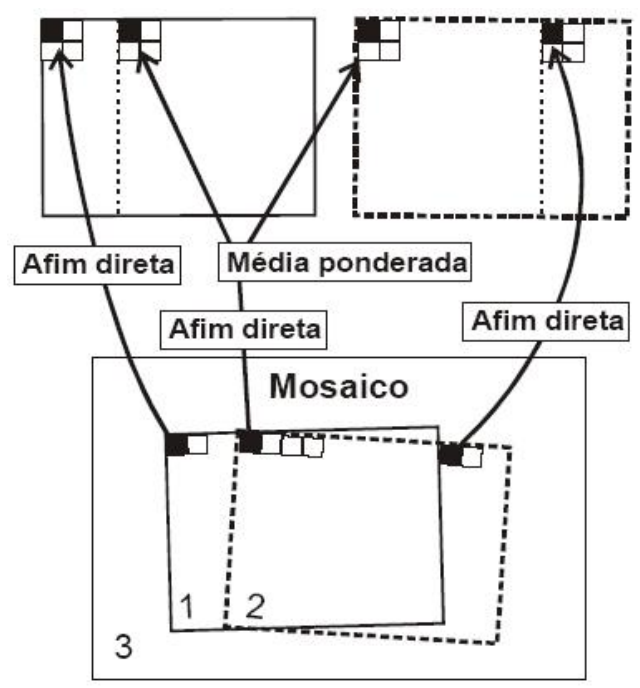

Figura 2.9: Esquema do método de mosaicagem com correção radiométrica (Hasegawa e Junior, 2004).

\subsection{Considerações}

Este capítulo apresentou algumas abordagens tradicionais para a geração de mosaicos a partir de um conjunto de fotografias aéreas. Embora elas se apóiem em conceitos de georeferenciamento para o posicionamento das imagens, a metodologia utilizada neste trabalho dispensa a utilização destes conceitos. Ao invés da utilização de pontos de controle presentes no conjunto de imagens ou de excessivos cálculos de integração entre dados de sensores (tais como GPS e UMI), a metodologia proposta utiliza um mapa de base de maior escala, ou seja, retratando uma área de visão maior da região que vai ser mosaicada, como referência para a realização da mosaicagem. A única necessidade pendente desta abordagem é a necessidade da realização de um pré-processamento sobre as imagens, alinhando-as em relação a um ponto comum (por exemplo, alinhadas em relação ao norte geográfico). Estas tarefas de pré-processamento podem ser facilmente realizadas através da aplicação de transformações afim simples bidimensionais. Uma vez que são tarefas bem estabelecidas e tratáveis por meio de programas disponíveis (for Geo-Information Science e Observation, 2004), a maneira pela qual é realizado este préprocessamento não será discutido neste trabalho.

O próximo capítulo descreve algumas técnicas que possibilitam a análise multi-escala de imagens de maneira que mosaicos possam ser gerados a partir de imagens em diferentes escalas. 


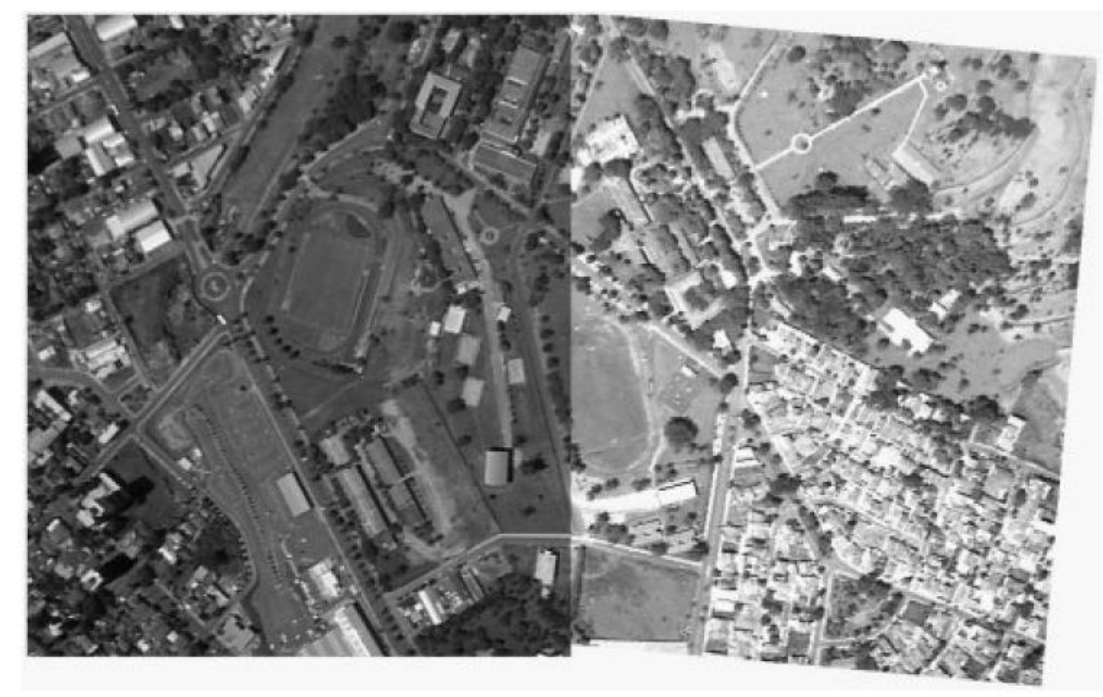

Figura 2.10: Imagens com falta de continuidade radiométrica mosaicadas pelo método geométrico (Hasegawa e Junior, 2004). É possível notar a forte descontinuidade de tonalidade no mosaico.

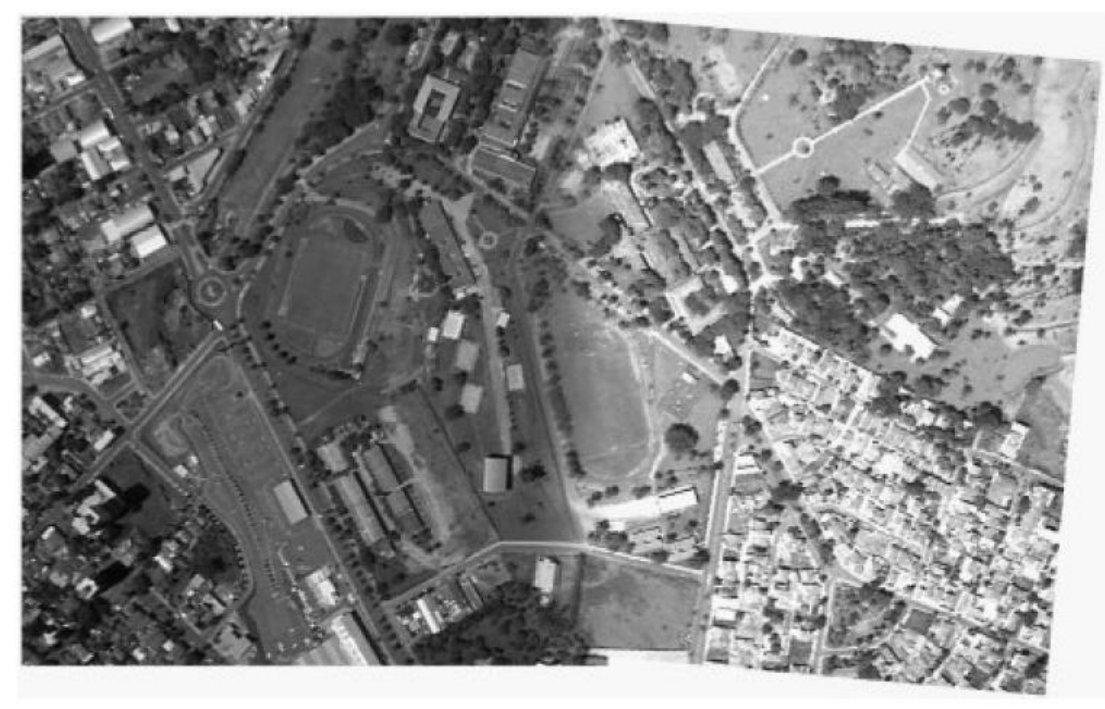

Figura 2.11: Imagens com falta de continuidade radiométrica mosaicadas pelo método com correção radiométrica (Hasegawa e Junior, 2004). Nota-se que houve uma suavização na junção das fotografias. 

Os objetivos de uma análise multi-escala (ou multi-resolução) é o de obter uma interpretação da imagem invariante da escala. A escala de uma imagem é definida como a distância entre a cena e o centro ótico da câmera. Quando a escala é alterada, a interpretação da imagem não deveria mudar (Castañon, 2003). Desta forma, é possível relacionar informações obtidas em uma escala com informações em uma outra escala. Esta relação é fundamental para a realização do presente trabalho uma vez que o eixo do mesmo é manter uma coerência entre imagens em escalas diferentes a fim de auxiliar a geração de mosaicos.

Com este propósito de manter uma coerência de informação entre escalas, existem diversas técnicas que podem ser empregadas. No presente trabalho são abordadas três delas bastante conhecidas: Espaço-Escala (Scale-Space), Wavelets e os filtros de Gabor. O funcionamento de cada uma dessas técnicas será descrito a seguir.

\subsection{Espaço-Escala}

A abordagem do Espaço-Escala apareceu primeiramente no trabalho de Stansfield (Stansfield, 1980), que estava procurando formas de extrair características de gráficos de preços de utensílios. Porém, o conceito só foi nomeado, formalizado e trazido para a área de análise de sinais e imagens por Witkin (Witkin, 1984).

Este método tem por característica descrever os sinais qualitativamente (Witkin, 1984). Através dele, é possível relacionar informações obtidas em diferentes escalas, uma vez que a representação de uma característica interessante do sinal descreve um caminho contínuo através de diferentes escalas. Se uma determinada característica de um sinal está presente numa dada escala $n$, então ela deve estar presente em todas as demais escalas até a escala original da representação da imagem (escala $\sigma=0$ ) (Leite e Dorini, 2006).

O sinal de entrada (por exemplo, uma imagem) passa por diversas convoluções com uma máscara gaussiana. Esta máscara é responsável pela redução de escala do sinal, reduzindo nele, a cada convolução, o nível de detalhes (redução de escala). Ela é escolhida gaussiana devido a suas propriedades de "bom comportamento", uma vez que a função 
gaussiana é simétrica e estritamente decrescente com relação à média, fazendo assim com que o peso atribuído aos valores do sinal diminua suavemente de acordo com a distância (Witkin, 1984). Supondo que tenhamos um sinal $f(x)$ n-dimensional e uma máscara gaussiana $g(x, \sigma)$. Este sinal suavizado em uma determinada escala $\sigma$ é dado por:

$$
F(x, \sigma)=f(x) * g(x, \sigma),
$$

onde "*” denota uma convolução em relação a $x$, e $F$ é uma função no espaço $(n+1)$ dimensional defininda como a Imagem Espaço-Escala (Scale-Space Image) do sinal $f(x)$. Um exemplo do resultado desta série de convoluções para um dado sinal de entrada de uma dimensão pode ser visto na figura 3.1.

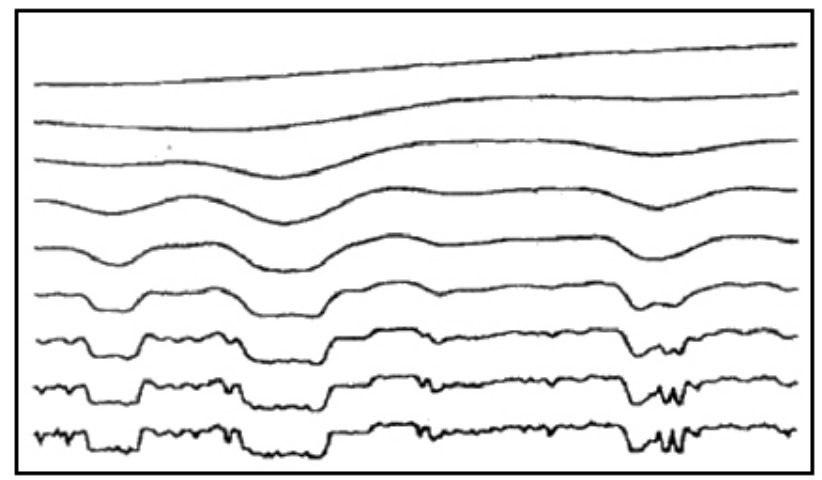

Figura 3.1: Sequência de suavizações gaussianas sobre um sinal, com $\sigma$ decrescente do topo para baixo (Witkin, 1984).

A figura 3.2 exibe uma imagem de contornos gerada pela abordagem Espaço-Escala para um sinal de uma dimensão. A cada aplicação da gaussiana, os pontos de inflexão do sinal são analisados. Essa análise gera uma imagem contendo a posição destes pontos no decorrer da função a cada estapa do processo que acaba gerando uma espécie de contorno dos mesmos. Cada linha deste contorno representa uma mudança no ponto de inflexão. Conforme estes pontos "caminham" pelo sinal devido às distorções causadas pela aplicação da gaussiana, estes contornos acabam gerando curvas. Cada vez que dois pontos de inflexão somem, isto é, a região entre estes dois pontos deixa de ser uma curva, dois contornos nesta imagem resultante se juntam, formando um arco. Através destes arcos, é possível ver o nível de detalhamento de uma determinada resolução. Para o caso de um sinal bi-dimensional, ou seja, uma imagem, estes arcos deslocam-se em um espaço tri-dimensional. a figura 3.3 exibe uma parte da Imagem Espaço-Escala e alguns arcos de maior significância desta imagem.

O Espaço-Escala é utilizado em diversas aplicações como aprimoramento de impressões digitais (Almansa e Lindeberg, 2000), reconhecimento de perfis de faces (Campos et al., 1993), detecção de bordas e quinas em imagens (Mokhtarian e Suomela, 1998) e reconhecimento de imagens através de seu contorno (ambas através de uma abordagem conhecida como Curvature Scale-Space) (Abbasi et al., 1999), entre outras.

\subsection{Wavelets}

Uma das técnicas mais populares no processamento de sinais é a transformada de Fourier. O seu objetivo é o de converter um sinal do domínio do espaço para o domínio 


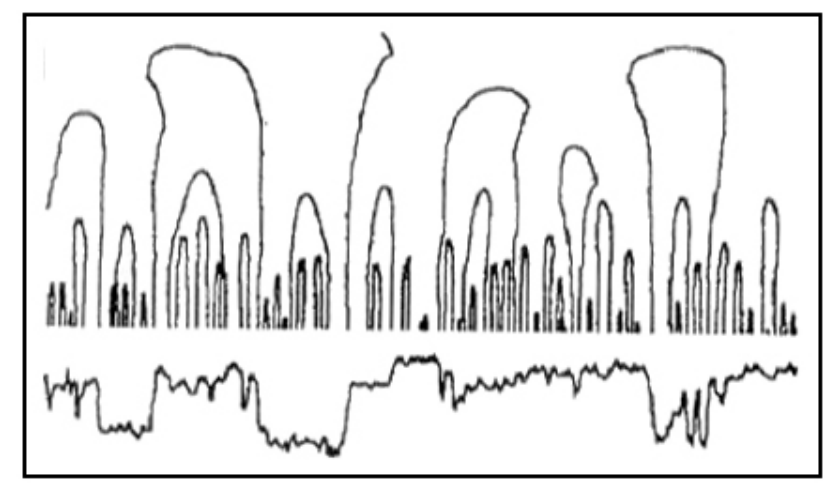

Figura 3.2: Contornos de uma Imagem Espaço-Escala de um sinal unidimensional (Witkin, 1984).

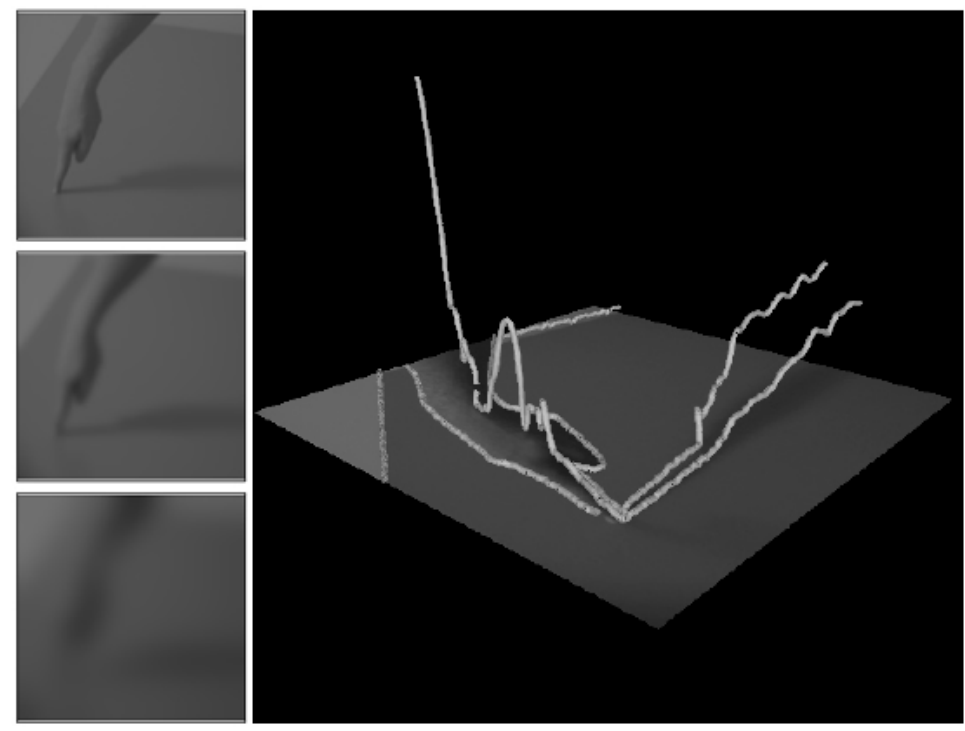

Figura 3.3: Alguns elementos de uma Imagem Espaço-Escala para uma determinada imagem (esquerda) e alguns dos contornos resultantes da aplicação do algoritmo Espaço-Escala (direita) (Lindeberg, 1996).

da freqüência (Wang, 2001). A função responsável pela transformação de Fourier de um sinal contínuo $f(t)$ é dada por:

$$
F[u]=\int f[t] e^{-i 2 \pi u t} d t
$$

Uma deficiência desta transformada é que a transformação não está localizada no domínio espacial, não representando adequadamente as mudanças que acontecem no sinal no espaço. Tal deficiência ocorre pelo fato da transformada estar baseada na integração de toda a função para o cálculo de cada freqüência. Como boa parte dos sinais mudam conforme o tempo, a transformada de Fourier acaba desprezando assim certas características transitórias dos sinais, que são, geralmente, a sua parte mais importante (Castañon, 2003). Para resolver este problema, foi desenvolvida a Transformada de Fourier com Janela Móvel (WFT - Windowed Fourier Transform), que aplica a transformada de Fourier em pequenas porções do sinal em um determinado tempo através de uma janela de obser- 
vação móvel. Considerando $j(t)$ a função que define a janela de transformação, a WFT de um sinal contínuo $f(t)$ pode ser definida como:

$$
F(u, t)=\int j\left(t-t_{0}\right) f[t] e^{-i 2 \pi u t} d t
$$

e dá a freqüência do sinal perto de $t=t_{0}$. O problema desta abordagem é que o tamanho das janelas é constante e alguns sinais podem precisar de um enfoque mais flexível, necessitando que o tamanho da janela mude com o objetivo de detectar o conteúdo local da freqüência (Castañon, 2003; Daubechies, 1992).

A transformada wavelet (Graps, 1995; Romberg et al., 2000) veio para suprir esta necessidade. Ela pode ser definida como uma técnica de processamento de sinais baseado em janelas com regiões de dimensão variável. As wavelets têm como base uma função de duração limitada, de domínio diferente de zero em uma extensão finita e igual a zero em todo o resto. Esta característica torna interessante sua utilização no caso de análise de imagens, pois as mudanças de regiões ou bordas podem ser detectadas mais facilmente (Castañon, 2003).

\subsubsection{Definição}

Uma transformada wavelet para um determinado sinal contínuo pode ser definida por:

$$
F(a, b)=\int f(t) \psi_{a, b}(t) d t
$$

onde os parâmetros $a$ e $b$ correspondem às informações de escala e tempo, respectivamente, variando continuamente ao longo de $\mathbb{R}$, e $\psi_{a, b}$ são as funções denominadas wavelets, definidas como:

$$
\psi_{a, b}(t)=\frac{1}{\sqrt{a}} \psi\left(\frac{t-b}{a}\right)
$$

A obtenção dos coeficientes wavelet em cada escala possível necessita de uma quantidade imensa de cálculo. Para simplificar os cálculos, utiliza-se a transformada discreta de wavelets, que escolhe um subconjunto de escalas e regiões do sinal sobre os quais serão realizados os cálculos. A transformada wavelet para sinais discretos é definida como:

$$
F_{m, n}(a, b)=a_{0}^{-m / 2} \int f(t) \psi\left(a_{0}^{-m} t-n b_{0}\right) d t
$$

O comportamento desta função se baseia em dilatações e translações a partir de uma wavelet mãe $\psi$ (Castañon, 2003). A wavelet mãe deve, obrigatoriamente, satisfazer a seguinte propriedade:

$$
\int \psi(t) d t=0
$$

As wavelets mãe $(\psi)$ são utilizadas para determinar os detalhes de um sinal e a informação de tendência é armazenada nos coeficientes obtidos pelas wavelets pai $(\phi)$. Embora a descrição de transformada wavelet apresentada até aqui seja apena uni-dimensional, sua extensão para dimensões maiores pode ser realizada de várias formas. A maneira mais tradicional, e de complexidade razoável, de extender a transformada para o domínio bidimensional é através do produto tensorial (Castañon, 2003). 
Dentre as transformadas wavelet mais utilizadas, podemos citar a de Haar (Meyer, 1993; Graps, 1995) e a de Daubechies (Daubechies, 1992), que é uma continuação da abordagem de Haar.

\section{Wavelets de Haar}

A wavelet de Haar é considerada a mais simples de todas, proposta por Alfred Haar em 1909 (Meyer, 1993). Seu funcionamento discretizado pode ser obtido através de um cálculo de "média e diferença" entre regiões vizinhas (ou pixels vizinhos), obtendo-se, assim, a resultante da aplicação da wavelet sobre o sinal de entrada. Ela pode ser descrita pela fórmula:

$$
\psi(x)=\left\{\begin{aligned}
1, & 0 \leq x<1 / 2 \\
-1, & 1 / 2 \geq x<1 \\
0, & \text { caso contrário }
\end{aligned}\right.
$$

Existem algumas limitações na utilização das wavelets de Haar. Como sua construção é uma função de passos descontínuos, ela pode não ser muito adeqüada para a análise de funções com regiões contínuas, isto é, sem variações. Desta forma, as wavelets de Haar não produzem resultados satisfatórios em diversas aplicações com imagens, uma vez que é comum elas possuírem regiões estáveis (Wang, 2001).

\section{Wavelets de Daubechies}

Para resolver o problema relacionado com os sinais estáveis, Daubechies desenvolveu um conjunto de wavelets formadas por funções contínuas, sendo assim, deriváveis, que ficaram conhecidas como as wavelets de Daubechies (Daubechies, 1992). Este conjunto inclui vários tipos de funções, desde altamente locais até bastante suaves. A mais simples de todas, por sua vez, é a própria wavelet de Haar, sendo este o único caso de função descontínua do conjunto. Alguns exemplos de wavelets de Daubechies podem ser vistos na figura 3.4.
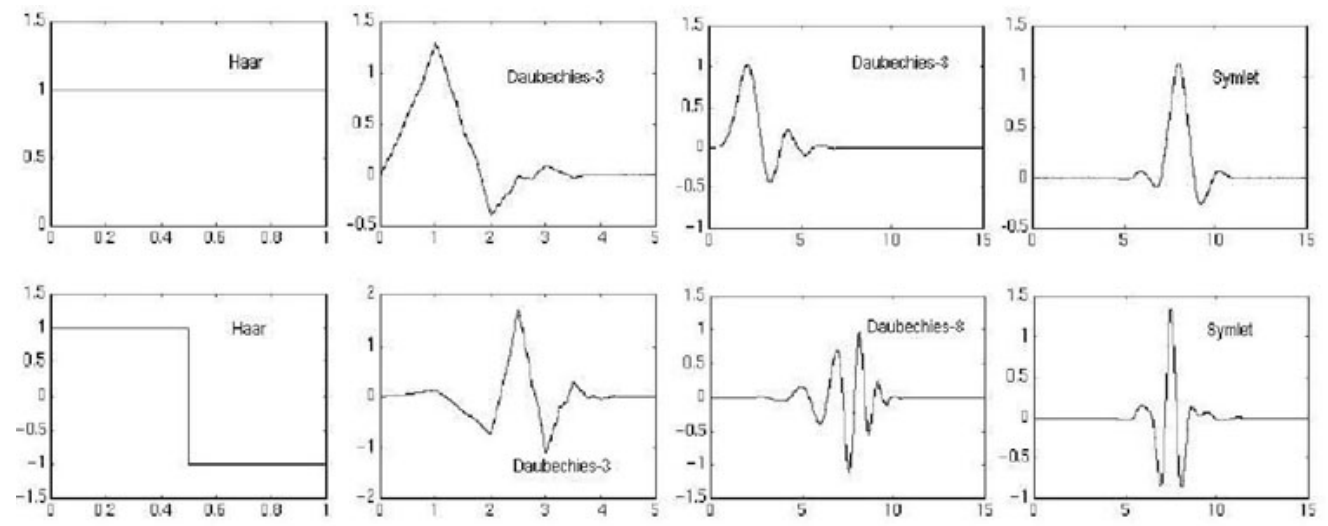

Figura 3.4: Conjunto de wavelets pai (acima) e mãe (abaixo) de Daubechies (Wang, 2001).

Devido a seu suporte compacto e sua capacidade de derivação, as wavelets de Daubechies obtém excelentes resultados em aplicações de processamento de imagens (Wang, 2001). O suporte compacto facilita a implementação, necessitando apenas da geração de filtros de tamanho finito. A capacidade de derivação faz com que um sinal contínuo 
seja decomposto mais eficientemente, evitando a geração de artefatos causados pela sua aplicação.

\subsubsection{Aplicações}

As transformadas de wavelets são utilizadas em várias áreas do processamento de sinais tais como detecção de bordas, suavização de imagens, classificação de imagens, image retrieval, entre outras (Wang, 2001). Porém, uma de suas aplicações mais conhecidas é a de compressão de imagens, devido ao fato de a transformada wavelet oferece uma boa localização no tempo e na freqüência (Wang, 2001). Na compressão de imagens, a informação da imagem é decomposta em médias e diferenças de intensidade dos pixels vizinhos, podendo assim guardar apenas uma versão em resolução considerávelmente baixa da imagem original e seus coeficientes de variação de freqüência. A figura 3.5 mostra uma decomposição em 3 níveis de uma imagem através da utilização de transformadas de wavelets.
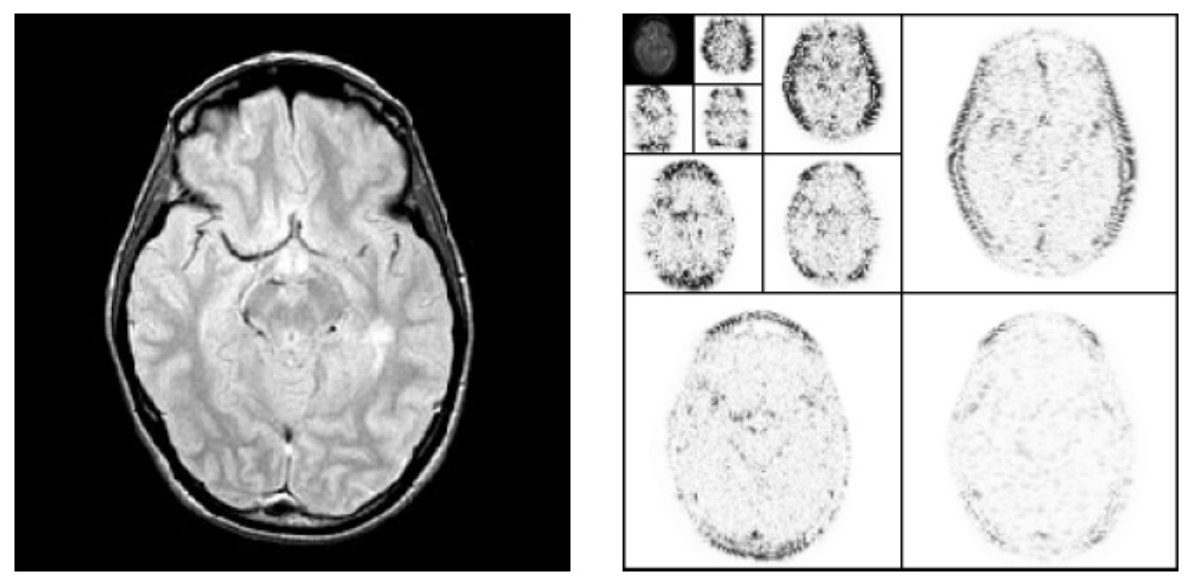

Figura 3.5: Aplicação da transformada wavelet de Daubechies de três níveis para uma imagem de MRI. Os pontos pretos indicam coeficientes diferentes de freqüência diferentes de zero (Wang, 2001).

\subsection{Filtros de Gabor}

Os filtros de Gabor, originalmente propostos como funções por Dennis Gabor (Gabor, 1946) para utilização em transmissão de som, são amplamente utilizados nas áreas de processamento de imagens ligadas à segmentação e à análise de texturas por motivos como: estarem otimamente localizadas no domínio do espaço e da freqüência; conter um maior número de parâmetros que a utilização de wavelets tradicionais (Castañon, 2003); e por possuir comportamento similar ao córtex visual de seres humanos e demais mamíferos (Daugman, 1985; Petkov e Kruizinga, 1997). Dentre algumas das diversas áreas englobadas pela utilização destes filtros estão a segmentação de texturas (Jain e Farrokhnia, 1991; Weldon e Higgins, 1994; Dunn e Higgins, 1993; Weldon e Higgins, 1996; Weldon et al., 1996; Weldon, 2006), image retrieval (Zhang et al., 2000; Wolf et al., 2000; Castañon, 2003; Chen et al., 2004), detecção de escadas para auxílio de pessoas com deficiência visual (Se e Brady, 2000), inspeção automática de superfícies (Tsai e Wu, 
2000), reconhecimento de faces em seqüências de vídeo (Feris et al., 2001), reconhecimento de impressões digitais (Ross et al., 2002a,b), entre outras.

\subsubsection{Formulação}

Uma função bidimensional de Gabor consiste de um plano senoidal de uma determinada frequência e orientação envolto por uma Gaussiana bidimensional (Jain e Farrokhnia, 1991). A função de Gabor no domínio espacial é dada por:

$$
h(x, y)=\exp \left\{-\frac{1}{2}\left[\frac{x^{2}}{\sigma_{x}^{2}}+\frac{y^{2}}{\sigma_{y}^{2}}\right]\right\} \cos \left(2 \pi \mu_{0} x+\phi\right),
$$

onde $\mu_{0}$ e $\phi$ são, respectivamente, a freqüência e a fase do plano senoidal ao longo do eixo $x$, isto é, na orientação de $0^{\circ}$, e $\sigma_{x}$ e $\sigma_{y}$ são as constante espaciais de tamanho da gaussiana nos eixos $x$ e $y$. Como se pode perceber, o parâmetro de orientação não entra na formulação. Mas, uma vez gerada a função de Gabor para a orientação de $0^{\circ}$, basta realizar uma rotação da mesma no plano $x-y$ para obter as demais orientações desejadas, evitando-se, assim, excessivos e repetitivos cálculos matemáticos (figura 3.6).

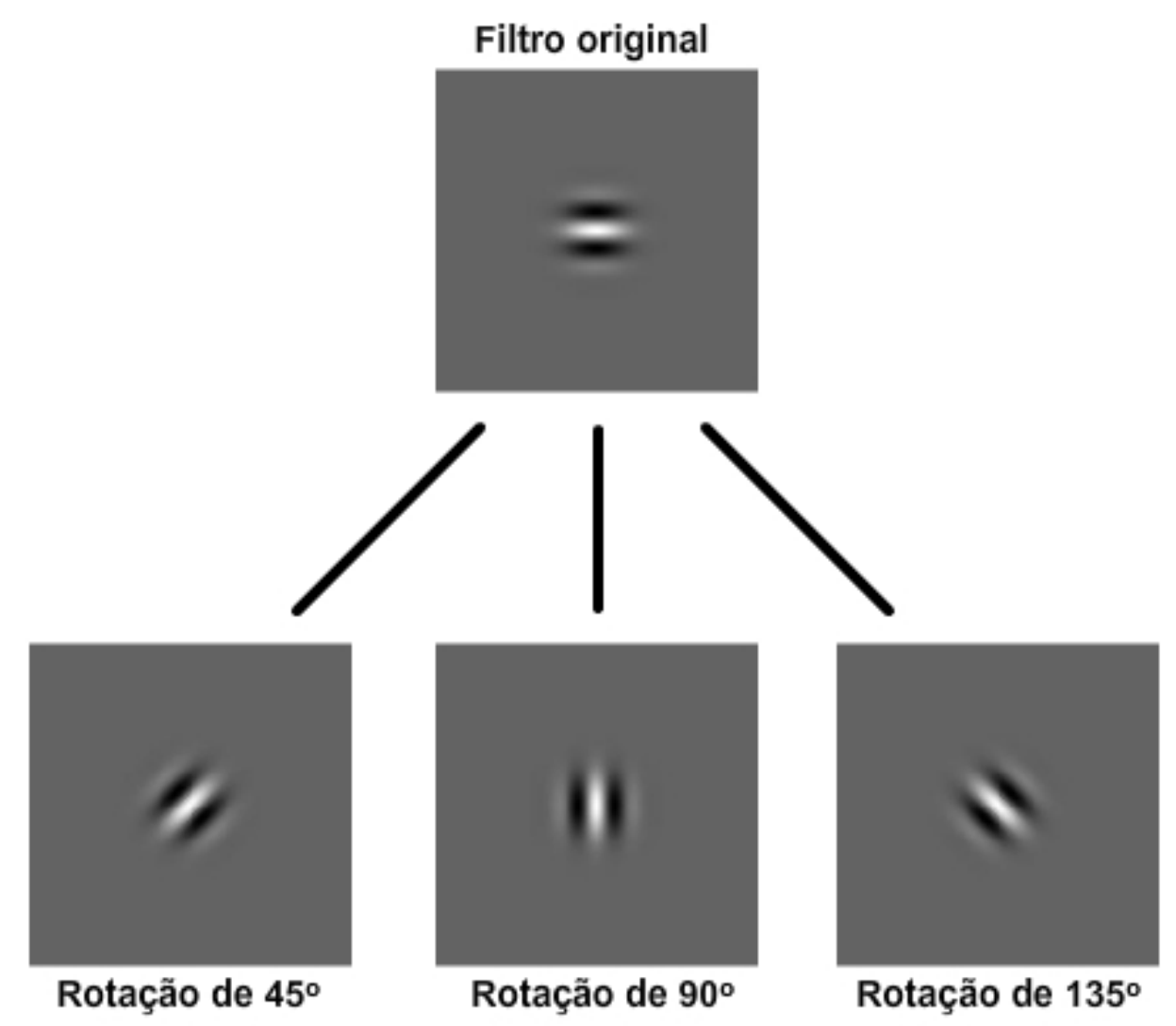

Figura 3.6: A partir de um filtro gerado em $0^{\circ}$, é possível obter os filtros em outras orientações através da rotação deste.

As propriedades de seleção de orientação e freqüência da função de Gabor são mais explícitas em sua representação no domínio de freqüência (Jain e Farrokhnia, 1991). A transformada Fourier da função Gabor dada pela equação 3.9, $\operatorname{com} \phi=0$, é dado por: 


$$
H(u, v)=A\left(\exp \left\{-\frac{1}{2}\left[\frac{\left(u-u_{0}\right)^{2}}{\sigma_{u}^{2}}+\frac{v^{2}}{\sigma_{v}^{2}}\right]\right\}+\exp \left\{-\frac{1}{2}\left[\frac{\left(u+u_{0}\right)^{2}}{\sigma_{u}^{2}}+\frac{v^{2}}{\sigma_{v}^{2}}\right]\right\}\right)
$$

onde $\sigma_{u}=1 / 2 \pi \sigma_{x}, \sigma_{v}=1 / 2 \pi \sigma_{y}$ e $A=2 \pi \sigma_{x} \sigma_{y}$. Esta representação (equação 3.10) especifica a quantidade pela qual o filtro modifica ou modula cada componente de freqüência da imagem de entrada (Jain e Farrokhnia, 1991). A figura 3.7 exibe as funções de Gabor no domínio espacial e no domínio de freqüencia.
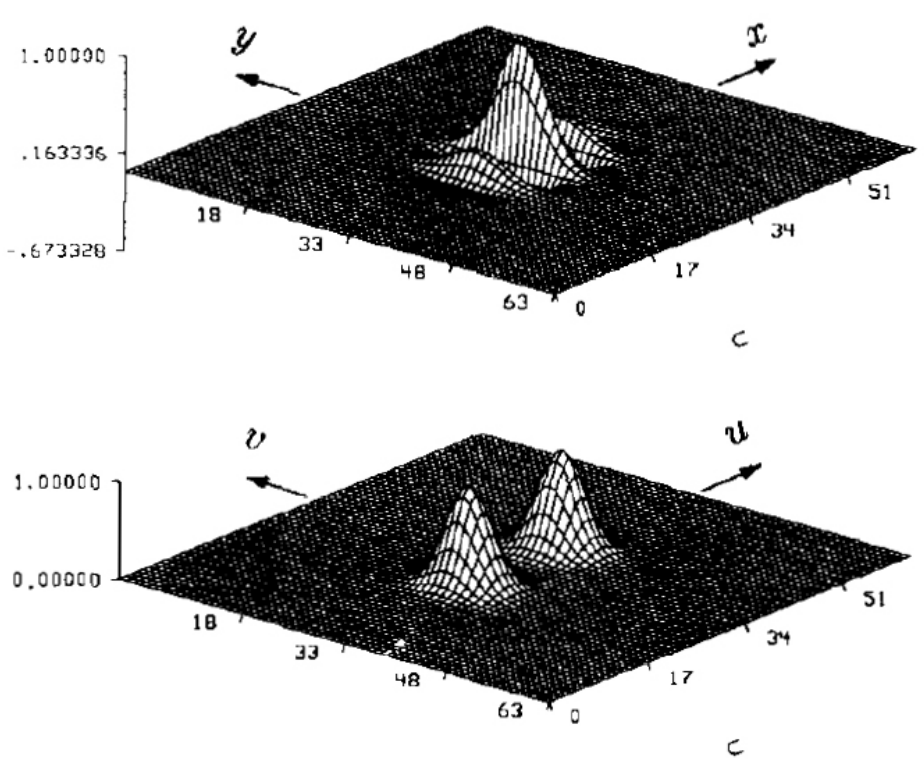

Figura 3.7: Filtro de Gabor no domínio espacial (acima) e domínio da freqüência (abaixo) (Jain e Farrokhnia, 1991).

\subsubsection{Escolha dos Parâmetros}

A escolha dos parâmetros que serão utilizados na geração das funções de Gabor depende muito da utilização que será dada a elas. Algumas abordagens empregam a utilização de um banco de filtros de Gabor pré-determinados por alguns parâmetros de entrada enquanto outras utilizam-se de um pequeno conjunto de filtros selecionados para resolver um problema específico (Weldon e Higgins, 1996). Os casos onde são utilizados poucos filtros são, geralmente, métodos supervisionados de segmentação e análise, requerendo mais interação humana. Já os casos em que são utilizados os bancos de filtros, abordagens não-supervisionadas podem ser formuladas, dependendo apenas de uma boa escolha de parâmetros iniciais.

Os parâmetros selecionados para o caso onde são utilizados bancos de filtros devem ser selecionados segundo algumas regras para reduzir problemas de redundância (Castañon, 2003):

- Separação uniforme na orientação, onde todos os filtros em uma escala específica deveriam ter o mesmo desvio-padrão angular; 
- Separação exponencial na escala, onde o comprimento dos filtros devem crescer exponencialmente de escala para escala de acordo com a multiplicação de um parâmetro escalar bem definido;

- Cobertura contínua do espaço de frequência, onde o contorno de dois filtros vizinhos tocam um ao outro nos eixos de escala e orientação, evitando ao máximo a sobreposição dos mesmos.

Para um exemplo de aplicação, a figura 3.8 exibe um conjunto de filtros gerados para oito orientações e sete escalas diferentes. Ainda na figura 3.8, é exibida a cobertura destes mesmos filtros no plano de freqüência espacial.

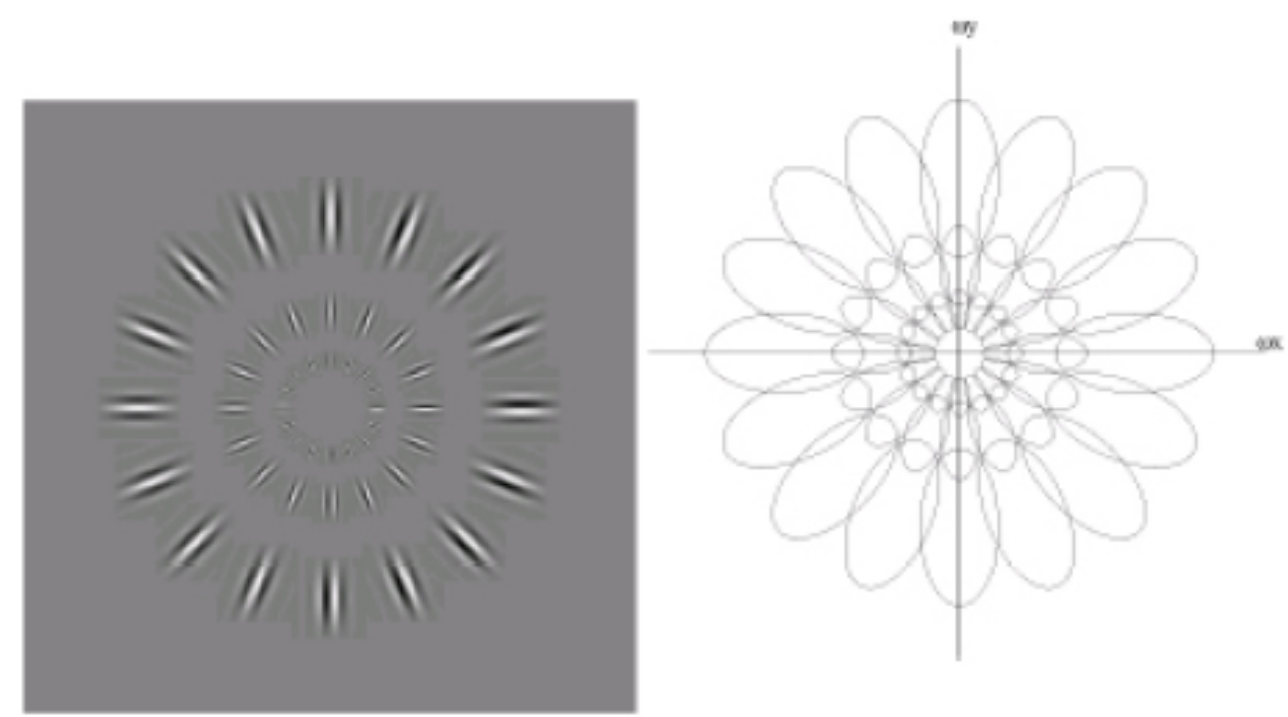

Figura 3.8: Conjunto de filtros de Gabor (esquerda) e sua cobertura no plano de freqüência (direita) (Castañon, 2003).

\subsection{Considerações}

Este capítulo apresentou algumas abordagens muito comuns no tratamento de problemas relacionados à análise multi-escala. Dentre os métodos descritos, optou-se pela utilização dos filtros de Gabor. Esta escolha se deu pelo fato de que estes filtros são sensíveis à orientação, permitindo realizar uma segmentação das texturas presentes na imagem de entrada baseada na orientação das mesmas. Isto se prova muito útil, uma vez que o conjunto de dados de entrada proposto pelo trabalho possui por natureza características fortes de alinhamento e orientação, como é o caso de várias imagens de cenas naturais. Imagens aéreas de plantações de eucalipto constituem um destes casos e serão analisados neste trabalho.

Embora a formulação mais tradicional dos filtros de Gabor sejam como foi apresentado pela equação 3.9, a formulação utilizada por este trabalho é similar à apresentada por Weldon (Weldon e Higgins, 1994, 1996; Weldon et al., 1996; Weldon, 2006). Esta formulação é dada por:

$$
h(x, y)=\frac{1}{A} \exp \left\{-\frac{1}{2}\left[\frac{x^{2}}{\sigma_{x}^{2}}+\frac{y^{2}}{\sigma_{y}^{2}}\right]\right\} \cos \left(2 \pi \mu_{0} x+\phi\right),
$$


onde $A=2 \pi \sigma_{x} \sigma_{y}$. Desta forma, evita-se que filtros com altos valores de $\sigma$ (filtros de grandes dimensões) produzam resultados sempre maiores que aqueles gerados por filtros com valores de $\sigma$ menores.

O próximo capítulo irá apresentar a metodologia empregada no desenvolvimento do trabalho, descrevendo em detalhes cada etapa de seu funcionamento. 


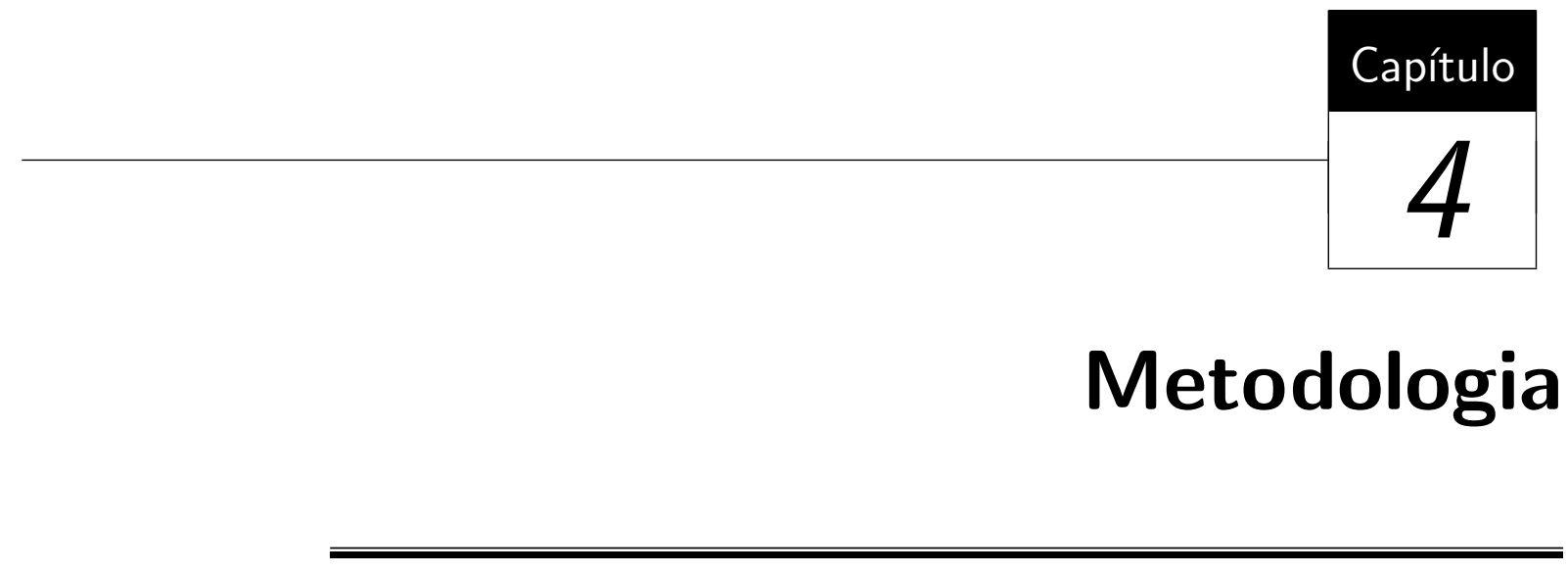

Este capítulo apresenta a metodologia utilizada no presente trabalho, cujo objetivo é o de obter um correlacionamento entre o conjunto de imagens a serem mosaicadas, em menor escala, e um mapa de base, de escala maior. Este correlacionamento é realizado quase que totalmente automaticamente, necessitando apenas de interações mínimas do usuário, como a seleção de uma imagem de referência e definição de um limiar (explicados nas seções a seguir). A partir destas informações de entrada, o método é capaz de selecionar automaticamente dentre um banco de filtros de Gabor o que melhor se adapta ao conjunto de imagens em questão. A partir desta seleção e da reaização de processos que serão explicados a seguir, o mosaico é produzido sem maiores necessidades de interação humana.

Para facilitar a compreensão, a metodologia pode ser subdividida em três etapas: a primeira realiza a escolha automática dos filtros de Gabor a serem utilizados; a segunda tem como objetivo definir a região de interesse para a geração do mosaico no mapa de base; por fim, a terceira compreende a geração do mosaico a partir das informações obtidas nas etapas anteriores. Cada uma destas etapas será descrita em maiores detalhes a seguir.

\subsection{Escolha dos Filtros de Gabor}

Esta etapa é responsável pela seleção automática dos filtros que serão utilizados no decorrer do processo de mosaicagem. É de fundamental importância que os filtros escolhidos nesta etapa estejam de acordo com o padrão necessitado para a realização do trabalho, ou seja, que sua orientação e dimensões (valores de $\sigma$ ) se adeqüem o melhor possível às características presentes nas imagens do conjunto a serem mosaicadas. Caso contrário, os resultados podem ser inadeqüados, acarretando problemas e dificuldades na geração do mosaico ou, até mesmo, gerando-o incorretamente. A figura 4.1 apresenta um diagrama de como esta etapa é realizada. 


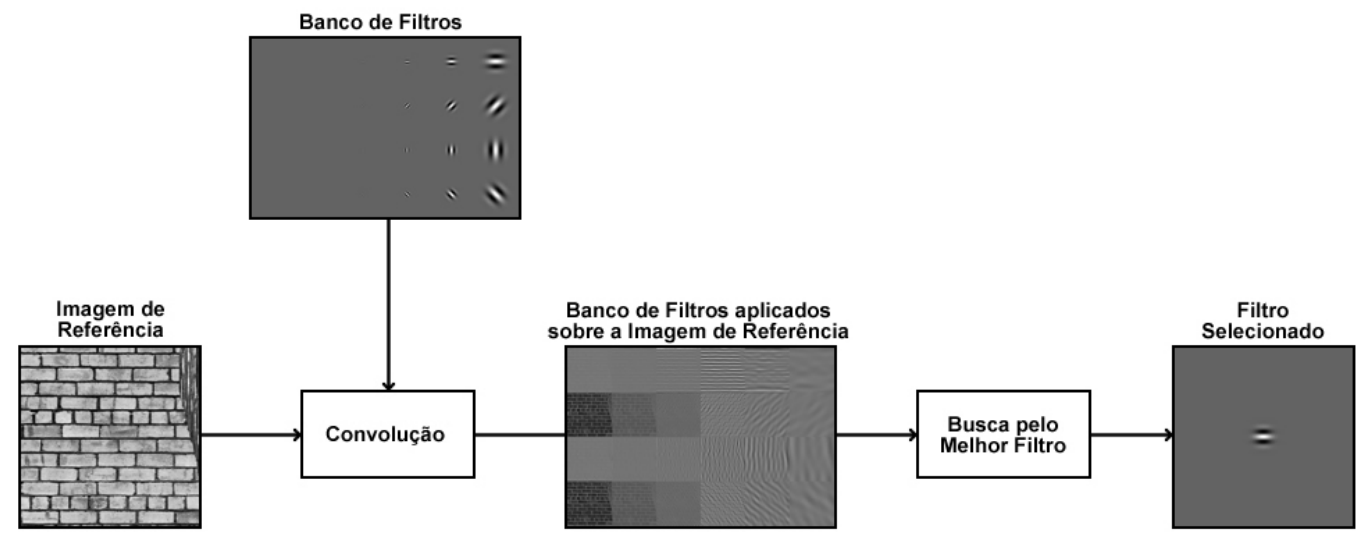

Figura 4.1: Etapa de seleção do filtro a ser utilizado. A partir de uma imagem de referência e de um banco de filtros gerados, é feita a escolha do filtro que melhor se adapta à mesma, ou seja, retorna a melhor resposta de sinal.

\subsubsection{Selecionando a Imagem de Referência}

Inicialmente, é preciso selecionar, entre as imagens do conjunto de imagens que formarão o mosaico, a que será utilizada como referência no decorrer do processo. Para isto, utiliza-se preferencialmente a que contenha, na maior parte de sua superfície, uma característica comum dentre as imagens do conjunto, como por exemplo, uma textura homogênea. Esta imagem será utilizada como uma imagem de referência para a escolha do filtro. A figura 4.2 mostra dois exemplos de imagens presentes na coleção de imagens a serem mosaicadas para um determinado mapa de base. Se o objetivo da mosaicagem em questão for, por exemplo, a geração do mosaico para imagens contendo texturas de paredes de tijolos, a imagem da esquerda é uma ótima escolha, uma vez que em praticamente toda a sua superfície, esta textura aparenta ser homogênea, sem grandes alterações ou regiões discrepantes. Já a imagem da direita pode ser considerada uma má escolha por não possuir a homogeneidade de textura presente na outra figura, o que pode causar erros na geração final do mosaico devido à uma má decisão do método sobre os filtros a serem utilizados no processo.

\subsubsection{Geração e convolução dos filtros}

Após a seleção da imagem de referência, definem-se e geram-se os filtros de Gabor que serão aplicados sobre a mesma de modo a encontrar aquele que produz melhores resultados na busca pela orientação e escala da imagem. Como exemplo, para a imagem em questão, selecionam-se filtros de Gabor em quatro orientações diferentes $\left(0^{\circ}, 45^{\circ}, 90^{\circ} \mathrm{e}\right.$ $135^{\circ}$ ) e com tamanho $(\sigma)$ variando de 2 a 64 pixels de diâmetro, onde cada filtro possui um tamanho igual ao dobro do filtro anterior, totalizando 6 variações de tamanho. A partir daí, o próximo passo a ser executado é a aplicação destes filtros sobre a imagem de referência. As 24 possíveis variações de filtro e a aplicação dos mesmos sobre a imagem de referência podem ser vistos nas figuras 4.3 e 4.4 . 


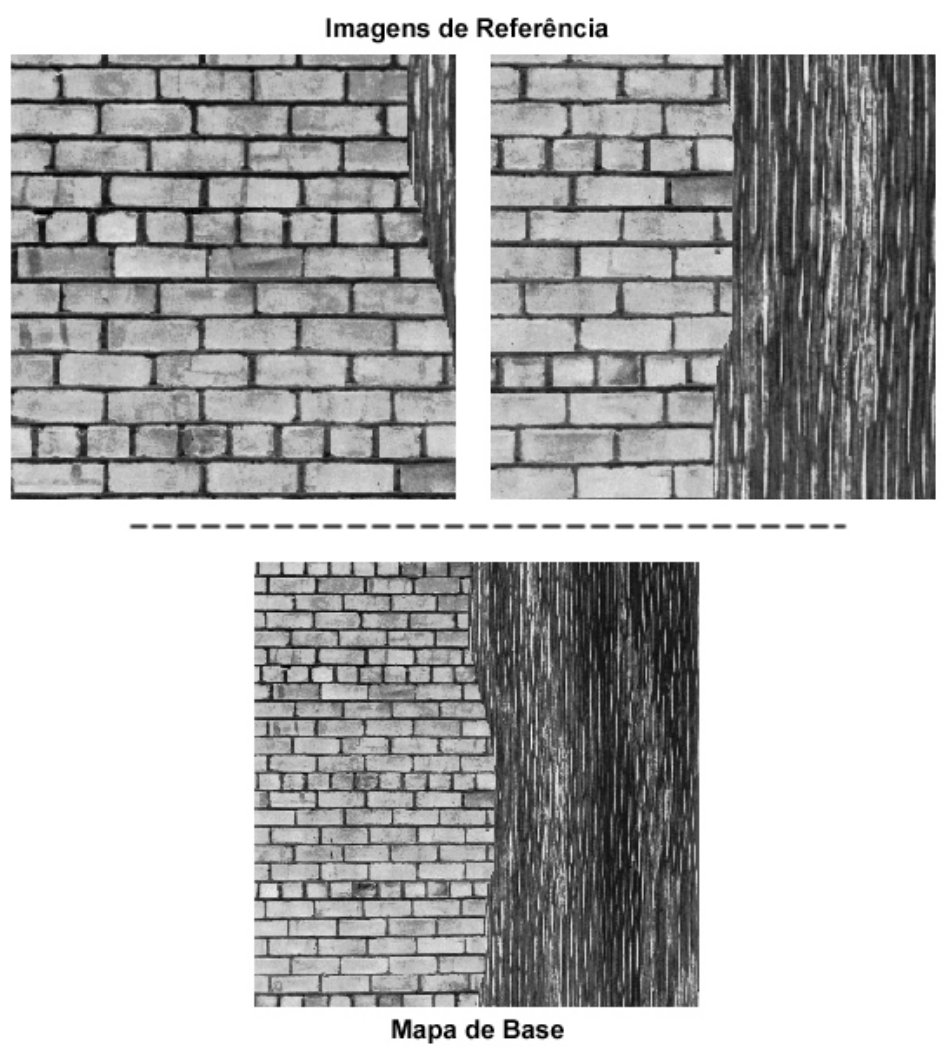

Figura 4.2: Exemplo de imagens de referência. A imagem da esquerda possui uma textura mais homogênea, sendo mais indicada para servir como referência em relação ao mapa de base (abaixo). Já a imagem da direita possui regiões que podem causar erros no decorrer do processo.

\subsubsection{Busca pelo melhor filtro}

Com os resultados da aplicação dos filtros, é possível decidir qual será o filtro que melhor representa a orientação e escala da imagem. Para isso, primeiramente, é realizada a geração de um único histograma para todo conjunto de imagens filtradas. Com o auxílio da acumulada deste histograma e um limiar, pode-se binarizar a imagem, no caso, uma porcentagem em relação à acumulada. A figura 4.5 exibe o histograma e sua respectiva acumulada para a imagem utilizada em questão. A linha tracejada representa o limiar, definido empiricamente com o valor de $70 \%$ sobre a acumulada. Com isto, consideramos 1 o valor de qualquer região da imagem cujo pixel correspondente esteja acima ou igual ao valor correspondente à esta marca no histograma e 0 o dos demais pixels, obtendo assim uma imagem binarizada (figura 4.6).

Com o conjunto de filtros aplicados binarizados em mãos, é realizado agora o processo de contagem, em cada imagem, da quantidade de linhas formadas por pontos consecutivos em cada uma das orientações selecionadas, conhecido como contagem de runs. Esta contagem retorna como resposta a quantidade de ocorrências de um determinado tamanho de segmento de linha contínuo de valor 1 presente em cada imagem. Através desta resposta, é possível decidir qual filtro obteve uma melhor resposta $(C)$ ao ser aplicado na imagem através da aplicação da fórmula 


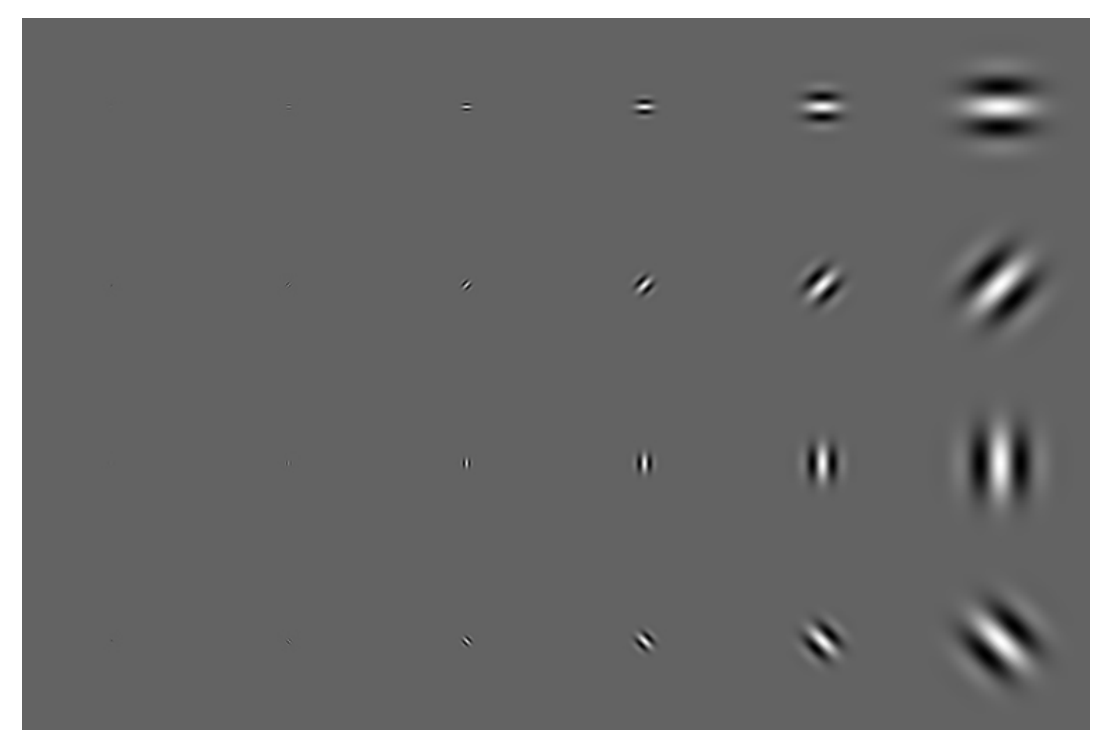

Figura 4.3: Filtros com orientações e tamanhos definidos pelos parâmetros de entrada.

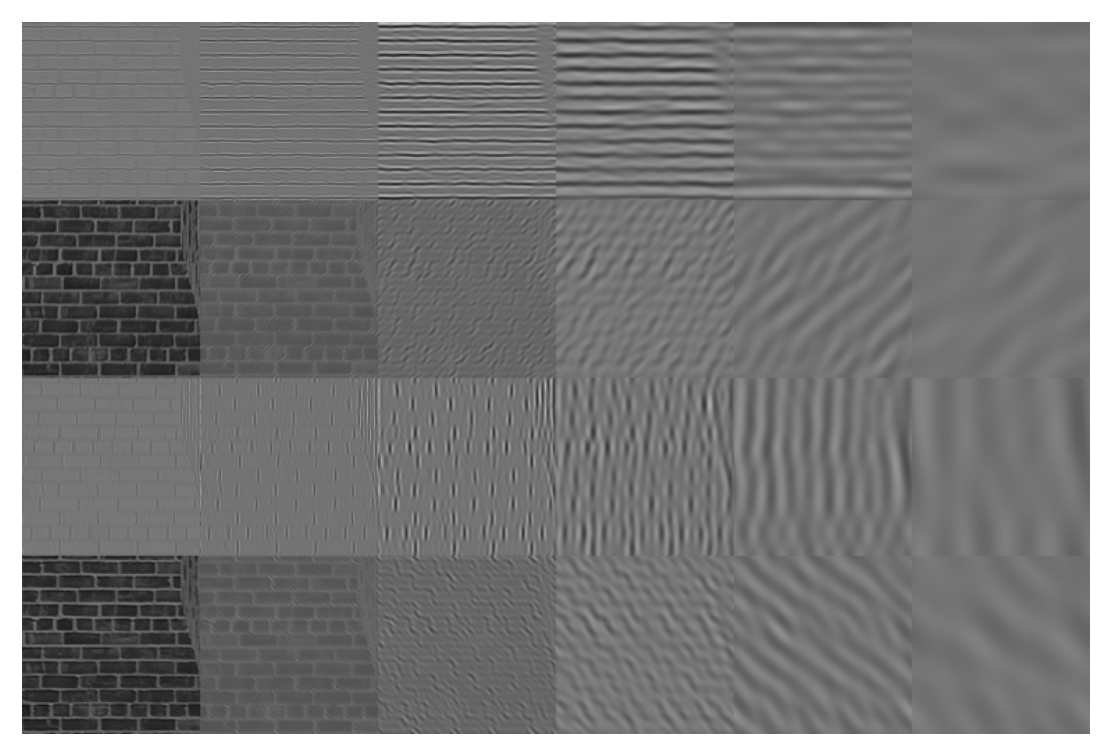

Figura 4.4: O resultado da aplicação dos filtros gerados sobre a imagem de referência.

$$
C=\sum_{i=1}^{N} s(i) i^{2},
$$

onde $N$ é o comprimento máximo possível de uma run e $s(i)$ é o número de runs de tamanho $i$. O filtro que produzir o maior coeficiente $C$ ao final de todo este processo será o escolhido. A figura 4.7 exibe o resultado da contagem de runs de um determinado tamanho de filtro em suas quatro orientações, incluindo os coeficientes obtidos através da aplicação da fórmula 4.1 .

O filtro escolhido é aquele que será aplicado sobre as imagens a serem mosaicadas. Já o filtro que será aplicado na imagem de base, que será intitulado aqui como "Filtro MB", será o filtro correspondente a este em relação à diferença de escala entre as duas. Se, por exemplo, a imagem de referência está em uma escala duas vezes maior que a do mapa de base, o filtro escolhido para ser aplicado ao mapa de base (Filtro MB) será de mesma 

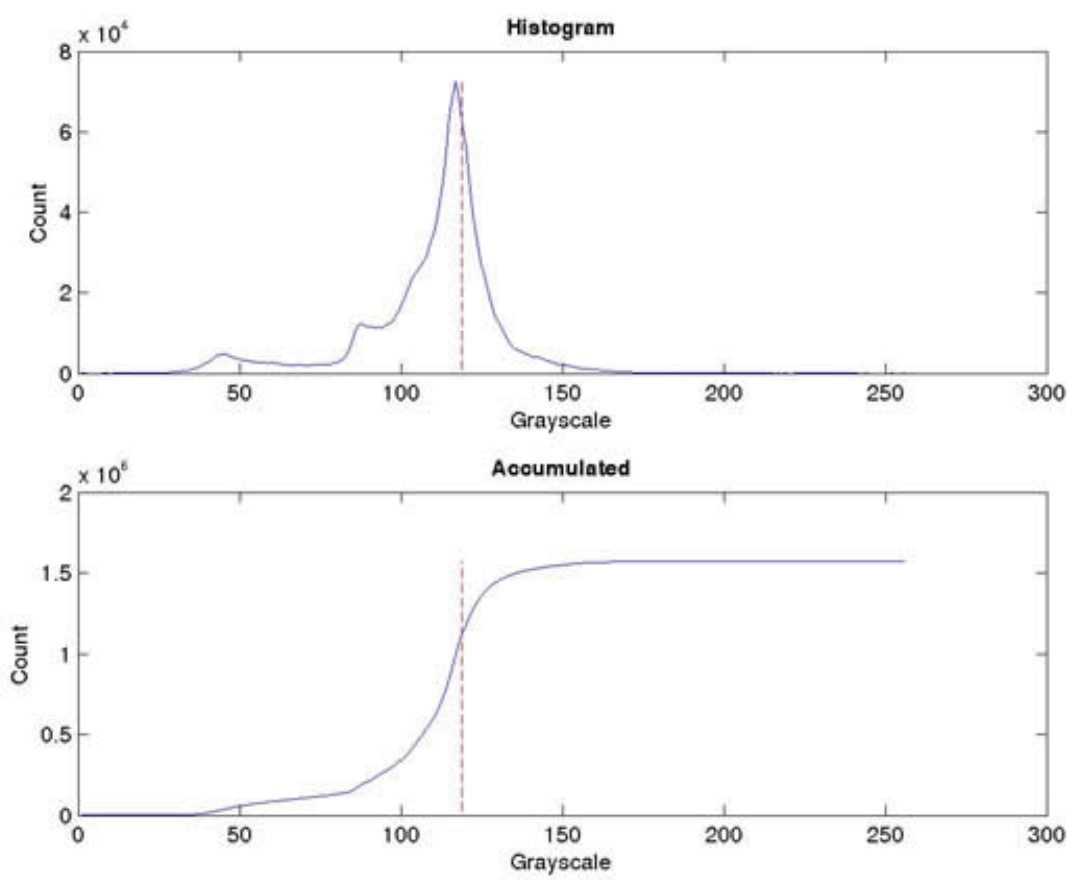

Figura 4.5: Histograma e Acumulada do conjunto de imagens filtradas correspondentes à imagem de referência utilizada de exemplo.

orientação, mas de tamanho equivalente à metade do tamanho do filtro escolhido (como mostra a figura 4.8).

\subsection{Definindo a Região de Interesse no Mapa de Base}

Esta etapa tem por objetivo encontrar no mapa de base as regiões que possuem a mesma orientação da imagem de referência mas na escala menor relativa à diferença de escala entre a imagem de referência e o mapa de base. Para isto, será aplicado sobre a imagem de base o filtro cuja seleção foi explicada na seção anterior. Os processos desta etapa são mostrados no diagrama da figura 4.9 .

O primeiro passo é a aplicação do Filtro MB sobre o mapa. A partir do resultado dessa aplicação, o mapa de base filtrado passa também pelo processo de binarização (descritos na seção anterior). Após estas etapas, a seleção da região de interesse se dá através de um outro processo de contagem de runs, similar ao já descrito anteriormente, utilizando a fórmula 4.1. A diferença está no fato de que, desta vez, esta contagem é realizada dentro de janelas deslizantes de dimensões bastante reduzidas, podendo ser, por exemplo, igual a 1/4 do tamanho das dimensões do mapa. Esta janela desloca-se pela imagem do mapa, binarizada e filtrada, ignorando um pré-determinado número de pixels de modo a acelerar o processo. Desta maneira, obtém-se uma matriz de coeficientes de contagem de runs, mapeando toda a imagem. Porém, como já é sabido de antemão o ângulo de orientação desejado da região de interesse, esta matriz possui apenas os coeficientes obtidos deste ângulo, mantendo com valor 0 as regiões onde, através do processo de contagem, uma outra orientação tenha produzido maior coeficiente. Uma versão binarizada da mesma é gerada através de um processo de limiarização onde valores muito baixos de coeficientes 


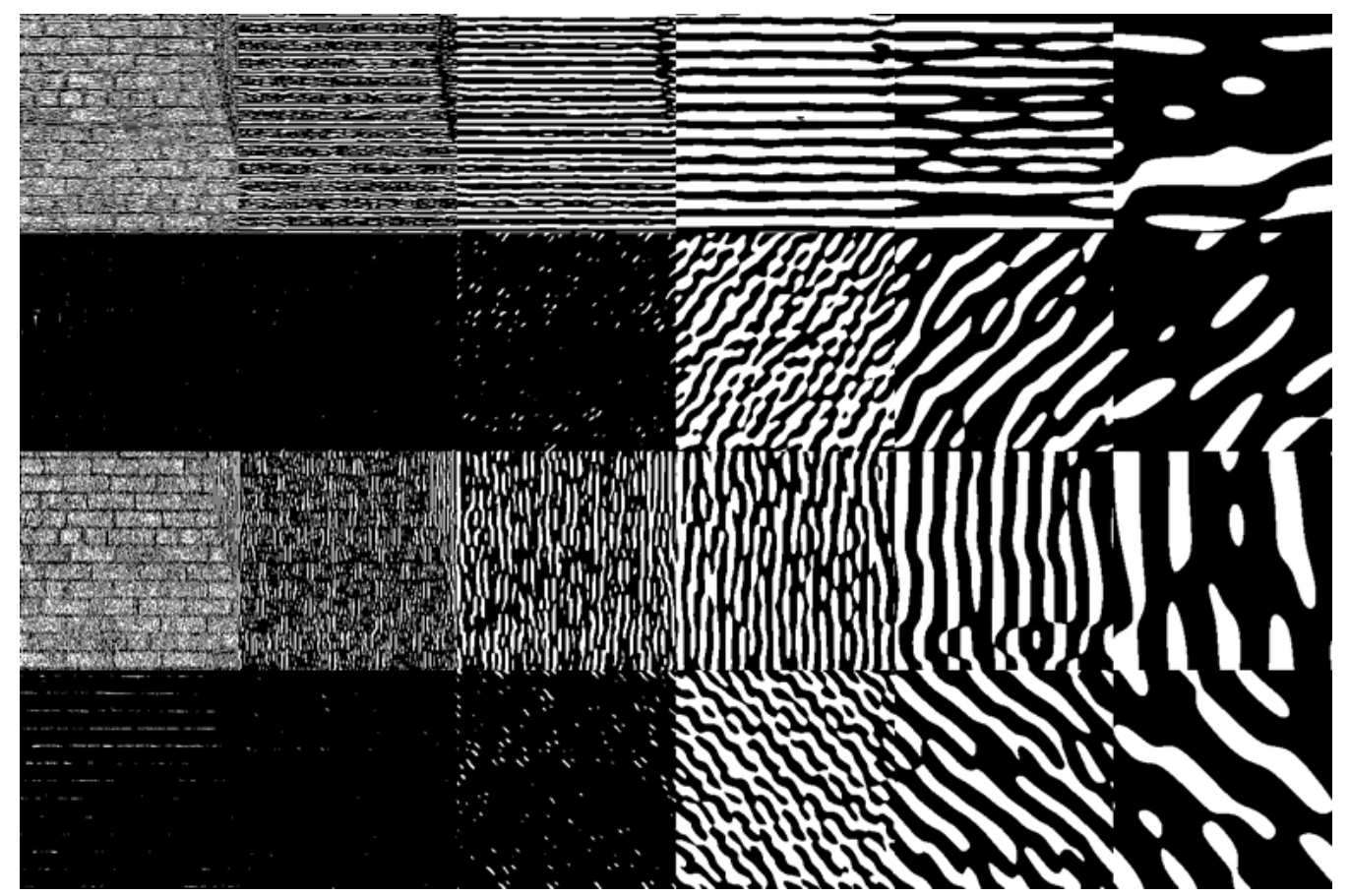

Figura 4.6: Resultado do processo de binarização do conjunto de filtros aplicados à imagem de referência.

são tidos como 0 e o resto da matriz como 1 . Um exemplo de matriz de coeficientes pode ser visto na figura 4.10 .

A partir desta matriz (em sua versão binarizada) é possível obter, finalmente, a região de interesse desejada no mapa de base. A figura 4.11 exibe um exemplo de mapa de base com sua região de interesse delimitada.

\subsection{Geração do Mosaico}

Após escolher o filtro a ser utilizado e definir no mapa de base a região de interesse sobre a qual será formada o mosaico, a única etapa a ser realizada é a concatenação das imagens para a geração do mosaico. Esta última etapa, basicamente, busca encontrar o posicionamento relativo das imagens de menor escala em relação ao mapa de base. Um diagrama desta etapa pode ser visto na figura 4.12 .

Primeiramente, as imagens que formarão o mosaico passam pelo filtro selecionado na primeira etapa. Esse conjunto de imagens filtradas é então escalonado através de uma transformação afim 2D simples de modo a ficar na mesma escala do mapa de base. A partir daí, é realizada para cada imagem uma busca dentro da região de interesse no mapa de base para encontrar a posição onde cada uma delas melhor se encaixa. Essa busca é feita deslocando-se as imagens por toda a extensão da região de interesse e, para cada coordenada $x, y$, é realizada uma operação de subtração dos valores de pixel correspondentes da imagem em relação ao mapa de base. A figura 4.13 exibe um esquema de aplicação desta subtração.

Este processo de subtração gera como resposta uma matriz de resultados contendo o valor absoluto da soma dos valores de pixel remanescentes em cada região subtraída após a subtração. O ponto desta matriz onde este valor for mínimo, provavelmente, é o lugar ideal da imagem, pois indica que a resposta do filtro sobre a imagem a ser mosaicada está 

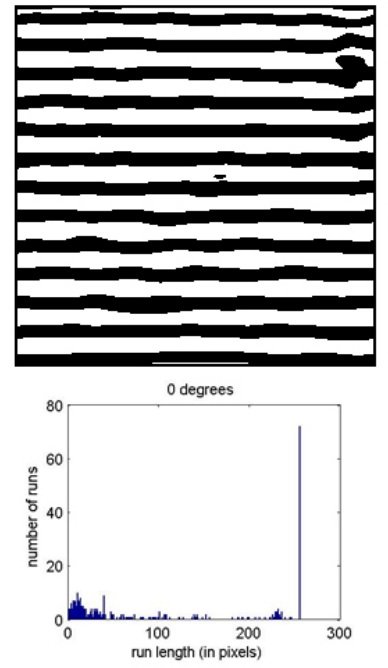

$C=7.087 .614$

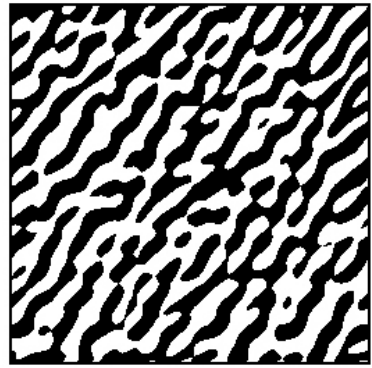

45 degrees

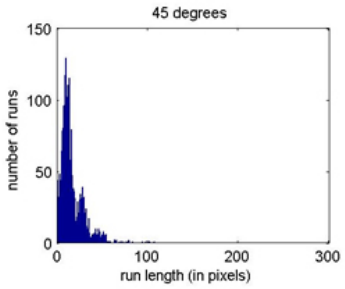

$C=850.207$
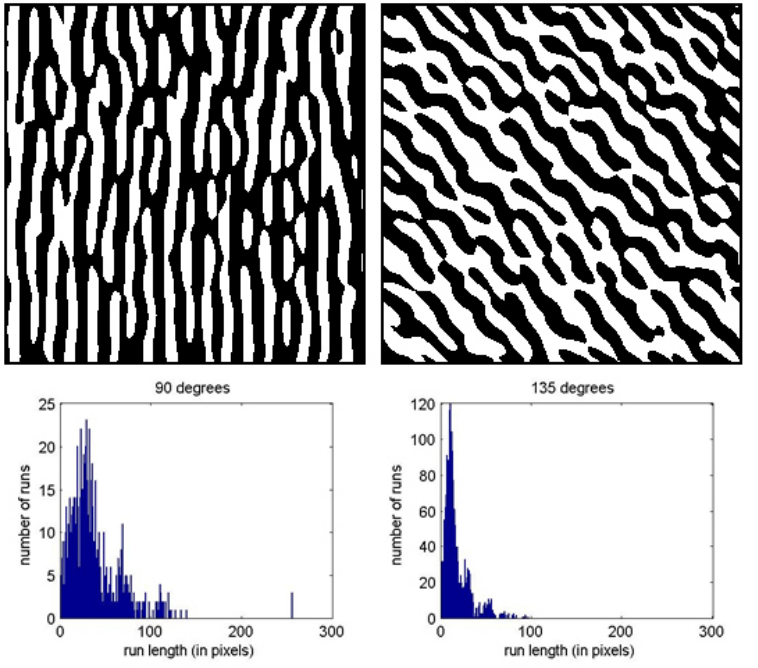

$C=1.703 .479$

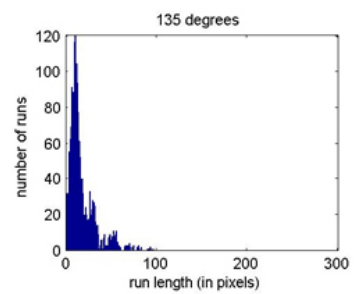

$C=999.880$

Figura 4.7: Contagem de runs em cada orientação de um determinado tamanho de filtro. Neste caso, pode-se notar que, o filtro de orientação igual a $0^{\circ}$ possui um coeficiente bastante superior às demais orientações.

bastante próxima à resposta do filtro relativo na região sobre a qual esta imagem está posicionada. A figura 4.14 ilustra, através de cores, o resultado dos valores obtidos pela subtração em cada ponto da imagem. As regiões mais próximas do vermelho são as piores posições para o posicionamento enquanto as regiões mais próximas do azul demonstram possíveis melhores posições. Os pontos brancos são os pontos onde este valor é mínimo. Desta forma, eles indicam as melhores escolhas de coordenada para o posicionamento.

Este processo é repetido para todas as imagens do conjunto de entrada. Após encontrar para cada imagem filtrada sua posição no mapa de base, basta calcular a posição relativa das imagens reais em sua escala original. Com a realização desta etapa para todas as imagens do conjunto, tem-se finalmente o mosaico gerado.

\subsection{Considerações}

Este capítulo apresentou a metodologia utilizada no trabalho. Como pode se perceber, esta metodologia combina as duas abordagens apresentadas na seção 3.3.2. Um grande conjunto de filtros é gerado para ser aplicado sobre a imagem de referência. Porém, para as demais imagens, utiliza-se apenas um conjunto mínimo de filtros selecionados, definidos automaticamente a partir dos resultados obtidos com a imagem de referência.

No próximo capítulo, serão apresentados os resultados de alguns experimentos realizados utilizando a metodologia aqui descrita. 


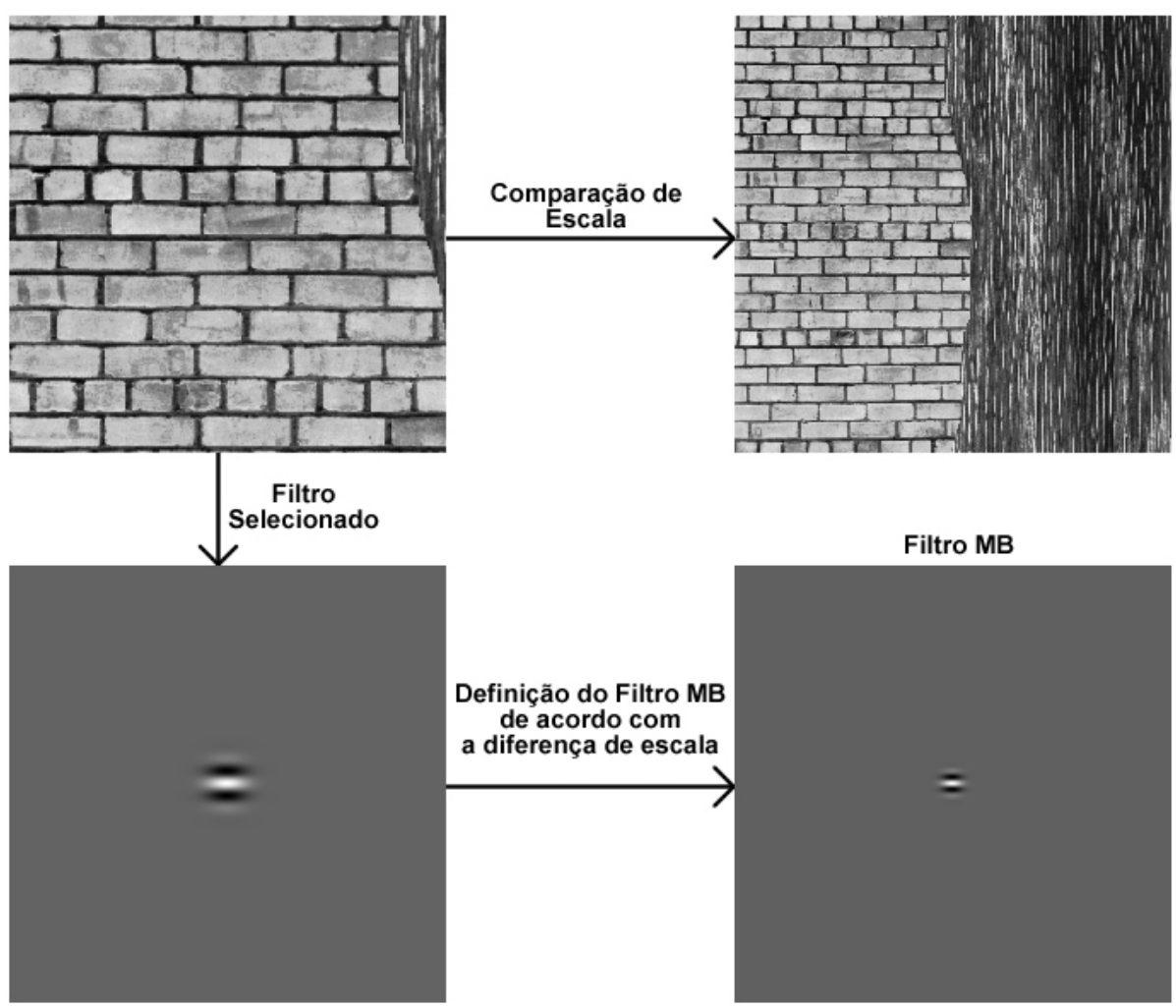

Figura 4.8: Seleção do filtro relativo (Filtro MB) ao filtro escolhido de acordo com a alteração de escala entre a imagem de referência e o mapa de base.

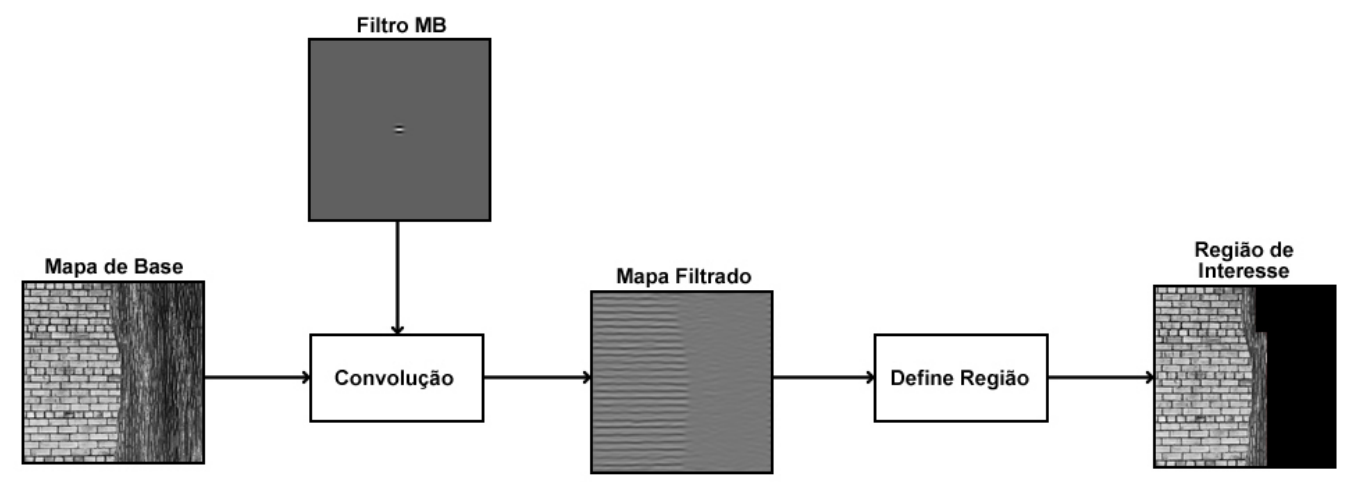

Figura 4.9: Etapa de definição da região de interesse sobre o mapa de base. Após a seleção do melhor filtro e definição do Filtro MB na etapa anterior, a partir do mapa filtrado é definida a região que possui características similares à da imagem de referência. 

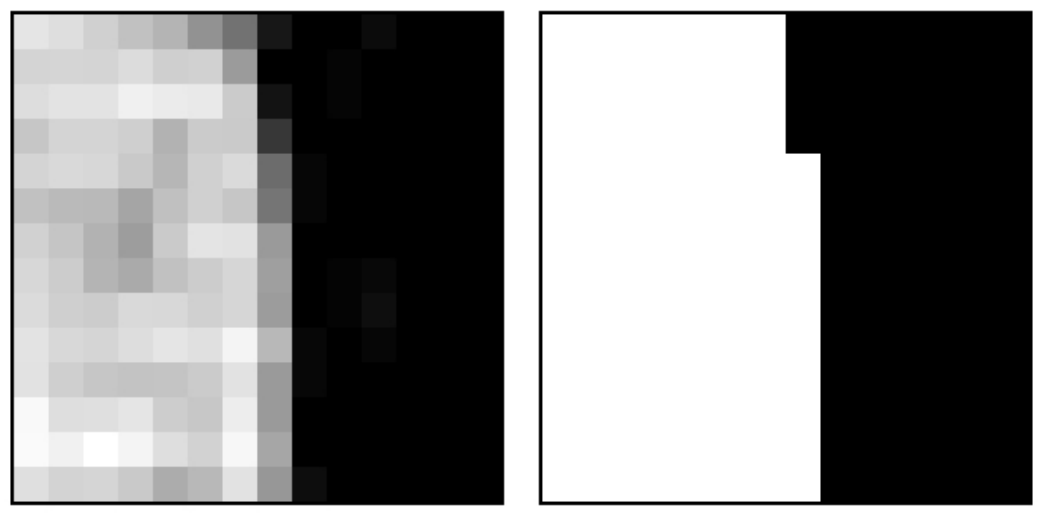

Figura 4.10: Matriz de coeficientes gerada através da utilização de uma janela de contagem de runs que se desloca sobre a imagem filtrada e binarizada do mapa de base.

À esquerda encontra-se em versão normalizada e à direita, em versão binarizada.

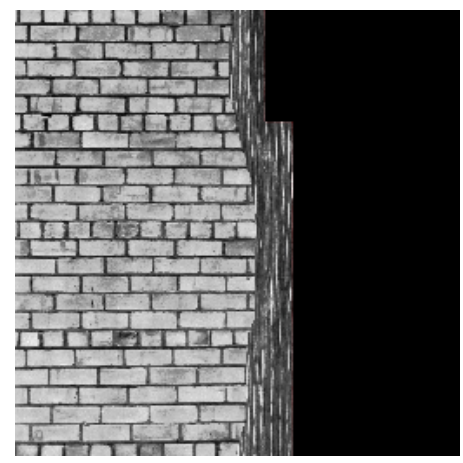

Figura 4.11: Região de interesse no selecionada mapa de base.

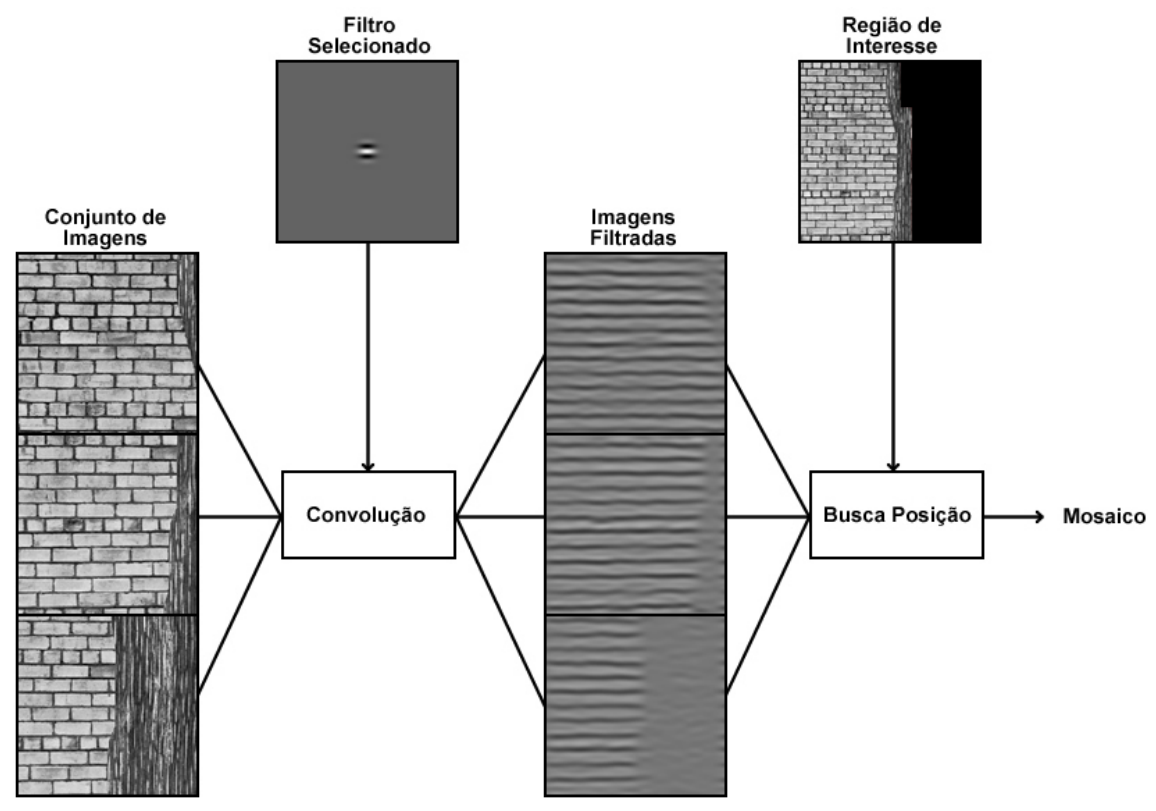

Figura 4.12: Etapa final de geração do mosaico. Com a região de interesse definida, esta etapa tem por objetivo definir o posicionamento das imagens do conjunto sobre o mapa de base. 

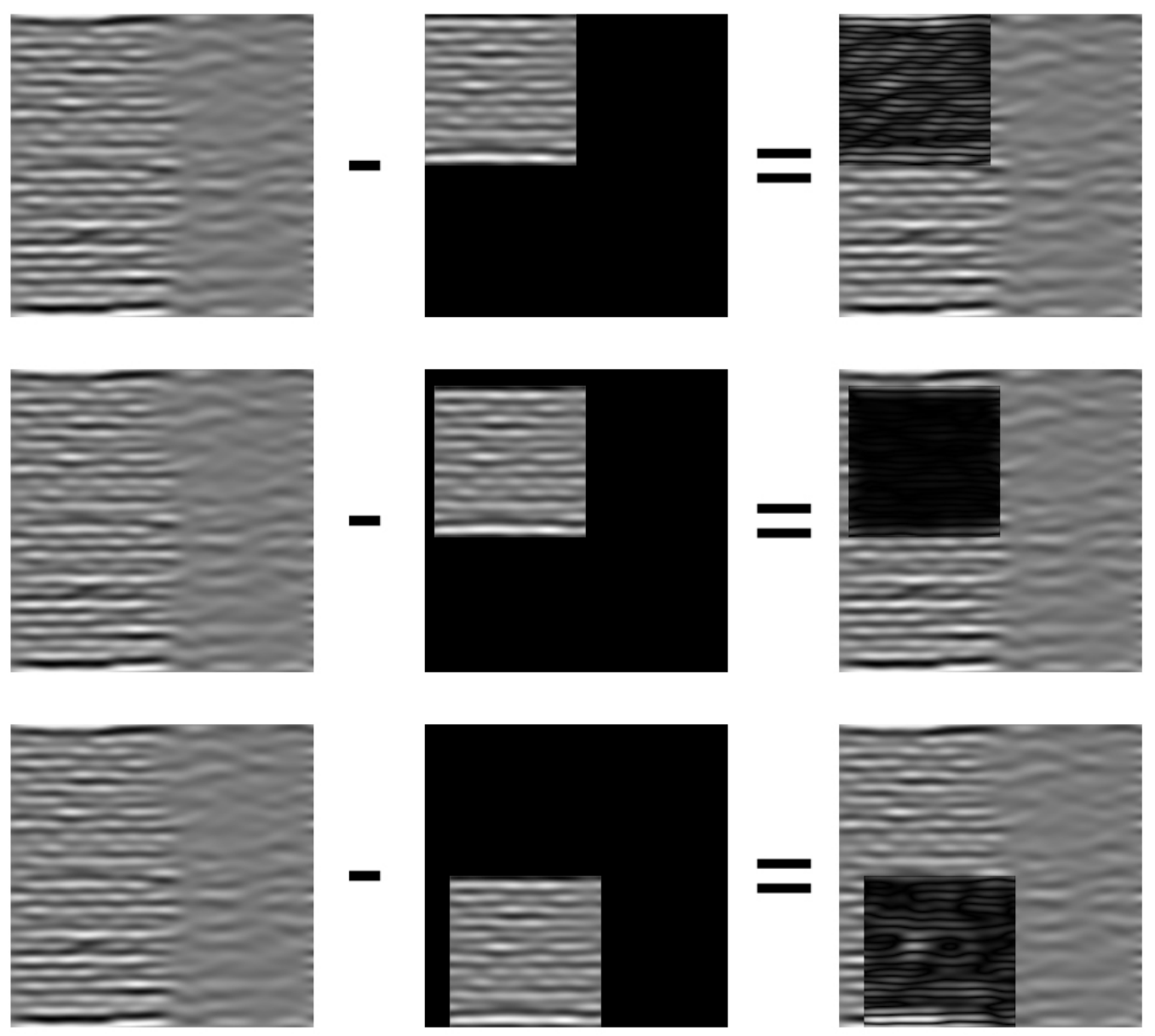

Figura 4.13: Comparação de uma imagem com o mapa de base através da subtração de modo a encontrar a sua posição ideal.
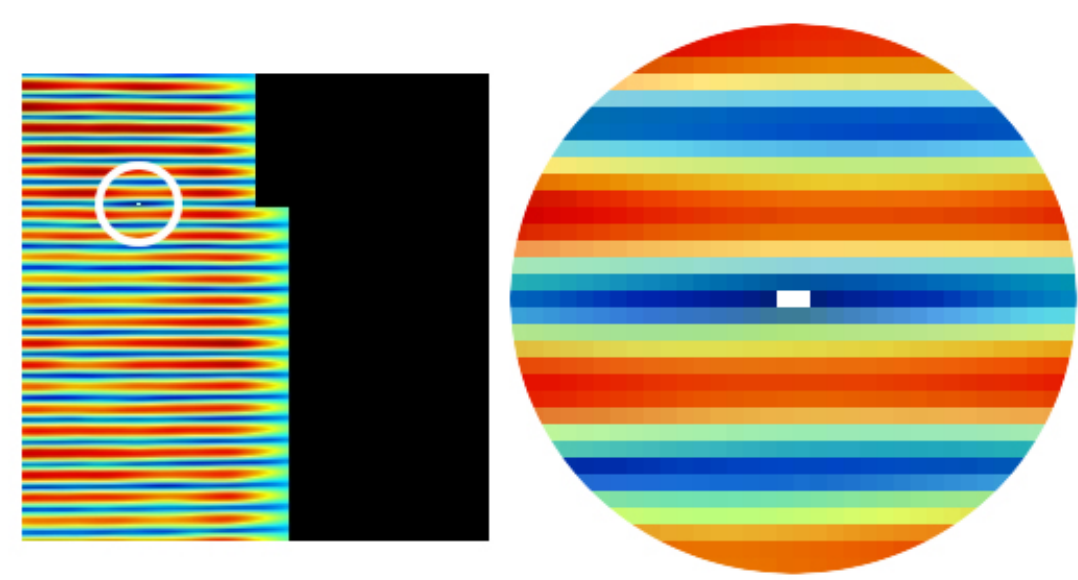

Figura 4.14: Resultado dos valores obtidos pela subtração da imagem a ser mosaicada sobre o mapa de base. Os pontos em branco (mostrados em destaque) são os pontos onde este valor é mínimo, portanto, são as melhores escolhas de posicionamento de uma das imagens do conjunto sobre o mapa de base. 
Este capítulo tem por objetivo mostrar alguns experimentos realizados utilizando a metodologia descrita no capítulo anterior. Para uma melhor análise de qualidade e eficiência dos resultados, na seção 5.4 serão mostrados o tempo de execução de cada etapa do processo de mosaicagem, bem como uma comparação entre a solução obtida e as coordenadas reais sobre as quais deveriam se encontrar as imagens mosaicadas. Este processo serve para mensurar a taxa de erro no posicionamento das mesmas.

Os experimentos foram organizados como segue: o primeiro deles, dividido em dois testes, utiliza-se de uma imagem gerada artificialmente, combinando as texturas de número 95 e 68 do conjunto de texturas naturais de Brodatz (Brodatz, 2006). Esta imagem é a mesma utilizada no exemplo mostrado no decorrer do capítulo sobre a metodologia do trabalho. O primeiro teste exibe os resultados obtidos em um caso de sucesso. Já o segundo, serve para mostrar os resultados advindos de uma má escolha inicial da imagem de referência. O segundo experimento é subdividido também em dois testes. No primeiro, foram utilizadas cenas naturais reais contendo imagens aéreas de plantações de eucalipto tiradas por satélite obtidas através do site do Google Maps (Google, 2006) e, no segundo, fotografias tiradas a partir de uma máquina digital acoplada aos aeromodelos do projeto Arara (Santos, 2004; Neris, 2001; Jorge, 2001); A terceira e última seção de experimentos também utiliza imagens aéreas. Este experimento demonstra a robustez do método quando aplicado a imagens ruidosas e borradas.

\subsection{Experimento 1: Imagem artificial gerada através da concatenação de texturas de Brodatz}

Este primeiro experimento foi produzido a partir de uma imagem gerada artificialmente através da concatenação de duas texturas do conjunto de Brodatz. Tanto o primeiro como o segundo teste desta seção de resultado utilizam o mesmo mapa de base e o mesmo conjunto de imagens a serem mosaicadas. Todas elas possuem tamanho de 256x256 pixels. Vale ressaltar que, os parâmetros de configuração utilizados são exatamente os mesmos 
em ambos os testes. O que diferencia um do outro é a escolha da imagem a ser tomada como referência. A figura 5.1 exibe as imagens utilizadas.

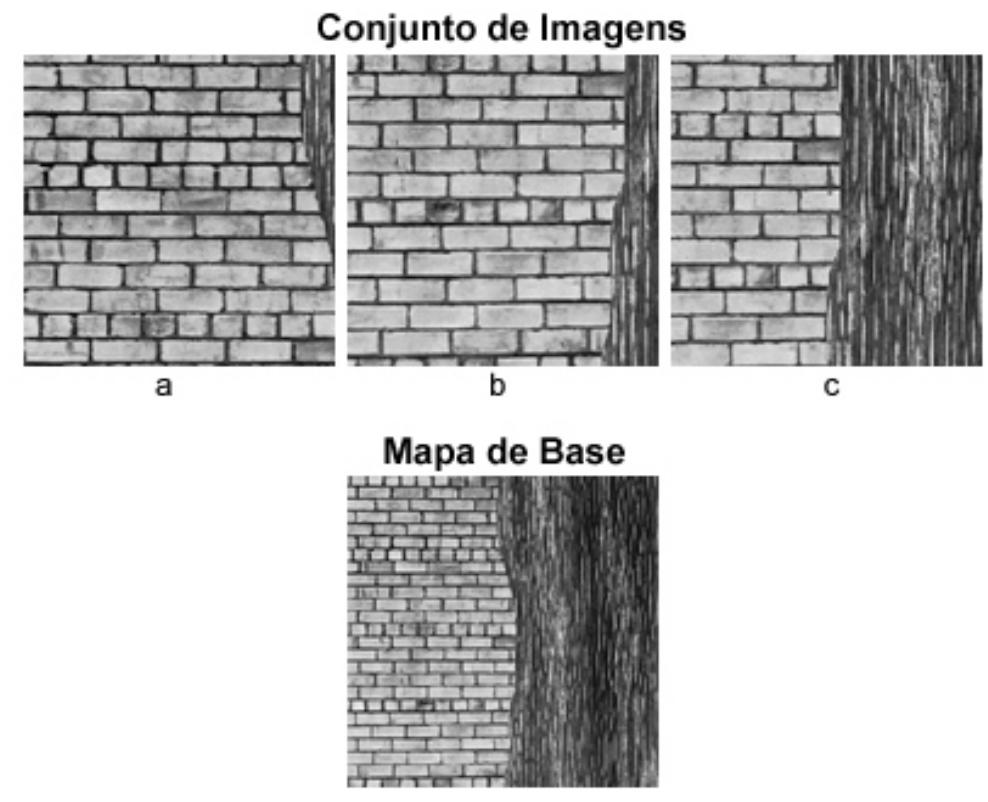

Figura 5.1: Imagens utilizadas na produção do experimento 1. Acima estão as imagens a serem mosaicadas ( $a, b$ e $c$ ) e abaixo, o Mapa de Base.

Para a realização destes testes, foi gerado um conjunto de filtros com seis variações de tamanho (de 2 a 64 pixels de diâmetro) em quatro orientações $\left(0^{\circ}, 45^{\circ}, 90^{\circ}\right.$ e $\left.135^{\circ}\right)$, como explicado na seção 4.1.2.

\subsubsection{Teste 1: Utilizando uma boa imagem de referência}

Este primeiro teste utiliza como imagem de referência a imagem $a$ do conjunto de imagens. Através da aplicação dos processos descritos na seção 4.1, o filtro escolhido foi o de 16 pixels de diâmetro na orientação de $0^{\circ}$ (exibido na figura 5.2).

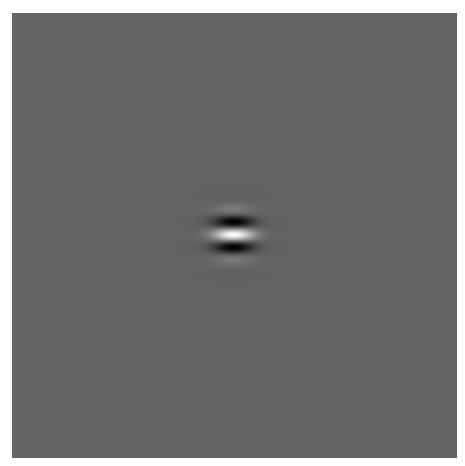

Figura 5.2: Filtro selecionado pela etapa de escolha do melhor filtro.

Como a diferença de escala entre a imagem de referência e o mapa de base é de duas vezes, o filtro relativo selecionado é o de 8 pixels de diâmetro. Através da aplicação deste filtro relativo sobre o mapa de base, tem-se como resultado a região de interesse exibida 
pela figura 5.3. O mosaico gerado por este teste, com dimensões iguais a 512x512 pixels, pode ser visto na figura 5.4.

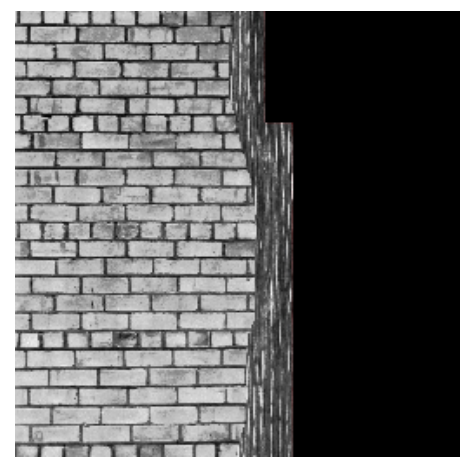

Figura 5.3: Região de interesse definida no teste 1 do experimento 1.
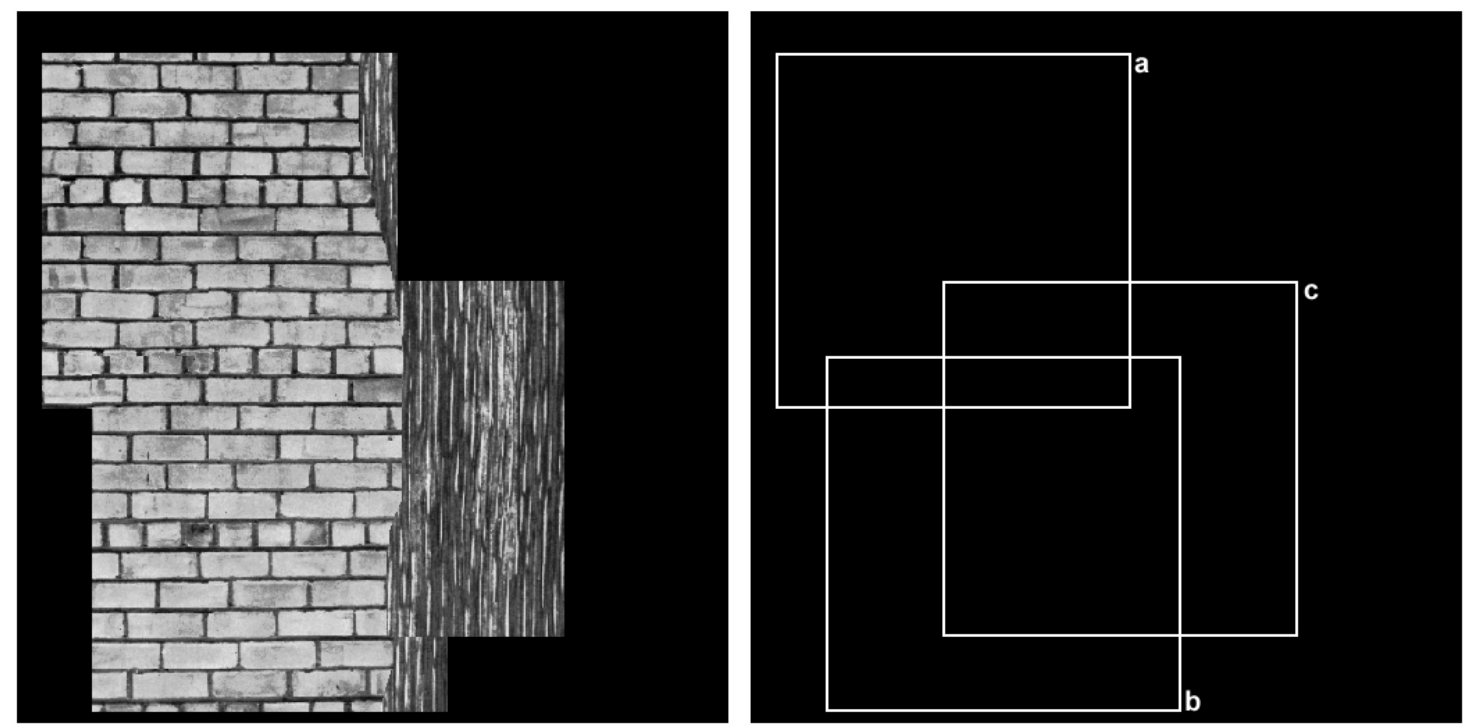

Figura 5.4: Mosaico gerado pelo teste 1 do experimento 1 (esquerda). À direita é exibido o posicionamento de cada imagem do conjunto de entrada no mosaico.

Como se pode notar através de uma comparação visual entre este resultado obtido e o mapa de base utilizado (figura 5.1), o mosaico teve uma boa formação, aproximando-se bastante do resultado esperado. Vale salientar aqui que o processo de construção deste mosaico foi todo realizado automaticamente, não necessitando mais do que o conjunto de imagens e o mapa de base como dados de entrada para a produção do mesmo.

\subsubsection{Teste 2: Utilizando uma má escolha como imagem de referên- cia}

Como foi dito na seção 4.1, uma má imagem de referência pode acarretar erros significativos. Para exemplificar este problema, utiliza-se como imagem de referência a imagem 5.1.c do conjunto. Ao fazer esta escolha e aplicar os filtros, o resultado do algoritmo de seleção de melhor resultado retorna como resposta o filtro de diâmetro igual a 64 pixels e de orientação igual a $90^{\circ}$ (figura 5.5). 


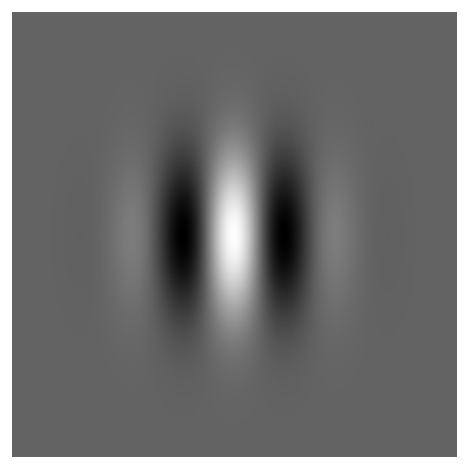

Figura 5.5: Filtro selecionado pela etapa de escolha do melhor filtro utilizando outra imagem de referência.

Desta forma, o filtro relativo para ser aplicado no mapa de base é o de tamanho igual a 32 pixels. A aplicação deste filtro sobre o mapa e posterior aplicação da busca pela região de interesse retorna como resultado a região exibida na figura 5.6. Como se pode perceber, foi realizada uma segmentação errônea do mapa de base, excluindo regiões que não deveriam ser excluídas e incluindo outras regiões que não deveriam estar presentes devido à aplicação do processo de contagem de runs descrito na seção $4.2 \mathrm{com}$ os parâmetros recebidos da primeira etapa do processo. Com isto, através da execução da terceira etapa do processo de geração do mosaico (seção 4.3), tem-se como resultado o mosaico exibido na figura 5.7.

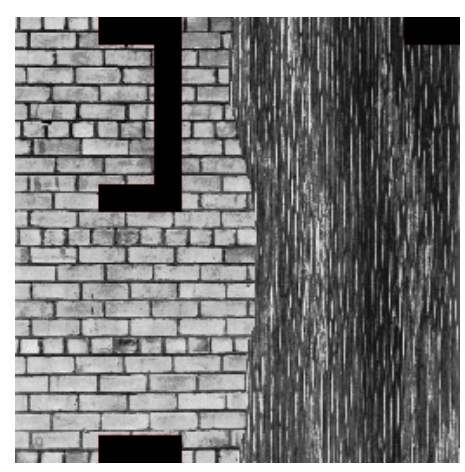

Figura 5.6: Região de interesse definida erroneamente no teste 2 do experimento 1.

Este teste demonstra o quão importante é a escolha de uma boa imagem de referência, uma vez que apenas o simples fato de inverter a ordem das imagens, mas com a utilização dos mesmos parâmetros de entrada, pode resultar em algo totalmente diferente e incorreto.

\subsection{Experimento 2: Cenas naturais de imagens aéreas}

Este experimento visa demonstrar o funcionamento do método para imagens de cenas naturais. Esta seção é composta de dois testes. O primeiro teste utiliza um conjunto pequeno de duas imagens obtidas através dos aviões do projeto Arara. O segundo teste é realizado com um conjunto de quatro imagens com dimensões maiores obtidas através do Google Maps. 

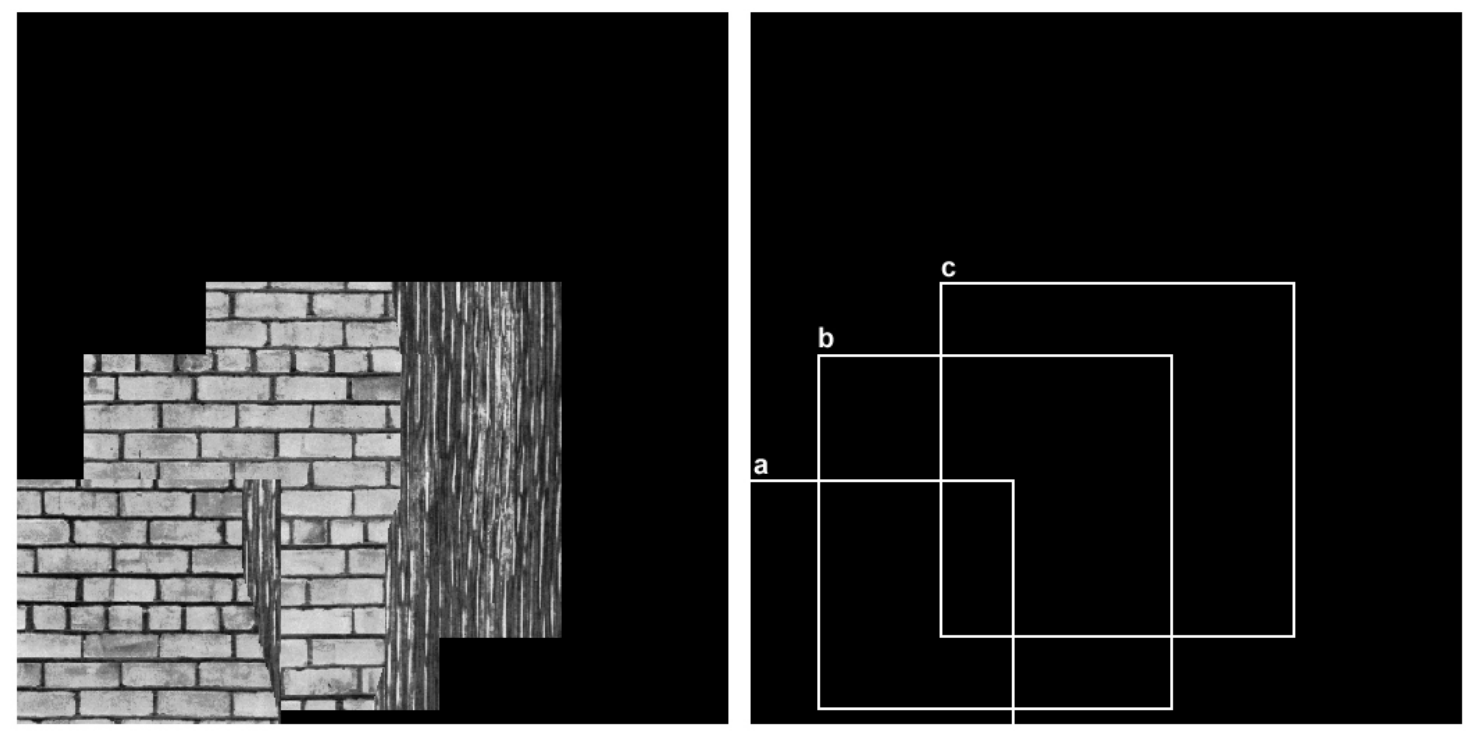

Figura 5.7: Mosaico gerado erroneamente pelo teste 2 do experimento 1 (esquerda) e o posicionamento das imagens do conjunto (direita).

\subsubsection{Teste 1: Imagens obtidas através do projeto Arara}

As imagens utilizadas neste teste foram tiradas a partir das máquinas instaladas nos aviões do projeto Arara. Porém, apenas uma pequena região de 256x256 pixels das mesmas foram utilizadas na realização deste deste. As imagens utilizadas, bem como o mapa de base, são mostrados na figura 5.8.
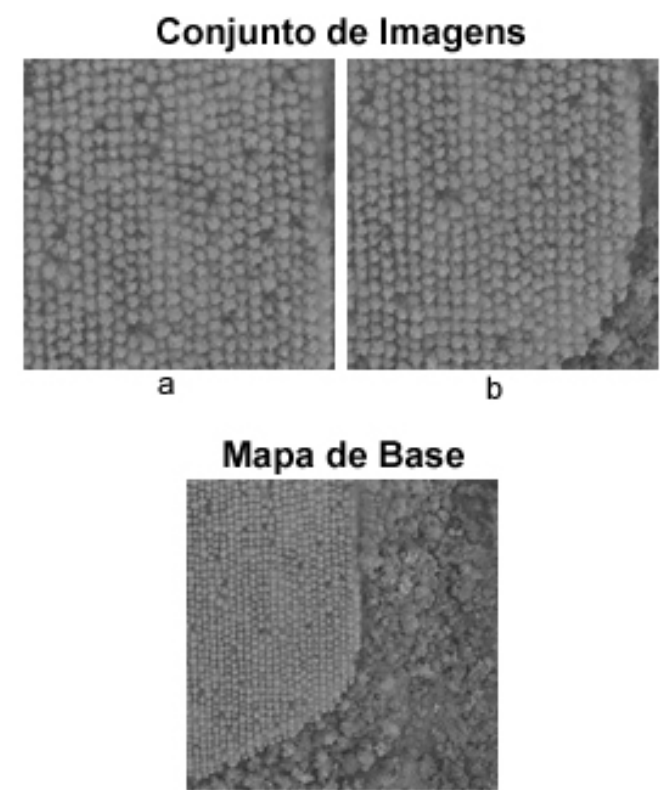

Figura 5.8: Imagens utilizadas na produção do teste 1 do experimento 2. Acima estão as imagens a serem mosaicadas ( $a$ e $b$ ) e abaixo, o Mapa de Base a ser utilizado.

Assim como no teste anterior, seis tamanhos de filtros em quatro orientações foram gerados. Como imagem de referência, foi utilizada a imagem $a$. A aplicação da etapa 
de escolha do melhor filtro obteve como resultado o filtro de tamanho igual a 8 pixels de diâmetro na orientação de $90^{\circ}$ (figura 5.9).

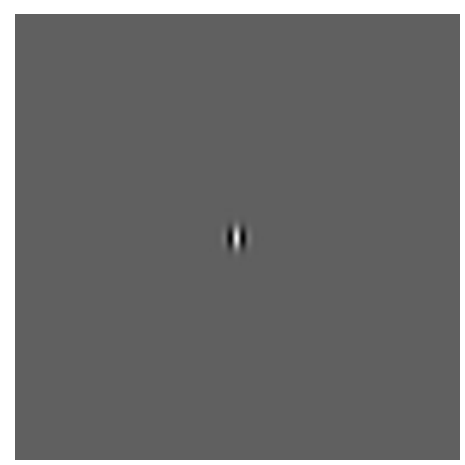

Figura 5.9: Filtro selecionado pela etapa de escolha do melhor filtro.

A aplicação do filtro de referência sobre o mapa de base e posterior busca pela região de interesse devolve como resposta a região definida pela figura 5.10. Como se pode perceber, a definição desta região foi bastante precisa. Com a eliminação de toda esta região indesejada, o processo de posicionamento das imagens sobre o mapa de base se torna mais ágil. O mosaico gerado por este teste, de dimensões iguais a 512x512 pixels, pode ser visto na figura 5.11.

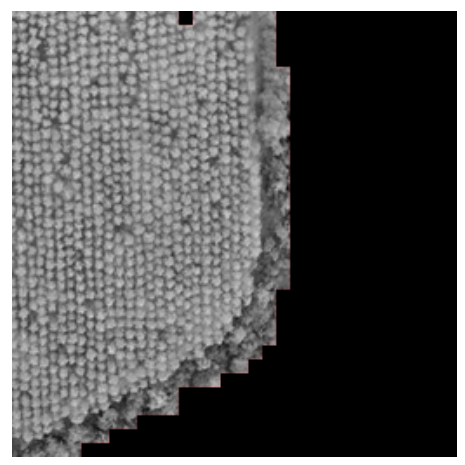

Figura 5.10: Região de interesse definida no teste 1 do experimento 2 .

Este teste tem por objetivo demonstrar a precisão na definição da região de interesse e também, serve como um bom teste de aplicação sobre imagens reais. Nota-se que para este conjunto de imagens de uma cena natural aérea, o mosaico resultante também apresenta-se bem montado, posicionando as imagens de entrada conforme o esperado.

\subsubsection{Teste 2: Imagens obtidas através do Google Maps}

As imagens utilizadas neste teste foram obtidas através de amostras retiradas do sítio do Google Maps. As imagens utilizadas representam fotografias aéras de eucaliptos na região do Espírito Santo e suas dimensões são de 512x512 pixels. O que se pretende demonstrar neste teste é a diferença de velocidade de execução quando se aumenta o tamanho das imagens de entrada. Além disso, devido a este aumento de tamanho, são utilizados sete tamanhos de filtros ao invés dos seis que vinham sendo utilizados até agora, incluindo nesta lista os filtros de tamanho igual a 128 pixels de diâmetro. As imagens utilizadas para este teste são mostradas na figura 5.12. 

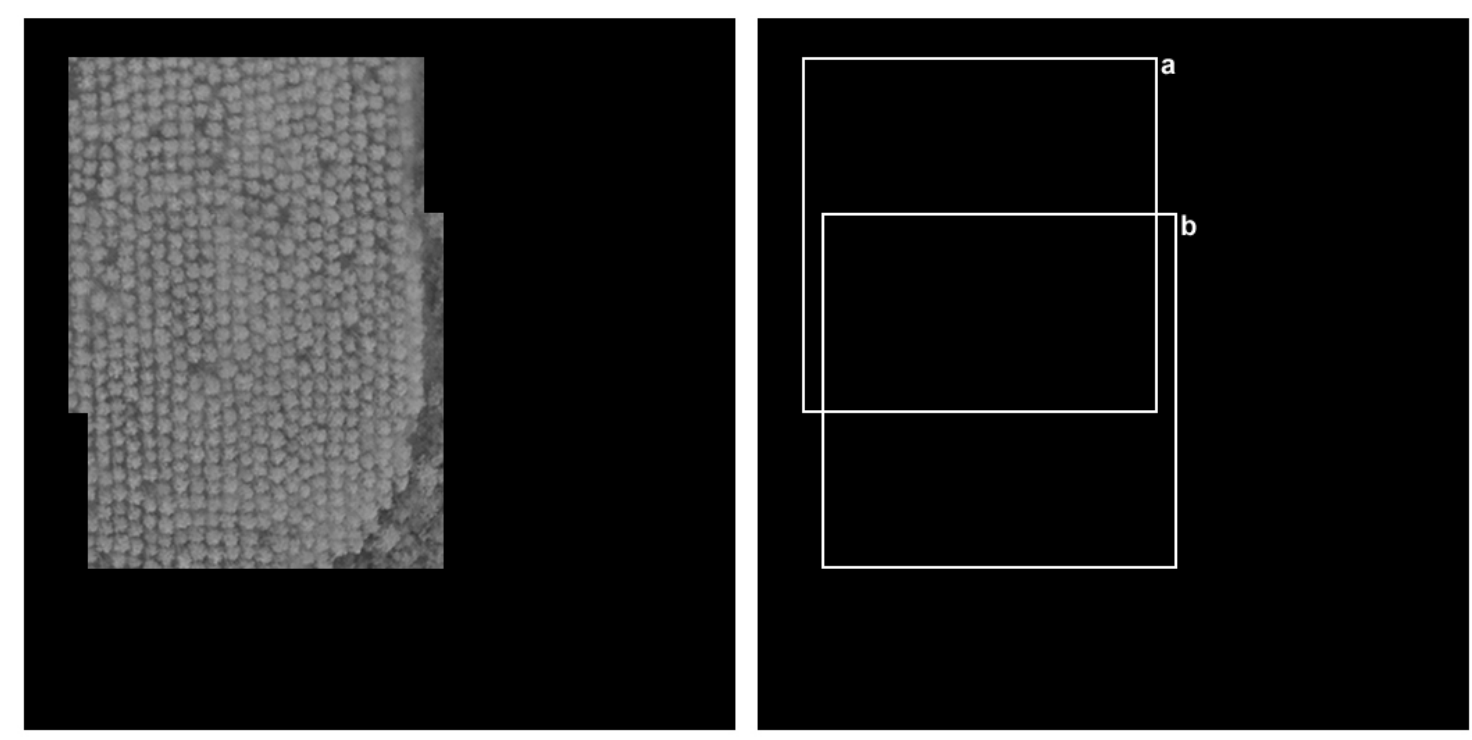

Figura 5.11: Mosaico gerado pelo teste 1 do experimento 2 (esquerda) e o posicionamento das imagens do conjunto (direita).

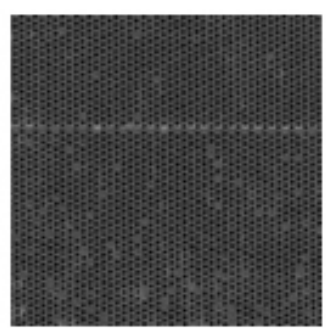

a

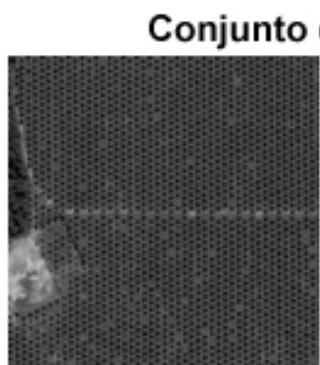

b

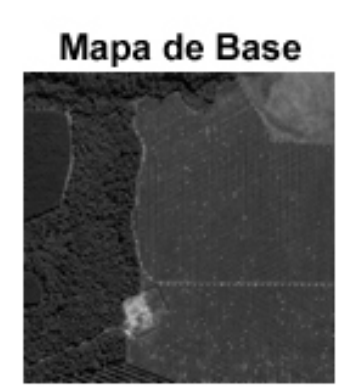

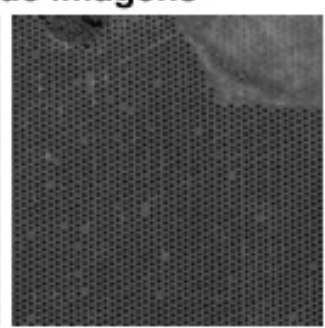

C

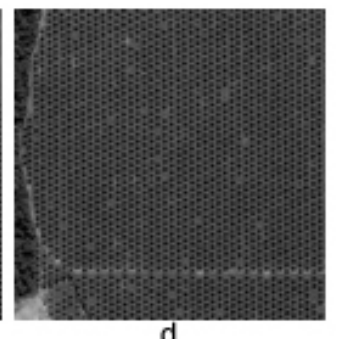

d

Figura 5.12: Imagens utilizadas na produção do teste 2 do experimento 2. Acima estão as imagens a serem mosaicadas $(a, b, c$ e $d$ ) e abaixo, o Mapa de Base a ser utilizado.

Utilizando como imagem de referência a imagem $a$, obtém-se como filtro de melhor resultado o de orientação igual a $90^{\circ}$ e de tamanho igual a 8 pixels de diâmetro (figura 5.13 e a aplicação do filtro relativo sobre o mapa de base e posterior busca pela região de interesse devolve como resposta a região definida como mostrada na figura 5.14. Por sua vez, o mosaico gerado por este teste, com dimensões de $1024 \times 1024$ pixels, pode ser visto na figura 5.15 .

Este teste visa apenas demonstrar mais um resultado positivo da aplicação da metodologia, só que para um conjunto de imagens de dimensões maiores. Embora este aumento no tamanho das imagens tenha aumentado a carga computacional do procedimento, o 


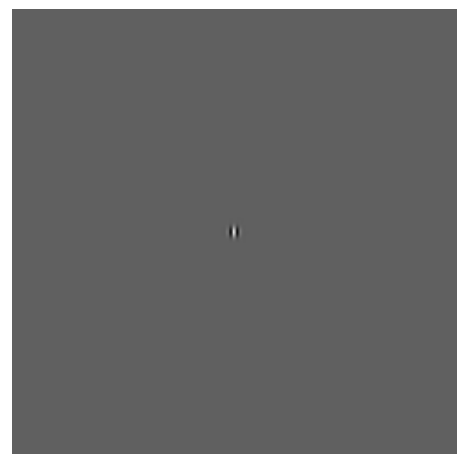

Figura 5.13: Filtro selecionado pela etapa de escolha do melhor filtro.

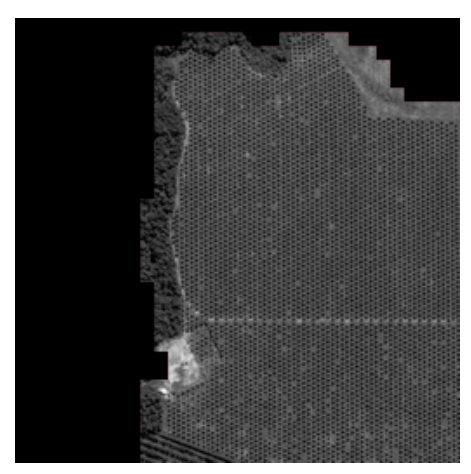

Figura 5.14: Região de interesse definida no teste 2 do experimento 2.
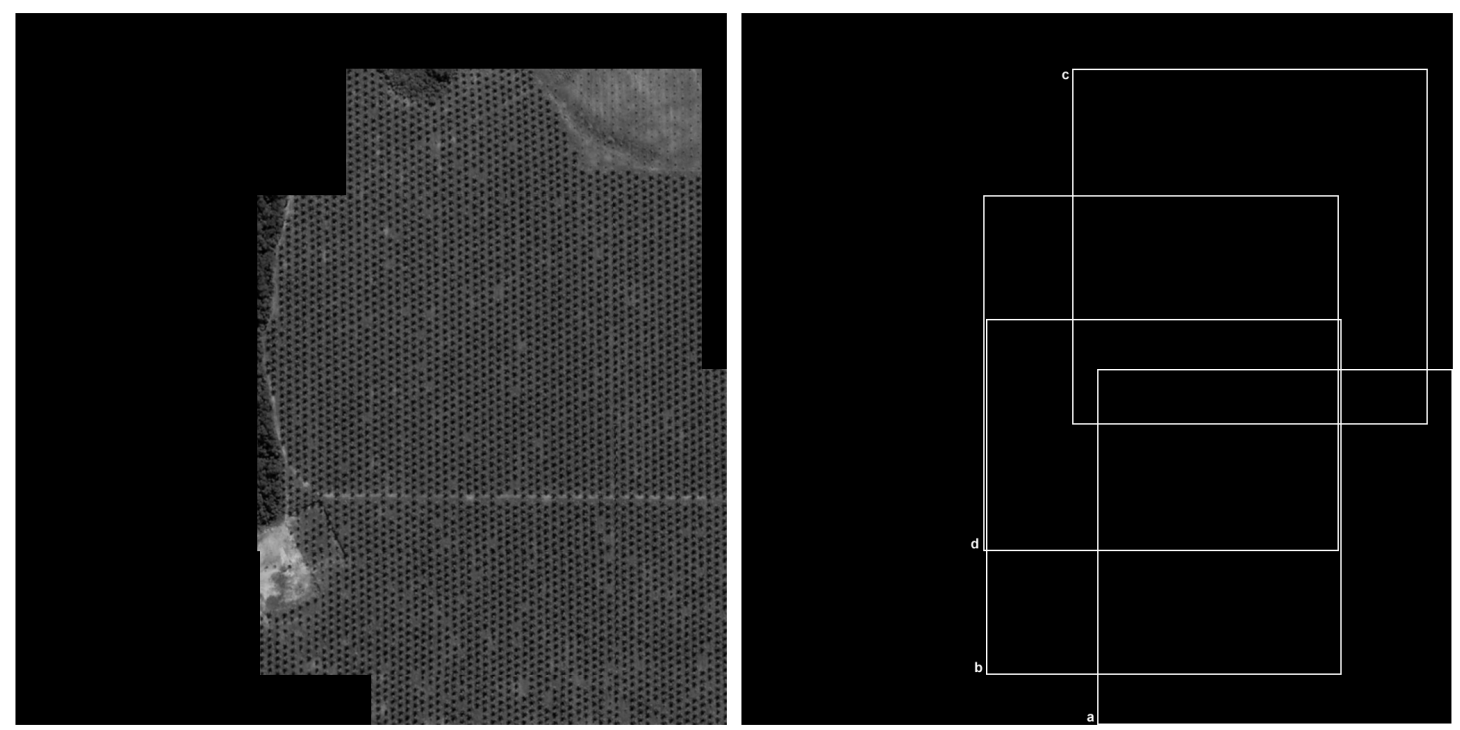

Figura 5.15: Mosaico gerado pelo teste 2 do experimento 2 (esquerda) e o posicionamento das imagens do conjunto (direita).

mosaico gerado tem um ótimo aspecto, retratando fielmente a área desejada. A discussão sobre o acréscimo de tempo utilizado neste processamento devido a este aumento de tamanho será realizada junto com a análise de tempo dos outros resultados na seção 5.4. 


\subsection{Experimento 3: Imagens ruidosas}

O experimento desta seção pretende mostrar um pouco mais da eficácia do método, realizando uma comparação entre dois testes realizados sobre o mesmo conjunto de imagens. A diferença entre os dois testes é que, no segundo, as imagens foram propositalmente borradas e adicionadas de ruído gaussiano, inclusive a imagem de referência. As imagens utilizadas neste teste foram obtidas através do projeto Arara, porém escalonadas e cortadas com dimensões iguais a 512x512 pixels. Os ruídos e distorções foram acrescidos manualmente em softwares de edição de imagens. Os conjunto de imagens originais e alterados podem ser vistos, respectivamente, nas figuras 5.16 e 5.17. A imagem $a$ de cada conjunto é utilizada como suas respectivas imagens de referência. O mapa de base utilizado para a produção deste resultado é o mesmo para ambos os conjuntos e pode ser visto na figura 5.18 .
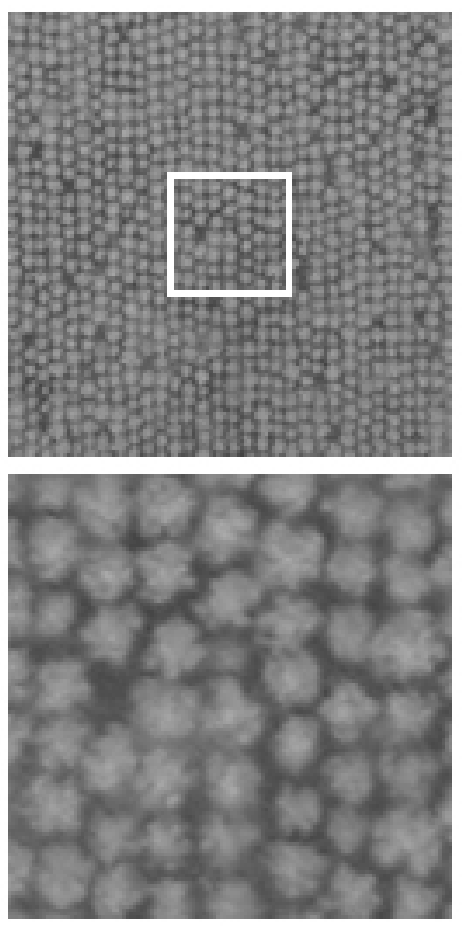

a
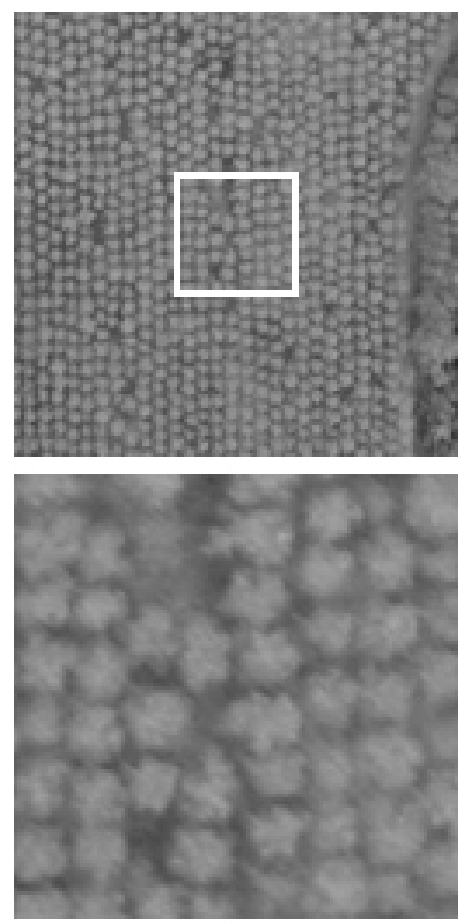

b
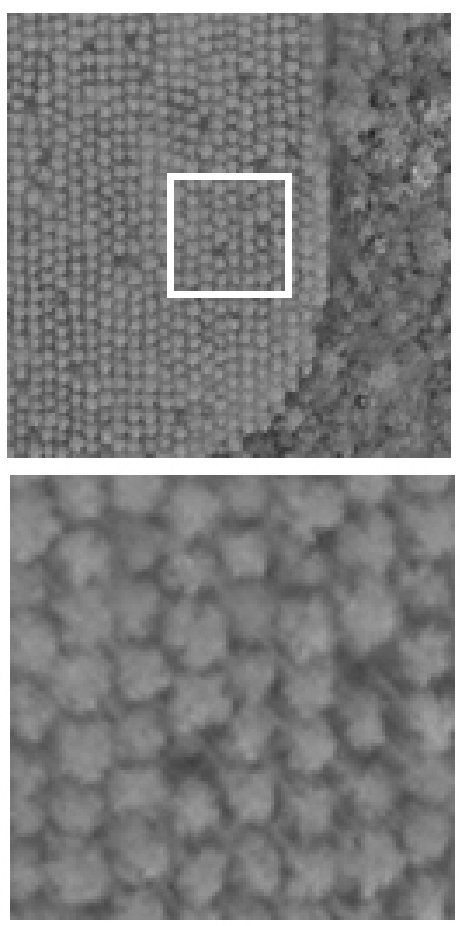

$\mathrm{C}$

Figura 5.16: Imagens originais utilizadas na realização do experimento 3. Acima estão presentes as imagens em tamanho reduzido e, abaixo, uma região de cada uma das mesmas é exibida ampliada para que se perceba a diferença entre os conjuntos de imagens.

\subsubsection{Aplicação dos filtros e seleção do melhor filtro}

Embora exista esta diferença de qualidade entre as imagens de referência dos dois conjuntos, a aplicação dos filtros sobre ambas as imagem de referência retorna como resposta, na busca pelo melhor filtro, o de tamanho igual a 16 pixels de diâmetro e orientação igual a $90^{\circ}$. Isto se deve ao fato de que, embora alguma informação da imagem tenha sido perdida na aplicação do efeito de borramento, no domínio da freqüência esta perda não se torna tão evidente, preservando assim grande parte das características da 

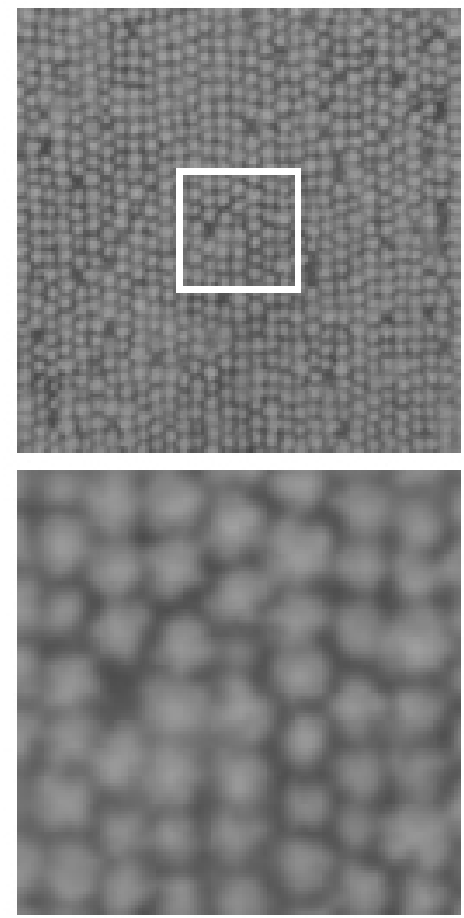

a
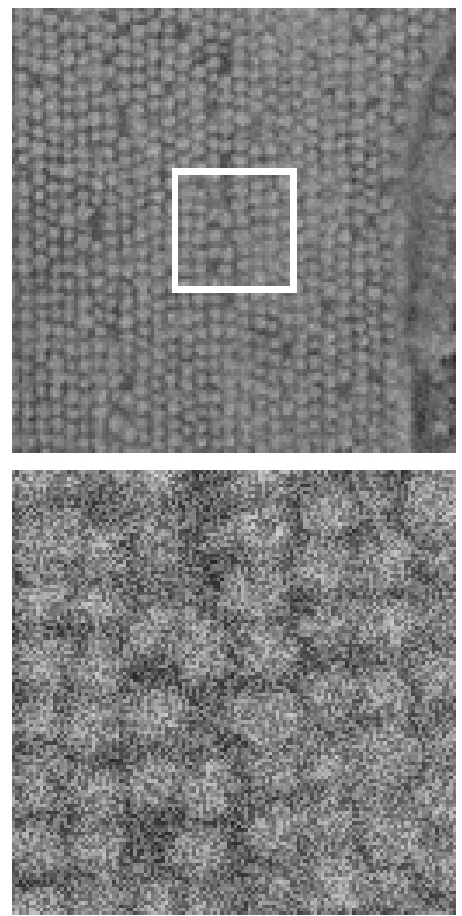

b
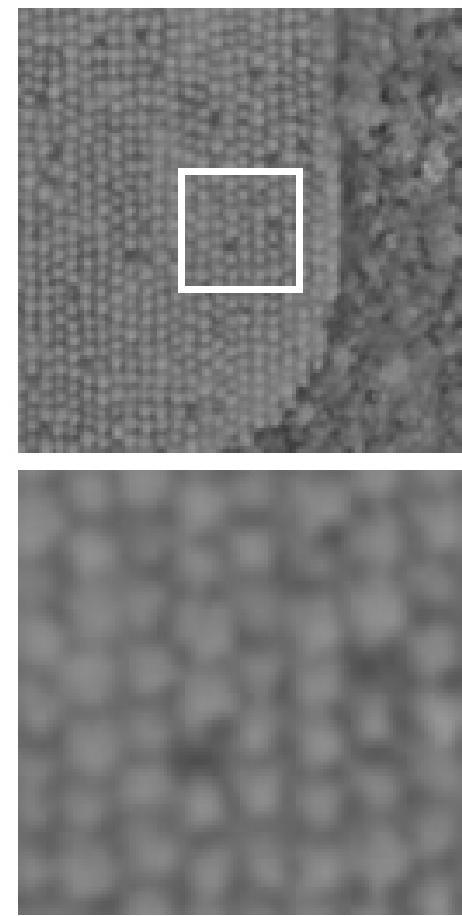

$\mathrm{C}$

Figura 5.17: Imagens ruidosas também utilizadas na realização do experimento 3. Acima estão presentes as imagens em tamanho reduzido e, abaixo, uma região de cada uma das mesmas é exibida ampliada para que se perceba a diferença entre os conjuntos de imagens. É possível notar os efeitos causados pelo borramento e adição de ruído.

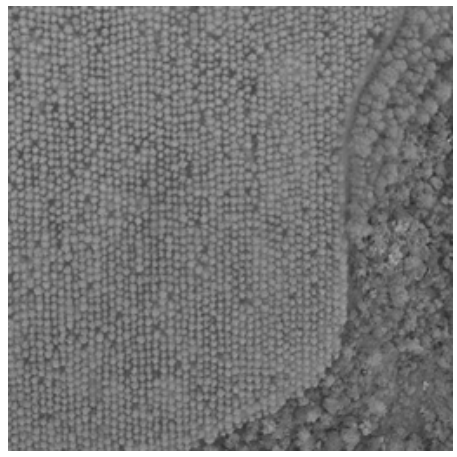

Figura 5.18: Mapa de base utilizado na produção do experimento 3.

imagem. Na figura 5.19 pode se ver que o resultado da aplicação deste filtro de Gabor sobre ambas as imagens de referência é praticamente o mesmo.

Como o mapa de base para os dois conjuntos de imagens é exatamente o mesmo, a aplicação do filtro relativo sobre o mapa e busca pela região de interesse devolve exatamente o mesmo resultado, não envolvendo grandes novidades. A região de interesse pode ser vista na figura 5.20.

\subsubsection{Geração do mosaico}

Com a região de interesse em mãos, é realizada agora a etapa de busca da posição ideal das imagens de cada conjunto sobre a região definida na etapa anterior. Como a 


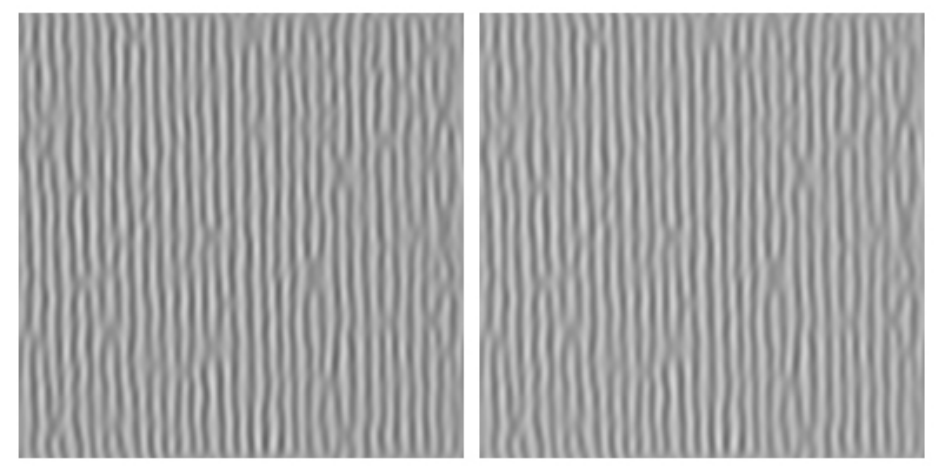

Figura 5.19: Aplicação do filtro de 16 pixels de diâmetro e orientação igual a $90^{\circ}$ para as imagens de referência do conjunto original (esquerda) e do conjunto ruidoso (direita).

É possível notar visualmente a forte semelhança entre as respostas obtidas após a aplicação do filtro.

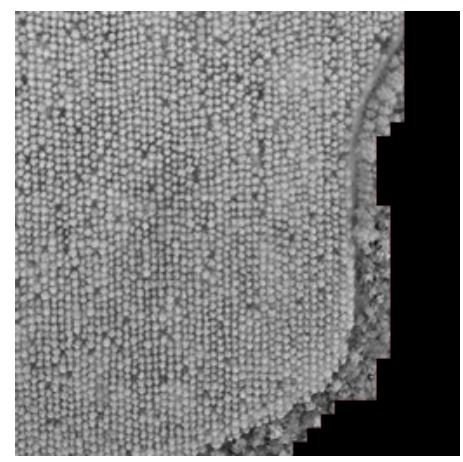

Figura 5.20: Região de interesse sobre o mapa de base encontrado por ambas as imagens de referência para o experimento 3.

diferença da resposta do filtro tanto para o conjunto original como o ruidoso é muito pequena, os cálculos de subtração geram resultados muito próximos. A figura 5.21 exibe a matriz de subtração gerada pela imagem $a$ de cada conjunto sobre a região do mapa de base. Como se pode notar, ambas apresentam aproximadamente o mesmo aspecto, ficando a diferença por conta da presença maior de regiões de coloração azul na matriz do conjunto ruidoso, mostrando que, devido à perda de qualidade da imagem, algumas regiões que antes não pareciam tão boas para o posicionamento da imagem sobre o mapa, agora tendem a produzir bons resultados para um possível posicionamento. Como se pode perceber no detalhe da figura 5.21, ao invés de apenas uma posição encontrada, devido ao ruído, foram encontradas duas posições. Mesmo assim, extremamente próximas da encontrada pelo conjunto original.

Após a aplicação destes cálculos para todas as imagens dos dois conjuntos, finalmente são gerados os mosaicos. Os mosaicos para o conjunto de imagens originais e ruidosas, com dimensões iguais a 1024x1024 pixels, podem ser vistos nas figuras 5.22 e 5.23, respectivamente. Mesmo com o acréscimo de ruído, a posição final encontrada pelo processo de mapeamento, para ambos os casos, foi praticamente o mesmo. E, visualmente, é possível perceber que tal posicionamento corresponde fielmente às posições nas quais as imagens do conjunto de imagens deveriam se encontrar. Maiores detalhes sobre tempo de execução e posicionamento serão discutidos na seção 5.4 . 

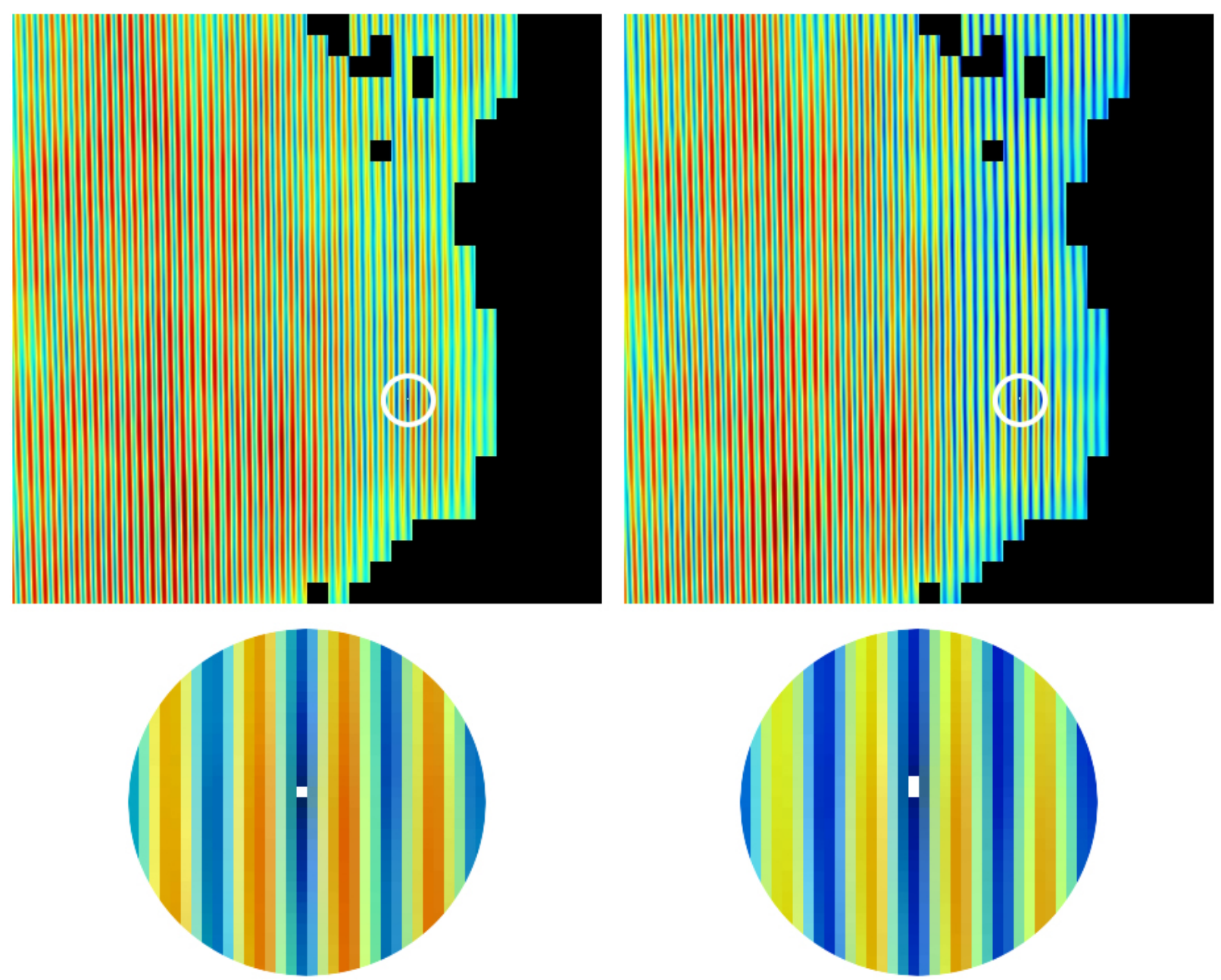

Figura 5.21: Matriz de subtrações gerado por uma imagem do conjunto original (esquerda) e do conjunto ruidoso (direita) sobre o mapa de base. Note a maior presença da coloração azul, indicando um aumento no número de possíveis regiões de bom posicionamento. No detalhe, é exibido a posição ideal encontrada para os dois casos.

\subsection{Considerações}

Esta seção discute alguns aspectos sobre os experimentos realizados. São levados em consideração os tempos de execução de cada etapa e a precisão obtida. Os experimentos exibidos foram realizados em uma máquina com processador Intel Core 2 Duo de 2.40 $\mathrm{GHz}, 2048 \mathrm{MB}$ de memória $R A M$ e sistema operacional Windows XP. Outro aspecto que deve ser levado em conta é que o sistema desenvolvido para a realização da metodologia utiliza como base o MatLab versão 6.5R13.

\subsubsection{Tempo de execução}

Em cada teste de cada experimento foram medidos o tempo de execução de várias partes distintas, como o tempo de geração do banco de filtros, de aplicação dos filtros sobre as imagens, de seleção do melhor filtro, de definição da região de interesse e do posicionamento das imagens para a geração do mosaico. 

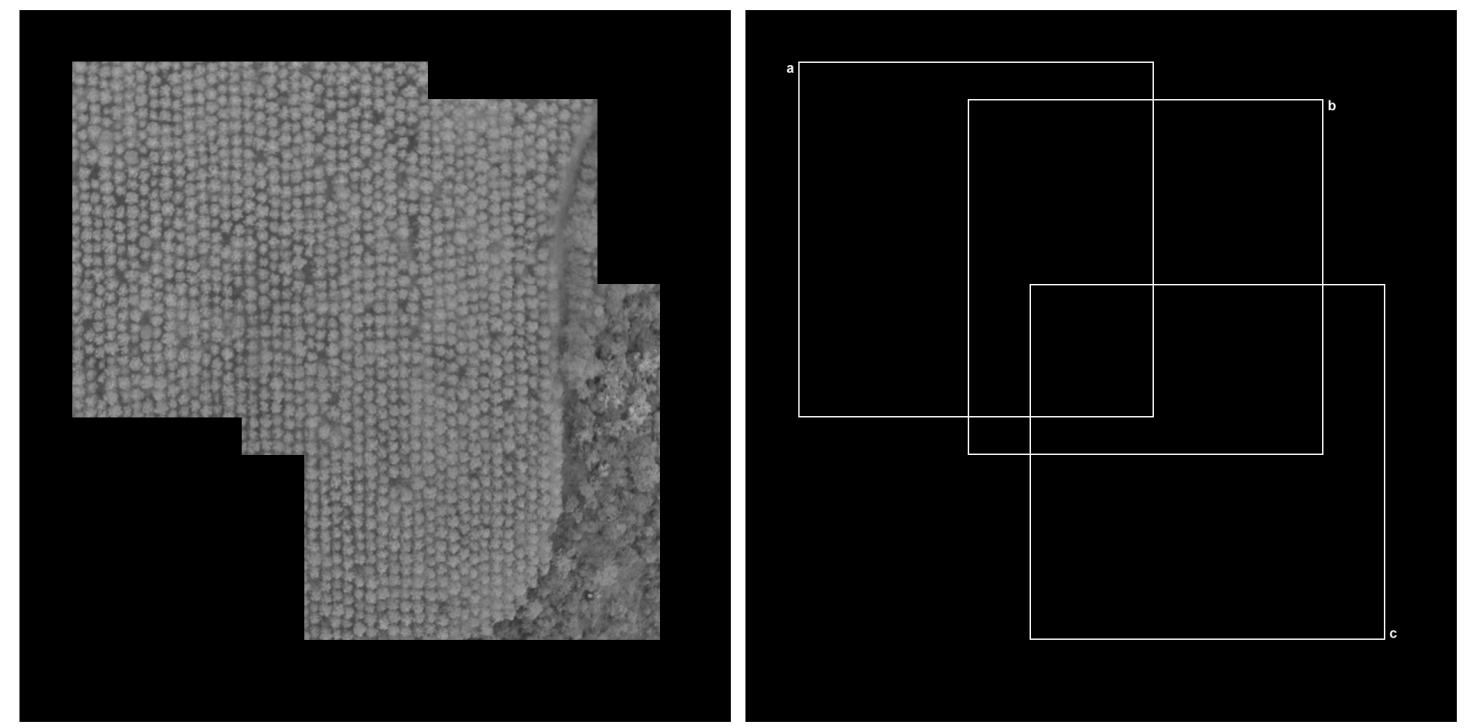

Figura 5.22: Mosaico gerado pelo experimento 3 para o conjunto de imagens originais (esquerda) e o posicionamento das imagens do conjunto (direita).
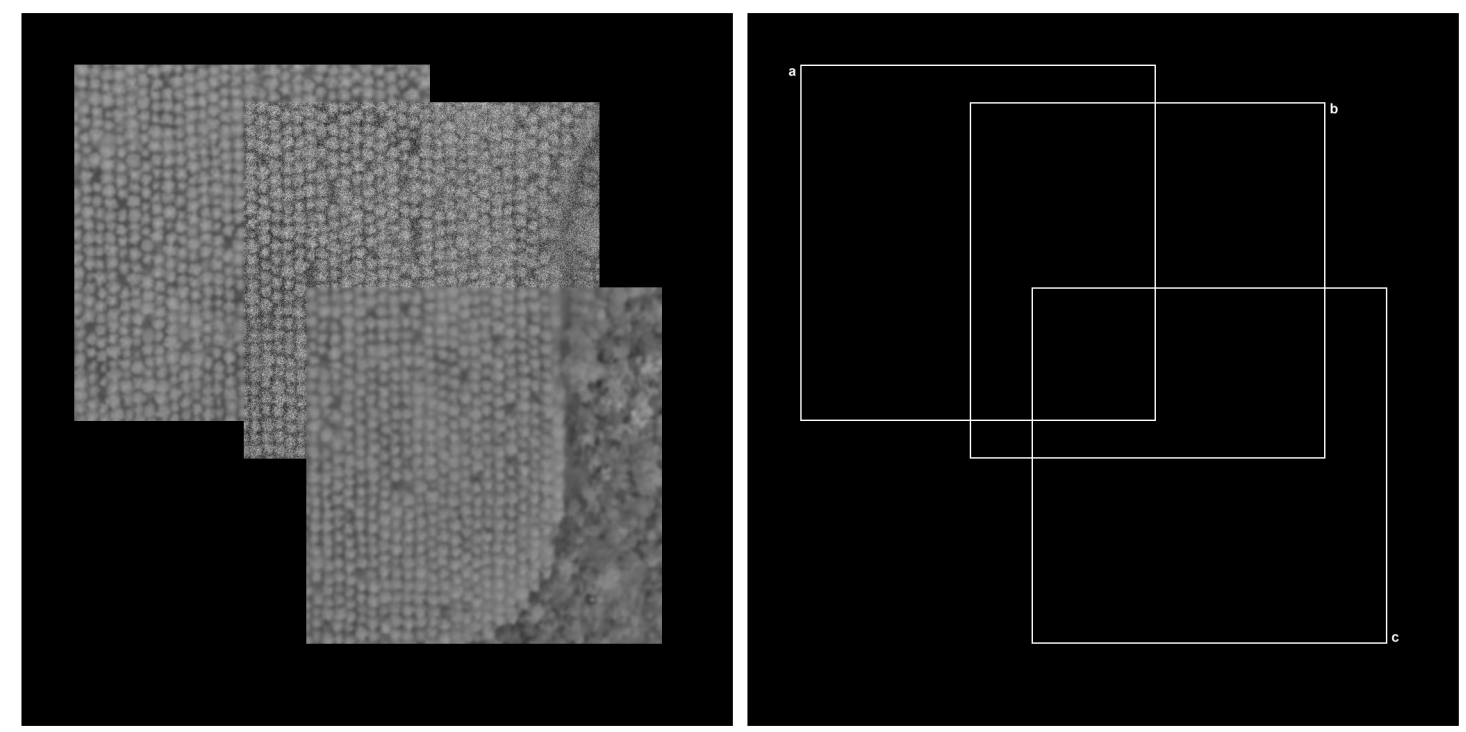

Figura 5.23: Mosaico gerado pelo experimento 3 para o conjunto de imagens ruidosas (esquerda) e o posicionamento das imagens do conjunto (direita).

\section{Geração do banco de filtros}

O tempo gasto na geração dos filtros independe das imagens que serão utilizadas em cada experimento. O que conta neste processo é o número de orientações e tamanhos dos filtros a serem gerados, além das dimensões dos mesmos. Flutuações nos valores podem ser causadas devido a utilização da memória por outros processos do sistema operacional rodando em paralelo. A tabela 5.1 mostra os tempos utilizados por cada um dos testes neste processo. Os valores E-T da coluna "Exp.-Teste" indicam, respectivamente, o experimento e o teste, apresentados nas seções anteriores deste capítulo.

Como se pode perceber, o crescimento das dimensões das imagens a serem utilizadas acarretam em um aumento exponencial no tempo de execução. Tal comportamento se 


\begin{tabular}{|c|c|c|c|c|}
\hline Exp.-Teste & $\begin{array}{l}\text { Número de } \\
\text { Orientações }\end{array}$ & $\begin{array}{c}\text { Tamanhos } \\
\text { de Filtros }\end{array}$ & $\begin{array}{c}\text { Dimensões } \\
\text { dos Filtros }\end{array}$ & $\begin{array}{l}\text { Tempo } \\
\text { Utilizado }\end{array}$ \\
\hline $1-1$ & 4 & 6 & $256 \times 256$ & $1,265 \mathrm{~s}$ \\
\hline $1-2$ & 4 & 6 & $256 \times 256$ & $1,265 \mathrm{~s}$ \\
\hline $2-1$ & 4 & 6 & $256 \times 256$ & $1,266 \mathrm{~s}$ \\
\hline $2-2$ & 4 & 7 & $512 \times 512$ & $9,797 \mathrm{~s}$ \\
\hline $3-1$ & 4 & 7 & $512 \times 512$ & $9,531 \mathrm{~s}$ \\
\hline $3-1$ & 4 & 7 & $512 \times 512$ & $9,704 \mathrm{~s}$ \\
\hline
\end{tabular}

Tabela 5.1: Tempo de execução do processo de geração dos bancos de filtros para cada experimento.

repete em quase todas as outras etapas do método, como pode ser observado no decorrer das considerações.

\section{Aplicação dos filtros sobre as imagens}

A aplicação dos filtros sobre as imagens é realizada por uma convolução simples. Desta forma, assim como o tempo de geração dos filtros, o tempo de aplicação independe da complexidade da imagem ou do tipo do filtro, dependendo apenas das dimensões das imagens a serem convoluídas, crescendo exponencialmente. A tabela 5.2 mostra os tempos utilizados para estas convoluções. Para a geração destes valores, foi computado o tempo gasto pela convolução dos filtros com a imagem de referência.

\begin{tabular}{|c|c|c|}
\hline Exp.-Teste & $\begin{array}{l}\text { Dimensões } \\
\text { da Imagem }\end{array}$ & $\begin{array}{l}\text { Tempo } \\
\text { Utilizado }\end{array}$ \\
\hline $1-1$ & $256 \times 256$ & $0,594 \mathrm{~s}$ \\
\hline $1-2$ & $256 \times 256$ & $0,594 \mathrm{~s}$ \\
\hline $2-1$ & $256 \times 256$ & $0,594 \mathrm{~s}$ \\
\hline $2-2$ & $512 \times 512$ & $3,515 \mathrm{~s}$ \\
\hline $3-1$ & $512 \times 512$ & $3,515 \mathrm{~s}$ \\
\hline $3-2$ & $512 \times 512$ & $3,500 \mathrm{~s}$ \\
\hline
\end{tabular}

Tabela 5.2: Tempo de execução do processo de convolução das imagens com os filtros do banco de filtros.

\section{Seleção do melhor filtro}

A seleção do melhor filtro se dá através do cálculo dos coeficientes obtidos através do processo de contagem de runs explicado na seção 4.1.3. O tempo gasto por esta etapa depende principalmente das dimensões da imagem de referência e do número de filtros gerados, uma vez que, neste processo, é preciso percorrer todos os resultados da convolução destes filtros com a imagem de referência em busca do maior coeficiente. A tabela 5.3 exibe os tempos utilizados em cada um dos experimentos realizados.

\section{Definindo a região de interesse}

A definição da região de interesse (como explicado na seção 4.2) é um processo bastante rápido devido à maneira de sua implementação. Tal velocidade pode ser comprovada 


\begin{tabular}{|c|c|c|}
\hline Exp.-Teste & $\begin{array}{l}\text { Dimensões } \\
\text { da Imagem }\end{array}$ & $\begin{array}{l}\text { Tempo } \\
\text { Utilizado }\end{array}$ \\
\hline $1-1$ & $256 \times 256$ & $8,953 \mathrm{~s}$ \\
\hline $1-2$ & $256 \times 256$ & $8,921 \mathrm{~s}$ \\
\hline $2-1$ & $256 \times 256$ & $9,000 \mathrm{~s}$ \\
\hline $2-2$ & $512 \times 512$ & $14,078 \mathrm{~s}$ \\
\hline $3-1$ & $512 \times 512$ & $13,953 \mathrm{~s}$ \\
\hline $3-2$ & $512 \times 512$ & $13,875 \mathrm{~s}$ \\
\hline
\end{tabular}

Tabela 5.3: Tempo de execução do processo de seleção do filtro que produz a melhor resposta ao ser aplicado sobre a imagem de referência.

analisando a tabela 5.4. As dimensões do mapa base são o fator primordial na definição do tempo de execução desta etapa. Mais uma vez, é possível notar o crescimento praticamente exponencial do tempo de execução da etapa conforme o aumento das dimensões do mapa.

\begin{tabular}{|c|c|c|}
\hline Exp.-Teste & $\begin{array}{l}\text { Dimensões } \\
\text { da Imagem }\end{array}$ & $\begin{array}{l}\text { Tempo } \\
\text { Utilizado }\end{array}$ \\
\hline $1-1$ & $256 \times 256$ & $0,047 \mathrm{~s}$ \\
\hline $1-2$ & $256 \times 256$ & $0,047 \mathrm{~s}$ \\
\hline $2-1$ & $256 \times 256$ & $0,140 \mathrm{~s}$ \\
\hline $2-2$ & $512 \times 512$ & $0,422 \mathrm{~s}$ \\
\hline $3-1$ & $512 \times 512$ & $0,422 \mathrm{~s}$ \\
\hline $3-2$ & $512 \times 512$ & $0,422 \mathrm{~s}$ \\
\hline
\end{tabular}

Tabela 5.4: Tempo de execução do processo de definição da região de interesse sobre o mapa de base.

\section{Geração do mosaico}

Esta última parte das considerações sobre tempo exibe os tempos gastos para a realização da etapa descrita na seção 4.3. Como se pode perceber através da tabela 5.5, embora o número de imagens a serem mosaicadas altere o tempo utilizado para a geração do mosaico, o aumento nas dimensões das imagens a serem mosaicadas é o principal causador do aumento do consumo de tempo. Mesmo que tal crescimento no tempo dê uma impressão de lentidão do método, uma pessoa normal em frente a um software gráfico pode levar um tempo consideravelmente maior para a execução desta tarefa.

\begin{tabular}{|c|c|c|c|}
\hline Exp.-Teste & $\begin{array}{c}\text { Dimensões } \\
\text { da Imagem }\end{array}$ & $\begin{array}{c}\text { Quantidade } \\
\text { de Imagens }\end{array}$ & $\begin{array}{l}\text { Tempo } \\
\text { Utilizado }\end{array}$ \\
\hline $1-1$ & $256 \times 256$ & 3 & $8,844 \mathrm{~s}$ \\
\hline $1-2$ & $256 \times 256$ & 3 & $9,656 \mathrm{~s}$ \\
\hline $2-1$ & $256 \times 256$ & 2 & $4,985 \mathrm{~s}$ \\
\hline $2-2$ & $512 \times 512$ & 4 & $178,423 \mathrm{~s}$ \\
\hline $3-1$ & $512 \times 512$ & 3 & $187,687 \mathrm{~s}$ \\
\hline $3-2$ & $512 \times 512$ & 3 & $195,265 \mathrm{~s}$ \\
\hline
\end{tabular}

Tabela 5.5: Tempo de execução do processo de posicionamento das imagens para a geração do mosaico. 


\subsubsection{Precisão do método}

Como estes experimentos foram realizados sobre um conjunto de imagens as quais ja eram conhecidas as coordenadas finais de posicionamento de cada uma delas na geração de seu respectivo mosaico, é possível analisar os resultados de acordo com sua precisão de posicionamento. As tabelas 5.6 a 5.11 exibem os dados de posicionamento de cada experimento. O índice de erro percentual foi calculado através da diferença, em pixels, da posição encontrada em relação à posição ideal multiplicado por $1 / R$, onde $R$ é a dimensão da imagem no eixo $x$ ou $y$, dependendo do eixo sobre o qual está sendo medido e, em seguida, é calculada a média entre os dois.

\begin{tabular}{|c|c|c|c|}
\cline { 2 - 4 } \multicolumn{1}{c|}{} & $\begin{array}{c}\text { Coordenada Ideal } \\
(\mathrm{x}, \mathrm{y})\end{array}$ & $\begin{array}{c}\text { Coordenada Encontrada } \\
(\mathrm{x}, \mathrm{y})\end{array}$ & Percentual de Erro \\
\hline Imagem 0 & $(17,29)$ & $(18,30)$ & $0,19531 \%$ \\
\hline Imagem 1 & $(48,248)$ & $(54,248)$ & $0,58594 \%$ \\
\hline Imagem 2 & $(137,194)$ & $(138,194)$ & $0,09766 \%$ \\
\hline
\end{tabular}

Tabela 5.6: Tabela do percentual de erro do teste 1 do experimento 1 , utilizando imagens geradas pela concatenação de texturas naturais de Brodatz.

\begin{tabular}{|c|c|c|c|}
\cline { 2 - 4 } \multicolumn{1}{c|}{} & $\begin{array}{c}\text { Coordenada Ideal } \\
(\mathrm{x}, \mathrm{y})\end{array}$ & $\begin{array}{c}\text { Coordenada Encontrada } \\
(\mathrm{x}, \mathrm{y})\end{array}$ & Percentual de Erro \\
\hline Imagem 0 & $(137,194)$ & $(136,194)$ & $0,09766 \%$ \\
\hline Imagem 1 & $(48,248)$ & $(48,246)$ & $0,19531 \%$ \\
\hline Imagem 2 & $(17,29)$ & $(-66,336)$ & $38,08594 \%$ \\
\hline
\end{tabular}

Tabela 5.7: Tabela do percentual de erro do teste 2 do experimento 1 , utilizando o mesmo conjunto de imagens do teste anterior, porém, utilizando uma outra imagem do conjunto como referência.

\begin{tabular}{|c|c|c|c|}
\cline { 2 - 4 } \multicolumn{1}{c|}{} & $\begin{array}{c}\text { Coordenada Ideal } \\
(\mathrm{x}, \mathrm{y})\end{array}$ & $\begin{array}{c}\text { Coordenada Encontrada } \\
(\mathrm{x}, \mathrm{y})\end{array}$ & Percentual de Erro \\
\hline Imagem 0 & $(31,27)$ & $(32,28)$ & $0,39062 \%$ \\
\hline Imagem 1 & $(45,138)$ & $(46,140)$ & $0,58594 \%$ \\
\hline
\end{tabular}

Tabela 5.8: Tabela do percentual de erro do teste 1 do experimento 2, utilizando de cenas aéreas naturais.

Como mostraram as tabelas, o percentual de erro de posicionamento das imagens na formação do mosaico é mínimo, exceto pelo caso onde ocorre a seleção de uma má imagem de referência, onde o erro é consideravelmente grande. Maior parte destes erros se deve à falta de um melhor ajuste fino na hora de posicionar a imagem. Mesmo assim, o resultado final é muito próximo do esperado, gerando mosaicos que se assemelham e muito com os mapas de base utilizados para a geração destes. 


\begin{tabular}{|c|c|c|c|}
\cline { 2 - 4 } \multicolumn{1}{c|}{} & $\begin{array}{c}\text { Coordenada Ideal } \\
(\mathrm{x}, \mathrm{y})\end{array}$ & $\begin{array}{c}\text { Coordenada Encontrada } \\
(\mathrm{x}, \mathrm{y})\end{array}$ & Percentual de Erro \\
\hline Imagem 0 & $(512,512)$ & $(512,512)$ & $0,0 \%$ \\
\hline Imagem 1 & $(351,438)$ & $(352,440)$ & $0,14648 \%$ \\
\hline Imagem 2 & $(476,82)$ & $(476,80)$ & $0,09766 \%$ \\
\hline Imagem 3 & $(348,262)$ & $(348,262)$ & $0,0 \%$ \\
\hline
\end{tabular}

Tabela 5.9: Tabela do percentual de erro do teste 2 do experimento 2, também utilizando-se de cenas aéreas naturais, porém, de dimensões maiores.

\begin{tabular}{|c|c|c|c|}
\cline { 2 - 4 } \multicolumn{1}{c|}{} & $\begin{array}{c}\text { Coordenada Ideal } \\
(\mathrm{x}, \mathrm{y})\end{array}$ & $\begin{array}{c}\text { Coordenada Encontrada } \\
(\mathrm{x}, \mathrm{y})\end{array}$ & Percentual de Erro \\
\hline Imagem 0 & $(76,74)$ & $(76,74)$ & $0,0 \%$ \\
\hline Imagem 1 & $(319,128)$ & $(320,128)$ & $0,04883 \%$ \\
\hline Imagem 2 & $(409,395)$ & $(410,394)$ & $0,09766 \%$ \\
\hline
\end{tabular}

Tabela 5.10: Tabela do percentual de erro do teste 1 do experimento 3, de comparação de funcionamento do método sobre um conjunto de imagens com e sem adição de ruído, sendo este primeiro teste utilizando imagens sem ruído.

\begin{tabular}{|l|c|c|c|}
\cline { 2 - 4 } \multicolumn{1}{c|}{} & $\begin{array}{c}\text { Coordenada Ideal } \\
(\mathrm{x}, \mathrm{y})\end{array}$ & $\begin{array}{c}\text { Coordenada Encontrada } \\
(\mathrm{x}, \mathrm{y})\end{array}$ & Percentual de Erro \\
\hline Imagem 0 & $(76,74)$ & $(76,74)$ & $0,0 \%$ \\
\hline Imagem 1 & $(319,128)$ & $(320,128)$ & $0,04883 \%$ \\
\hline Imagem 2 & $(409,395)$ & $(410,394)$ & $0,09766 \%$ \\
\hline
\end{tabular}

Tabela 5.11: Tabela do percentual de erro do teste 2 do experimento 3, onde ocorreu a aplicação de ruído sobre as imagens do teste anterior. 



\section{Capítulo \\ 6 \\ Conclusão}

Este trabalho apresentou uma abordagem para geração automática de mosaicos baseada em técnicas de análise multiescala, mais precisamente, utilizando-se de filtros de Gabor. A metodologia apresentada é resultado de meses de pesquisa sobre diversos trabalhos e abordagens que tratassem de problemas semelhantes ao proposto pelo trabalho. Parte das técnicas utilizadas na realização das etapas presentes na metodologia provém de adaptações de técnicas utilizadas por outros trabalhos pesquisados, ou criadas no decorrer do desenvolvimento da pesquisa especificamente para a solução do problema proposto, introduzindo algumas características de inovação ao trabalho apresentado.

A próxima seção apresenta algumas discussões sobre as vantagens e desvantagens presentes na abordagem escolhida podem ser examinadas. Por fim, uma última seção apresenta uma breve discussão sobre possíveis trabalhos futuros a partir deste.

\subsection{Vantagens e desvantagens do método}

O método utilizado neste trabalho possui várias pontos positivos e negativos. Entre os que podemos considerar positivos temos:

- Geração de mosaicos sem necessidade de georeferenciamento: as imagens não precisam ser identificadas por pontos de controle posicionados estrategicamente sobre o solo na hora da tomada das fotografias aéres e também não há a necessidade de realização de cálculos de posicionamento utilizando dados provenientes de equipamentos de medição, necessitando apenas de um mapa de base para a realização do mesmo;

- Velocidade: um mosaico gerado pelo método, mesmo que de resolução pequena, consome consideravelmente menos tempo de produção do que se fosse gerado por um especialista de frente a um software gráfico, onde é necessário analisar imagem por imagem e buscar, visualmente, por pontos de similaridade entre as mesmas ou mesmo entre o mapa de base. Isto poderia ser uma tarefa bastante complicada, 
uma vez que estas imagens, especialmente as de cenas naturais, acabam sendo muito parecidas entre si, dificultando a busca por pontos de intersecção;

- Baixo índice de erro: as coordenadas encontradas pelo método para as imagens no mosaico resultante é bastante próximo do esperado, como mostrado no capítulo 5. Este índice depende apenas de uma boa escolha inicial da imagem de referência a ser utilizada no decorrer do processo;

- Dispensa necessidade de especialistas: qualquer pessoa com um mínimo de conhecimento sobre as imagens que serão mosaicadas pode iniciar o processo de geração do mosaico, não havendo a necessidade de um especialista em processos de mosaicagem para a utilização do mesmo.

Já entre os pontos negativos, podemos citar:

- Necessidade de imagens de orientação bem marcante: as imagens de plantações de eucalipto utilizadas pelo trabalho produzem bons resultados por não possuírem muitos detalhes internos nos elementos que compôem as regiões orientadas das imagens, no caso, as árvores. Imagens aéreas de uma cidade, por exemplo, se tornam um conjunto de imagens inviável para o método, mesmo que os quarteirões apresentem certa orientação. Os detalhes presentes no meio dos mesmos pode acabar afetando o resultado final, produzindo erros de mosaicagem;

- Necessidade de um computador de alto desempenho: os cálculos realizados para a obtenção dos resultados apresentados neste trabalho necessitam de uma grande quantidade de processamento. Um computador mediano pode levar tempo demais para a execução do método, exigindo assim uma máquina mais moderna e computacionalmente mais potente para garantir um bom funcionamento;

- Crescimento exponencial do tempo de geração dos mosaicos de acordo com o crescimento do tamanho das imagens: embora o método funcione muito bem para imagens de dimensões pequenas e médias, o tempo de processamento para um conjunto de imagens de dimensões muito grandes pode consumir um tempo muito elevado de CPU.

\subsection{Trabalhos Futuros}

Uma continuação direta para o desenvolvimento deste trabalho seria torná-lo independente da plataforma MatLab. Embora muitos cálculos matemáticos sejam facilitados pelo uso deste sistema, perde-se certo desempenho devido ao peso computacional do mesmo, tanto em termos de processamento como de utilização de memória, o que acaba exigindo computadores mais avançados para uma rápida realização de um processo de mosaicagem. Embora os resultados dos experimentos tenham exibido uma boa performance em termos de tempo, para um conjunto de imagens de resolução muito superior, talvez a utilização deste sistema como base para o funcionamento do trabalho poderia se tornar impraticável, levando muito mais tempo do que o realmente necessário para a realização desta tarefa.

Em termos de extensão de pesquisa, várias idéias podem ser seguidas como: melhoria do funcionamento geral do método como criar maneiras de permitir ou estimar uma melhor escolha dos parâmetros iniciais, gerando melhores resultados; elaboração de melhores 
algoritmos para realizar o casamento entre as imagens do conjunto sobre o mapa de base de modo a melhorar o seu desempenho baseando-se talvez em alguma técnica de inteligência computacional; extender a utilização do método para outros tipos de conjuntos de imagens orientadas, tais como imagens aéreas de algumas cidades, por exemplo. 



\section{Referências Bibliográficas}

Abbasi, S.; Mokhtarian, F.; Kittler, J. Curvature scale space image in shape similarity retrieval. Multimedia Syst., v. 7, n. 6, p. 467-476, 1999.

Albuquerque Nóbrega, R. A. Análise do balanceamento de imagens aplicado à fotogrametria. Dissertação de Mestrado, Escola Politécnica da Universidade de São Paulo, 2002.

Almansa, A.; LindeBerg, T. Fingerprint enhancement by shape adaptation of scalespace operators with automatic scale selection. Image Processing, v. 9, n. 12, p. 20272042, 2000.

Andrade, J. B. Fotogrametria. 1a ed. Curitiba - PR: SBEE, 1998.

Brodatz, P. Brodatz textures. 2006.

Disponível em: http://www.ux.uis.no/ tranden/brodatz.html (Acessado em Dezembro/2006)

Campos, J.; Linney, A.; Moss, J. The analysis of facial profiles using scale space techniques. Pattern Recognition, v. 26, n. 6, p. 819-824, 1993.

Castañon, C. A. B. Recuperação de imagens por conteúdo através de análise multiresolução por wavelets. Dissertação de Mestrado, Instituto de Ciências Matemáticas e de Computação (ICMC), 2003.

Chen, L.; Lu, G.; Zhang, D. Effects of different gabor filter parameters on image retrieval by texture. $M M M$, p. 273, 2004.

Cramer, M. Direct geocoding - is aerial triangulation obsolete? In: Photogrammetric Week, 99, Wichmann Verlag, Heidelberg, 1999, p. 59-70.

Cramer, M. On the use of direct georeferencing in airborne photogrammetry. In: 3rd. International Symposium on Mobile Mapping Technology, Cairo, Egito, 2001.

Cramer, M.; HaAla, N. Direct exterior orientation of airborne sensors - an accuracy investigation of an integrated gps/inertial system. Journal GIM International, v. 13, p. 46-49, 1999. 
Cramer, M.; Stallmann, D.; HaAla, N. Direct georeferencing using gps/inertial exterior orientations for photogrammetric applications. In: IAPRS - International Archives of Photogrammetry and Remote Sensing, Amsterdam, Holanda, 2000, p. 198206.

Daubechies, I. Ten lectures on wavelets. Philadelphia, PA, USA: Society for Industrial and Applied Mathematics, 1992.

Daugman, J. G. Uncertainty relation for resolution in space, spatial frequency, and orientation optimized by two-dimensional visual cortical filters. Journal of the Optical Society of America A, v. 2, p. 1160-1169, 1985.

Dunn, D. F.; Higgins, W. E. Optimal gabor-filter design for texture segmentation. IEEE International Conference on Acoustics, Speech, and Signal Processing, v. 5, p. 3740, 1993.

Estatística, I. B. Noções básicas de cartografia. 1997.

Disponível em: http://www.ibge.gov.br/home/geociencias/cartografia/manual_ nocoes/indice.htm (Acessado em Maio/2005)

Estes, J. E.; Hemphill, J. Introduction to photo interpretation and photogrammetry. 1998.

Disponível em: http://www.r-s-c-c.org/rscc/v1.html (Acessado em Maio/2005)

Feris, R. S.; JR, R. M. C.; Kruger, V. Efficient real-time face tracking in wavelet subspace. IEEE ICCV Workshop on Recognition, Analysis, and Tracking of Faces and Gestures in Real-Time Systems (RATFG-RTS'01), v. 2, p. 96-101, 2001.

GABOR, D. Theory of communication. JIEE, v. 93, n. 3, p. 429-459, 1946.

Geo-Information Science, I. I.; Observation, E. Ilwis 3.2 - the remote sensing and gis software. 2004.

Disponível em: http://www.itc.nl/ilwis/default.asp (Acessado em Maio/2005)

GoOgle Maps. 2006.

Disponível em: http://maps.google.com/ (Acessado em Novembro/2006)

Graps, A. An introduction to wavelets. IEEE Comput. Sci. Eng., v. 2, n. 2, p. 50-61, 1995.

Grejner-BrzezinskA, D. A. Direct exterior orientation of airborne imagery with gps/ins system: Performance analysis. Navigation, v. 46, n. 4, p. 261-270, 1999.

Hasegawa, J. K.; Imai, N. N.; Camargo, P. D. O. Sistema de aquisição e processamento de dados georreferenciados para aplicações em agricultura de precisão. In: Congresso Brasileiro de Cadastro Técnico Multifinalitário, Florianópolis - SC, 2004.

Hasegawa, J. K.; Junior, E. R. D. A. Mosaico com imagens digitais. Boletim de Ciências Geodésicas, v. 10, n. 1, p. 31-50, 2004.

Jain, A. K.; FARrokhniA, F. Unsupervised texture segmentation using gabor filters. Pattern Recogn., v. 24, n. 12, p. 1167-1186, 1991. 
Jorge, A. C. L. Determinação da cobertura do solo em fotografias aéreas do projeto arara. Dissertação de Mestrado, Instituto de Ciências Matemáticas e de Computação - Universidade de São Paulo, 2001.

Kalman, Rudolph, E. A new approach to linear filtering and prediction problems. Transactions of the ASME-Journal of Basic Engineering, v. 82, n. Series D, p. 35-45, 1960.

Leite, N. J.; Dorini, L. B. A scaled morphological toggle operator for image transformations. Sibgrapi, v. 0, p. 323-330, 2006.

LindeBERG, T. Scale-space: A framework for handling image structures at multiple scales. In: Proceedings of CERN School of Computing, Egmond aan Zee, The Netherlands, 1996, p. 8-21.

Marcheti, D. A. B.; Garcia, G. J. Princípios de fotogrametria e fotointerpretação. 1a ed. São Paulo - SP: Nobel, 1989.

MEYER, Y. Wavelets: Algorithms and applications. first ed. Philadelphia: SIAM (Society for Industrial and Applied Mathematics), |c1993, 1993.

Mokhtarian, F.; Suomela, R. Robust image corner detection through curvature scale space. IEEE Transactions on Pattern Analysis and Machine Intelligence, v. 20, n. 12 , p. 1376-1381, 1998.

NERIS, L. O. Um piloto automático para as aeronaves do projeto arara. Dissertação de Mestrado, Instituto de Ciências Matemáticas e de Computação - Universidade de São Paulo, 2001.

Petkov, N.; Kruizinga, P. Computational models of visual neurons specialised in the detection of periodic and aperiodic oriented visual stimuli: Bar and grating cells. Biological Cybernetics, v. 2, n. 76, p. 83-96, 1997.

Romberg, J.; Choi, H.; Baraniuk, R.; Kingsbury, N. Multiscale classification using complex wavelets. In: IEEE International Conference on Image Processing, Vancouver, Canada, 2000.

Ross, A.; Jain, A.; Reisman, J. A hybrid fingerprint matcher. 16th International Conference on Pattern Recognition (ICPR'02), v. 3, p. 795-798, 2002a.

Ross, A.; Reisman, J.; JAIn, A. K. Fingerprint matching using feature space correlation. In: ECCV '02: Proceedings of the International ECCV 2002 Workshop Copenhagen on Biometric Authentication, London, UK: Springer-Verlag, 2002b, p. 4857.

Santos, R. B. Metodologias para geração e atualização de mosaicos de fotos aéreas no projeto arara. Dissertação de Mestrado, Instituto de Ciências Matemáticas e de Computação - Universidade de São Paulo, 2004.

SE, S.; Brady, M. Vision-based detection of stair-cases. In: Fourth Asian Conference on Computer Vision ACCV 2000, Taipei, 2000, p. 535-540. 
Skaloud, J.; Cramer, M.; Schwarz, K. Exterior orientation by direct measurement of camera position and orientation. In: XVIII ISPRS - International Society for Photogrammetry and Remote Sensing - Congress, Comission III, Working Group I, Viena, Austria, 1996, p. 125-130.

Stansfield, J. L. Conclusions from the commodity expert project. MIT A.I. Memo 601, Massachusetts Inst. of Technology, 1980.

Tотн, C. K. Experiences with frame ccd arrays and georeference. In: Photogrammetric Week, 99, Stuttgart, Germany, 1999, p. 95-109.

TsAI, D.-M.; Wu, S.-K. Automated surface inspection using gabor filters. The International Journal of Advanced Manufacturing Technology, v. 16, n. 7, p. 474-482, 2000.

WANG, J. Z. Wavelets and imaging informatics: a review of the literature. Comput. Biomed. Res., v. 34, n. 2, p. 129-141, 2001.

WELDON, T. P. Improved image segmentation with a modified bayesian classifier. In: IEEE International Conference on Acoustics, Speech and Signal Processing (ICASSP 2006), 2006, p. 697-700.

Weldon, T. P.; Higgins, W. E. Multiscale rician approach to gabor filter design for texture segmentation. In: ICIP, 1994, p. 620-624.

Weldon, T. P.; Higains, W. E. Design of multiple gabor filters for texture segmentation. ICASSP, v. 4, p. 2243-2246, 1996.

Weldon, T. P.; Higgins, W. E.; Dunn, D. F. Efficient gabor filter design for texture segmentation. Pattern Recognition, v. 29, n. 12, p. 2005-2015, 1996.

Witkin, A. P. Scale-space filtering: A new approach to multi-scale description. Acoustics, Speech, and Signal Processing, IEEE International Conference on ICASSP '84, v. 9, p. 150-153, 1984.

Wolf, C.; Kropatsch, W.; Bischof, H.; Jolion, J.-M. Content based image retrieval using interest points and texture features. ICPR, v. 4, p. 234-237, 2000.

Wolf, P. R. Elements of photogrammetry with air photo interpretation and remote sensing. 2a ed. New York - NY: McGraw-Hill, 1983.

Zhang, D.; Wong, A.; Idrawan, M.; Lu, G. Content-based image retrieval using gabor texture features. In: IEEE Pacifin-Rim Conference on Multimedia, Sydney, Australia: IEEE, 2000, p. 392-395. 